


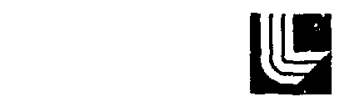

LAWFENCE INERMORE LAEORATOPY

University of Cefitomia, Livermoro, Caltomia - 94550

UCRL-50400 Vol. 1 Rev. 2

\section{ECSIL, A SYSTEM FOR STORAGE, RETRIEVAL, AND DISPLAY OF EXPERIMENTAL NEUTRON DATA}

D. E. Cullen, K. L. Hill, R. J. Howerton, and $S . T$. Perkins

Revised March I, 1974

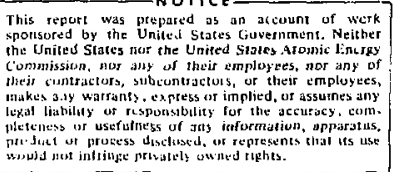




\section{Foreword}

The UCRL-50400 series describes an integrated and computer-oriented system for the production and application of neutronics and photonics calculational constants.

The system must supply reliable upto-date data, select specific types of data on request, provide output in a variety of forms - ultimately in the form of input to other computer codes, and function rapidly and efficiently. The system has now been developed to a point where these goals are being realized.

The UCRL-5U400 series, An Integrated System for Production of Neutronics and Photonics Calculational Constants, comprises the following volumes:

- Vol. 1, ECSIL, A System for Storage, Retrieval and Display of Experimental Neutron Data, March 1974.

- Vol. 2, A Bibliography of the Experimental Data of Neutron-Induced Interactions, March 1974.

- Vol. 3, An Index of the Experimental Data of Neutron-Induced Interactions, March 1974.

- Vol. 4, Evaluated Nuclear CrossSection Library, April 1971.

- Vol. 5, CLYDE: A Ivuclear DataProcessing Computer Program for
Producing Calculational Constants, May 1971.

- Vol. 6, Photon Cross sections $1 \mathrm{keV}$ to $100 \mathrm{MeV}$, October 1968 .

- Vol. 7, Graphical Experimental Data for Major Neutron-Induced Interactions, April 1974.

- Vol. 8, Graphical Experimental Data for Supplemental NeutronInduced interacions, to be published.

- Vol. 9, Thresholds of Nuclear Reactions Induced by Neutrons, Photons, Deuterons, Tritons, and Alpha Particles, September 1970.

- Vol. 10, Tabulated Experimental Data for Neutron-Induced Interactions, May 1974.

- Vol. 11, Experimental Data, Indexes and Techniques of Obtaining a Selected Set of Neutron Resonance Parameters, May 1972.

- Vol. 12, An Atlas of Resolved Neutron Resonance Parnmeters, July 1972 .

- Vol. 13, An Atlas of Unresolved Neutron Resonance Parameters, September 1972.

- Vol. 14, TARTNP: A Coupled Neutron-Photon Monte Carlo Transport Code, June 1974. 
Relationship to Other Volumes . . . . . . . . . . . . . . . . iy

Acknowledgments

Abstract

Introduction

Tire ECSIL System

ECSIL. Conventions

ECSIL Numeric Data Card Format

ECSII Numeric Data Library Format

Jibrary Organization

Library File Structure

ECSLL Bibliographic Information Format

Fixed Field Input

Variable Field Input

ECSIL Program System

Overview

Cominon Design Features

Input Cards .

Output Listings

Filenames

Program Operation

Program Names

Program Availability

Library Availability

ECSCHK - Checking Data Cards

ECSORT - Sorting Data Cards

ECSMRG - Merging Sorted Data Cards

ECSUPD - Updating the Data Library

ECSDEL - Deleting from the Data Library

ECSRET - Retrieving from the Data Library

ECSCEN - Checking/Ciensus of Data Library

ECSDEX - Indexes to Data Library

ECSPL.T - Plots, Listings from Data Library or Cards

ECSBIB - Updating, Retrieving from Bibliographic Library

ECSPOP - Indexes to Bibliographic Library

Extended ECSIL Conventions

Extended ECSLL Data Card Format . . . . . . . . . . . . • 49

Extended ECSIL Data Lihrary Organization and Format . . . . . . 51

References . . . . . . . . . . . . . . . . 52

Appendix A: Example Reference . . . . . . . . . . . 53 


\section{Relationship to Other Volumes}

This volume, ciescribing the ECSIL. system, is closely relared to other volumes of the UCRL-50400 series. It defines ECSIL conventions and explains how to use ECSIL's supporting programs.

Volume 2 contains bibliographic inclexes that can be used to determine whether a given reference is included in the ESCIL system, and which experimental data are associated with the reference.

Volume 3 lists data indexes that may be used to determine the data in the library for a given isotope or reaction.

Volume 7 is a graphical presentation of all total, elastic, capture, and fission integral cross sections. It also supplies data on $\overline{\boldsymbol{\nu}}$ (neutrons/fission), $\alpha$ (capture/ fission ratio) and $\eta$ (reutrons/nonelastic event).

Volume $\mathrm{A}$ is a graphical presentation of all other integrated (as opposed to angular distribution) cross sections, including $\left(n, n^{1}\right),(n, \alpha)$, etc.

Volume 10 contains the integrated cross sections tabulated on microfiche.

Volume 11 lists indexes and tabulated resonance parameters contained in ECSIL.

Volume 12 lists tabulated selected resolved resonance parameters.

Volume 13 lists tabulated selected unresolved resonance parameters.

\section{Acknowledgments}

We gratefully acknowledge the cooperation we have received from the National Neutron Cross Section Center at Brookhaven National Laboratory, the ElvEA Center for collection of neutron data at Saclay, the IAEA nuclear data section at Vienna, and the Nuclear Data Section a OBNINSK. The National Neutron Cross Section Center has routinely suppiied us with experimental data collected at the four centeri.

Many experimenter's have furnished us with their data in advance of publication. To them, especially, we oiffer our grateful thanks. Finally, we would like to express our sincere gratitude to Mrs. Violet Gamble for her effort in maintait.ing the bibliographic file. 


\title{
ECSIL, A SYSTEM FOR STORAGE, RETRIEVAL, AND DISPLAY OF EXPERIMENTAL NEUTRON DATA
}

\begin{abstract}
A description of the experimental cross

and supporting programs. The forms section information iibrary (ECSIL) as of March 1, 1974 is presented, together with its associated formats, conventions, (i.e., plots and listings) and the order in which data and bibliograpinc information may be obtained are also given.
\end{abstract}

\section{Introduction}

In 1958, a computerized system for the siorage and retrieval of experimental neuiron-interaction data was installed at Lawrence Livermore Laboratory. The system has developed gradually and it is still being improved.

The present system is made up of two separate files: A rumeric data file and a bibliographic information file. The two files are linked through the use of a four digit number which is uniquely assigned to each reference.

In 1959 and 1960, tabulations of integrated and differential neutron cross sections below $15 \mathrm{MeV}$ were published.
Since that time the number of entries in the system has increased by more than an order of magnitude. Consequently, there is too much data in the current library (almost one million data foints) to publish tabulations of this information: the resulting volumes would be prohibitively expensive and bulky. However, by presenting the data in graphs 1,2 and on microfiche, ${ }^{3}$ we can significantly reduce the expense and the bulk. Moreover, the reduction in bulk means that indexes ${ }^{4}$ and bibliographies ${ }^{5}$ can be added to help in the manipulation of the data.

\section{The ECSIL System}

This volume describes

- The conventions used in ECSII to classify experimental neutroninduced cross sections and related information.
- The two formats used to handle the numeric data. The numeric cata file is large, encompassing 985,158 points expressed in 7,100,0100 computer words. This is stored in a binary format for rapid computer 
readout and interpretation. There is also a card image format, used to prepare new numeric data for inclusion is or retrieval from the diate library.

- The single format used throughout the bibliograghic information system. The bibliographic information file is relatively small; its 3371 teferences are stored for simplicity as 13,000 card images. The same card image format is used tc prepare new bibliographic irformation for inclusion in or retrieval from the library.

- The system of programs lised not only to maintain tr.e cur rent, numeric data file and bibliographic information file, but also to prepare indexes, listings, and plots of the data. These indexes, listings, and plots are routinely prepared after every update and published periodically. ${ }^{1-5}$

- An extension of the ECSIL conventions and numeric data formats to allow the system to handle cross sections for any incident particle (e.g., $\sigma\left(p, p^{\prime}\right)$ ), and to describe any emerging particle (e.g., angular distribution of either $\mathrm{n}$ or $\mathrm{p}$ from the reaction $\left.\sigma\left(n, n^{\prime} p\right)\right)$. The new data conventions and formats will not affect the pibliographic system. At present this new for $n$ at is implemented on an experimental basis to handie data on charged particles, photons, etc. Barring complications it will be adopted in the future as a replacement for the current ECSIL format.

\section{ECSIL Conventions}

The ECSIL Nata System describes experimental neutron-induced cross sections and related infurmation by indicating:

Target-The ZA number is used to describe the target. There are several speciai conventions. For exarnple, $\mathrm{A}$ is set equal to zero for elemental mixtures. For compounds, the $\mathrm{Z}$ of the element that appears first in the mole zular formula is used, and $A$ is defined as 300 plus the rnolecular weight (e.g., $\mathrm{H}_{2} \mathrm{O}$ is assigned $2:=I$ and $A=318$ ). For unstable targets, tize longest-lived isomer is assigned the $Z$ A of the target; short lived isomers are assigned the $Z$ of the target, and $A$ is defined as 600 plus the $A$ of the target (6. g., $242 \mathrm{~g}_{\mathrm{Am}}$ is assigned $\mathrm{Z}=95$ and $A=842$ ). See Table 1 for a complete list of compounds and special isotopes.
Table 1. Compounds and special isotopes (assigned ZA's).

\begin{tabular}{|c|c|c|c|}
\hline $\begin{array}{c}\text { Assigned } \\
\text { ZA }\end{array}$ & Material & $\begin{array}{c}\text { Assigned } \\
Z A\end{array}$ & Material \\
\hline 1302 & $\mathrm{H}_{2}$ (gas) & 14360 & $\mathrm{SiO}_{?}$ \\
\hline 1318 & $\mathrm{H}_{2} \mathrm{O}$ & 16364 & $\mathrm{SO}_{2}$ \\
\hline 1320 & $\mathrm{D}_{2} \mathrm{O}$ & 22349 & $\mathrm{TiH}_{0.6}$ \\
\hline 5370 & $\mathrm{~B}_{2} \mathrm{O}_{3}$ & 22350 & $\mathrm{TiH}_{1.9}$ \\
\hline 6328 & $\mathrm{C}_{2} \mathrm{H}_{4}$ & 26460 & $\mathrm{Fe}_{2} \mathrm{O}_{3}$ \\
\hline 6331 & $\mathrm{CH}_{3} \mathrm{OH}$ & 27660 & $60 \mathrm{~m}_{\mathrm{Co}}$ \\
\hline 6376 & $\mathrm{C}_{6} \mathrm{H}_{6}$ & 40351 & $\mathrm{ZrH}_{0,63}$ \\
\hline 6384 & $\mathrm{C}_{6} \mathrm{H}_{12}$ & 40392 & $\mathrm{ZrH}_{0.98}$ \\
\hline 6386 & $\mathrm{C}_{6} \mathrm{H}_{14}$ & 40.393 & $\mathrm{Zr} \mathrm{H}_{1.5}$ \\
\hline 6392 & $\mathrm{C}_{3} \mathrm{H}_{8} \mathrm{O}_{3}$ & 40394 & $\mathrm{Zr}_{\mathbf{r}} \mathrm{H}_{1.9 \mathrm{~B}}$ \\
\hline 6404 & $\mathrm{C}_{8} \mathrm{H}_{\mathrm{B}}$ & $40 \div 23$ & $\mathrm{ZrO}_{2}$ \\
\hline 6652 & $\mathrm{C}_{25} \mathrm{H}_{52}$ & 60636 & $\mathrm{Nd}_{2} \mathrm{O}_{3}$ \\
\hline 7328 & $\mathrm{~N}_{2}$ (gas) & 61748 & ${ }^{148} \mathrm{~g}_{\mathrm{Pa} 1}$ \\
\hline 7353 & $\mathrm{NH}_{4} \mathrm{Cl}$ & 82999 & RADIO-Pb \\
\hline 7398 & $\mathrm{NH}_{4}^{4} \mathrm{Br}$ & 92570 & $\mathrm{UO}_{2}$ \\
\hline 7445 & $\mathrm{NH}_{4} \mathrm{I}$ & 95842 & $242 \mathrm{gAm}$ \\
\hline 8332 & O.2(gas) & 95844 & $24 \mathrm{AB}_{\mathrm{Am}}$ \\
\hline 12340 & $\mathrm{MgO}$ & 99854 & ${ }^{254 m}$ Es \\
\hline 13402 & $\mathrm{Al}_{2} \mathrm{O}_{3}$ & & \\
\hline
\end{tabular}


Interaction-A numerical equivalent is used to designate the interaction: total, elastic, capture, etc. In ECSIL this numerical equivalent is referred to as the basic $\mathrm{C}$ number. Table 2 gives a complete list of all basic $C$ numbers.

Interaction Property-A numerical equivalent designates the interaction properties that are measured, such as cross section, angular distribution, or energy distribution. In ECSIL this numerical equivalent is referred to as the $C$ increment number. The total $C$ number used to describe the interaction and its property is the sum of the $C$ number increment and the basic $C$ number le.g., 11 indicates the total $\left(n, n^{\prime}\right)$ cross section, whereas 311 indicates the $\left(n, n^{\prime}\right)$ secondary neutron energy spectrum]. Table 3 gives a complete list of all $\mathrm{C}$ number

Table 2. Basir reaction designator (basic C).

\begin{tabular}{|c|c|c|c|}
\hline Basic & Cross section type & $\underset{\mathrm{C}}{\text { Basic }}$ & Cross section type \\
\hline 1 & Total & 26 & $(n, p)$ \\
\hline 2 & Elastic & $2 ?$ & $(n, x p)$ \\
\hline 3 & Nonelastic & 28 & $(n, D)$ \\
\hline 4 & $\begin{array}{l}\text { Neutron emission (elastic } \\
+ \text { nonelastic) }\end{array}$ & $\begin{array}{l}29 \\
30\end{array}$ & $\begin{array}{l}(\mathrm{n}, \mathrm{XD}) \\
(\mathrm{n}, \mathrm{T})\end{array}$ \\
\hline 5 & $\begin{array}{l}\text { Total scattering (inelastic } \\
\text { + elastic? }\end{array}$ & 31 & $(\mathrm{n}, \mathrm{XT})$ \\
\hline 6 & Neutron nonelastic emission & 32 & $\left(\mathrm{n},{ }_{3}^{3} \mathrm{He}\right)$ \\
\hline 7 & Removal & 33 & $\left(n, x^{3} \mathrm{He}\right)$ \\
\hline$B$ & - & 34 & $(\mathbf{n}, a)$ \\
\hline 9 & - & 35 & $(n, X \alpha)$ \\
\hline 10 & - & 36 & Activation \\
\hline 11 & $\left(n, n^{\prime \prime}\right)$ & 37 & $(n, 2 \alpha)$ \\
\hline 12 & $(n, 2 n)$ & 38 & - \\
\hline 13 & $(n, 3 n)$ & 39 & - \\
\hline 14 & $\left(n, r_{1}{ }^{t} p\right)$ & 40 & 一 \\
\hline 15 & $\left(n, n^{\prime} D\right)$ & 41 & Bound atom \\
\hline 16 & $\left(n, n^{\prime} T\right)$ & 42 & Free atom \\
\hline 17 & $\left(n, n^{\prime}, 3_{\mathrm{He}}\right)$ & 43 & Coherent scaitering \\
\hline 18 & $\left(n, n^{\prime}, \alpha\right)$ & 44 & incoherent scattering \\
\hline 19 & $(n, 4 n)$ & 45 & - \\
\hline 20 & - & 46 & $\bar{\nu}_{\text {p }} \begin{array}{l}\text { prompt neutrons per fission } \\
\text { (average) }\end{array}$ \\
\hline $\begin{array}{l}21 \\
22\end{array}$ & $\begin{array}{l}\text { Absorption } \\
\text { (n,fission) }\end{array}$ & 47 & $\bar{\nu}_{\mathrm{d}}, \begin{array}{l}\text { delayed neutrons per fission } \\
\text { (average) }\end{array}$ \\
\hline $\begin{array}{l}23 \\
24\end{array}$ & $(\mathrm{n}, \gamma)$ & 48 & $\begin{array}{l}n \text {, neutrons produced per non- } \\
\text { elastic event }\end{array}$ \\
\hline 25 & (n, X) char:ged-farticle emission & 49 & $\alpha$, capture-to-fission ratio \\
\hline
\end{tabular}


increments, Table 4 lists miscellaneous quantities which are not included in the basic $C$, $C$ increment scheme.

Interaction Modifier-A numerical equivalent is used to further qualify or describe the interaction. This quantity indjuates conditions such as the target temperatire, the cross section for excitation of one or more levelis of the residual nucleus, and the cross section for production of one or more photons. In ECSIL this numerical equivalent is referred to as the $S$ number. Table 5 gives a complete list of all $\mathrm{S}$ numbers.

Table 3. Reaction designator increments (C increment).

\begin{tabular}{|c|c|c|}
\hline increment & $\begin{array}{l}\text { Reaction property } \\
\text { (units) }\end{array}$ & Definition \\
\hline 0 & $\begin{array}{l}\text { Integrated cross sections } \\
\text { (barns), or related parameters }\end{array}$ & $\sigma$ \\
\hline 50 & $\begin{array}{l}\text { Spectrum-averaged cross sec- } \\
\text { tion (barns) }\end{array}$ & $\bar{\sigma}$ \\
\hline $100^{\mathrm{a}}$ & $\begin{array}{l}\text { P.lar distributions (barns/ } \\
\text { steradian) }\end{array}$ & $\sigma(E, \theta)$ \\
\hline 200 & $\begin{array}{l}\text { Energy distributions (barns/ } \\
\text { MeV) }\end{array}$ & $\sigma\left(E, E^{*}\right)$ \\
\hline 250 & $\begin{array}{l}\text { Angular distributions integrated } \\
\text { between fixed angular limits } \\
\text { (barns) }\end{array}$ & $\sigma\left(\mathrm{E}, \theta_{\min }, \theta_{\max }\right)_{1 a b}$ \\
\hline 300 & $\begin{array}{l}\text { Differential energy distributions } \\
\text { (harns/steradian MeV) }\end{array}$ & $\sigma\left(E, E^{\prime}, A\right)$ lab \\
\hline 350 & $\begin{array}{l}\text { Partial distributions integrated } \\
\text { between fixed energy and angular } \\
\text { limits (barns) }\end{array}$ & $\sigma\left(E, E^{\prime} \min , E^{\prime} \max ^{\prime} \theta_{\min ^{\prime}} \theta_{\max }{ }^{\prime} l a b\right.$ \\
\hline 400 & $\begin{array}{l}\text { Energy distiributions integrated } \\
\text { between fixed energy limits } \\
\text { (barnsi }\end{array}$ & $\sigma\left(E_{,}, E_{\min }^{\prime}, E_{\text {max }}^{\prime}\right\rangle$ \\
\hline $450^{\mathrm{a}}$ & $\begin{array}{l}\text { Legendre expansion of angular } \\
\text { distributions }-g_{\ell}(\mathrm{E}) \text { (dimen- } \\
\text { sionless) }\end{array}$ & $\sigma(E, \theta)=\sigma(E) \sum_{\ell=0}^{\infty} \frac{2 \ell+1}{4 \pi} g_{\ell}(E) F_{\ell}(\cos \theta)$ \\
\hline 500 & Pesonanco integrals (barns) & R.I. $=\int_{E_{\min }}^{E_{\max }} \sigma(E) \frac{d E}{E}$ \\
\hline $550^{\mathrm{a}}$ & Polarization (dimensionless) & $P(E, \theta)$ \\
\hline 600 & $\begin{array}{l}\text { Partial ristributions integrated } \\
\text { between fixed-energy limits } \\
\text { (barns/steradian) }\end{array}$ & $\sigma\left(\mathrm{E}, \mathrm{E}_{\min }^{\prime}, \mathrm{E}_{\max }^{\prime}, 6\right)_{\text {lab }}$ \\
\hline 650 & $\begin{array}{l}\text { Partial distributions integrated } \\
\text { between fixe: angular limits } \\
\text { (barns/MeV) }\end{array}$ & $\sigma\left(\mathrm{E}, \mathrm{E}^{\prime}, \theta_{\min ^{\prime}} \theta_{\max }\right)^{\prime} \mathrm{ab}$ \\
\hline 800 & C/s ratios (dimensionless) & \\
\hline 900 & Miscellaneous quantities & See: Table 4 \\
\hline
\end{tabular}

${ }^{a}$ Angular distributions for all unique two-body reactions are expressed in the centerof-mass system. Multibody reactiors are expressed in the laboratory frame of reference. 
Table 4. Reaction designator ior miscellaneous quantities.

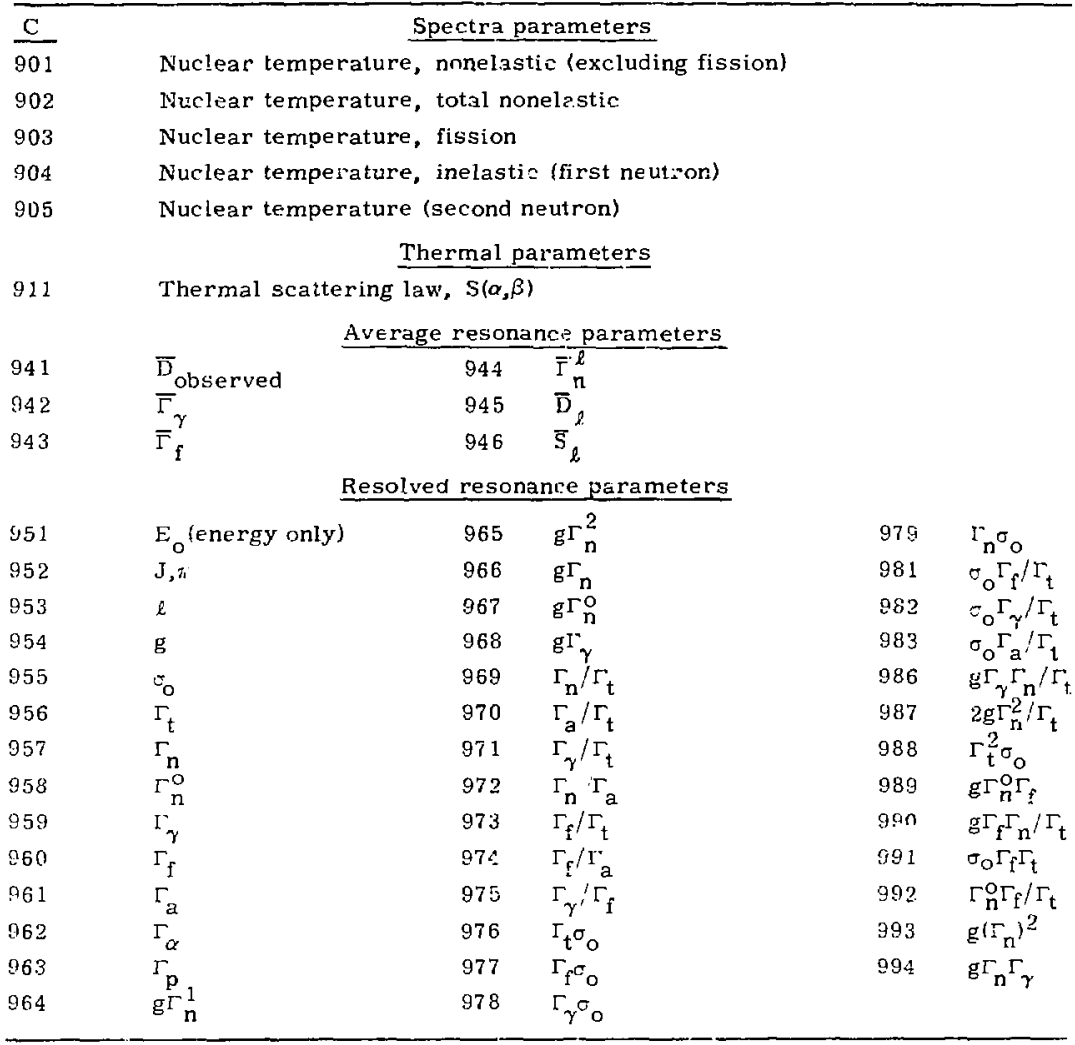

Table 5. Reaction designator modifier ${ }^{\mathrm{a}}$ (S rumber).

\begin{tabular}{|c|c|c|c|}
\hline $\mathrm{S}$ & Modification (units) & $S$ & Modifica'ion (units) \\
\hline 1 & Level excitation ( $\mathrm{MeV}$ ) & 9 & Material temperature (Kelvin) \\
\hline 2 & Isomer production (seconds) & 10 & Unresolved photon production $(\mathrm{MeV})$ \\
\hline 3 & Isom er production (minutes) & 11 & Spin state (dimensionless) \\
\hline 4 & isomer production (hours) & 12 & Isotope bound in material \\
\hline $\mathrm{b}$ & Isomer production (days) & & \\
\hline 6 & Isomer production (years) & 13 & Oriented crystal (Miller number) \\
\hline 7 & Photon production (MeV) & 14 & Electron production (MeV) \\
\hline 8 & Unresolved level excitation (MeV) & 20 & $\begin{array}{l}\text { Transmission measurement } \\
\text { (barns/atom) }\end{array}$ \\
\hline
\end{tabular}

$\mathrm{a}_{\mathrm{S}}+80$ indicates relative distribution. 


\section{ECSIL Numeric Data Card Format}

Each data poini in the ECSIL numeric data card format is described by 8 re. quired quantities and from 4 to 10 experimentally ineasured components. All fields in the format are numeric las opposed to alpharumeric) and must be right adjusted. The end of a file is indicated by an end-of-file card, replacing tice end-of-data sentinel (i.e., $Z=300$ ) used in earlier versions of ECSIL.
The card format allows six of the measured components to appear on a first $\rightleftharpoons d$ ard the remaining four on a second card. The second card is present only if more than six components are required to describe the data point. Therefore each data point is described by either one or two card images. Table 6 described the ECSIL numeric data card format.

Table 6. ECSIL numeric data card format.

\begin{tabular}{|c|c|c|c|c|c|c|}
\hline Card & Field & Formal & Columns & Definition & & Relevant tables \\
\hline \multirow[t]{14}{*}{1} & 1 & i3 3 & $1-3$ & \multicolumn{2}{|c|}{$Z$ (atomic number of target) } & 1 \\
\hline & 2 & 13 & $4-6$ & \multicolumn{2}{|c|}{ A (atomic weight of target) } & 1 \\
\hline & 8 & I3 & $7-9$ & \multicolumn{2}{|c|}{$\begin{array}{l}\text { C (interaction num erical } \\
\text { ex̧uivalent) }\end{array}$} & $2,3,4$ \\
\hline & 4 & {$[2$} & $10-11$ & \multicolumn{2}{|c|}{ S (interaction modifier) } & 7 \\
\hline & 5 & E 10.3 & $12-21$ & \multirow{6}{*}{\multicolumn{2}{|c|}{ Measured components ( 4 to 10 ) }} & \multirow[t]{6}{*}{8} \\
\hline & 6 & $\mathrm{E} 10.3$ & $22-31$ & & & \\
\hline & 7 & E10.3 & $32-41$ & & & \\
\hline & 8 & E10.3 & $42-51$ & & & \\
\hline & 9 & $\mathrm{E} 10.3$ & $52-61$ & & & \\
\hline & io & E10.3 & $62-71$ & & & \\
\hline & 11 & 11 & 72 & \multicolumn{2}{|l|}{ Status $^{b}$} & 9 \\
\hline & 12 & 12 & $73-74$ & \multicolumn{3}{|c|}{ Year (last two digits: e.g., $1972 \Rightarrow 72$ ) } \\
\hline & 13 & 14 & $75-78$ & \multicolumn{3}{|c|}{ Reference number } \\
\hline & 14 & $\mathrm{I} 2$ & $79-80$ & \multicolumn{3}{|l|}{ Sub-reference number } \\
\hline \multirow[t]{10}{*}{$2^{a, b}$} & & & $1-11$ & \multicolumn{3}{|c|}{$(\text { Blank })^{C}$} \\
\hline & 15 & E10.3 & $12-21$ & \multirow{4}{*}{\multicolumn{2}{|c|}{ Measured components (continued) }} & \multirow[t]{5}{*}{8} \\
\hline & 16 & E10.3 & $22-31$ & & & \\
\hline & 17 & E10.3 & $32-41$ & & & \\
\hline & 18 & $E 10.3$ & $42-51$ & & & \\
\hline & & & $52-71$ & \multirow{2}{*}{\multicolumn{3}{|c|}{$\begin{array}{l}\text { (Blank) } \\
\text { Status }^{b}\end{array}$}} \\
\hline & 19 & $\mathrm{I} 1$ & 72 & & & \\
\hline & 20 & $\mathrm{I} 2$ & $73-74$ & Year & \multirow{3}{*}{\multicolumn{2}{|c|}{$\begin{array}{l}\text { Must be identical to } \\
\text { ccrresponding columns } \\
\text { on first cardc }\end{array}$}} \\
\hline & 21 & 14 & $75-78$ & Reference number & & \\
\hline & 22 & 12 & $79-80$ & Sub-reference number & & \\
\hline
\end{tabular}


a Second or continuation card is present only if data point requires more than $s 1 x$ motasured components to describe it.

b presence of second card is indicated by adding 5 to status $\left(\mathrm{K} . \mathrm{g}\right.$, , status $=1$ - $\mathrm{H}^{\mathrm{O}-}$ Inminary data, one card for data point; status $=6$ - preliminary aata, two cards iur data point).

${ }^{c}$ Only the status field indicates continuatiun, these fields are used to check that the continuation card, if required, is indeed present.

CARD 1

\begin{tabular}{|c|c|c|c|c|c|c|c|c|c|c|c|c|}
\hline 1 & 2 & 3 & 4 & 5 & 6 & 7 & 8 & 9 & $\begin{array}{r}\text { tatus } \\
10\end{array}$ & 11 & $2 \digamma_{13}^{\text {Year }}$ & 14 \\
\hline$z$ & A & 6 & $S$ & $\mathrm{D}_{1}$ & $\mathrm{D}_{2}$ & $\mathrm{D}_{3}$ & $D_{4}$ & $\mathrm{D}_{5}$ & $D_{6}$ & & Ref. No. & $\begin{array}{l}\text { Sub- } \\
\text { Ref }\end{array}$ \\
\hline 1.3 & $4-6$ & $7-9$ & $10-1$ & $12-21$ & $22-31$ & $32-41$ & $42-51$ & $52-6$ & $62-7 !$ & 72 & $75-78$ & $79-80$ \\
\hline
\end{tabular}

Field 1, (Z) Atomic Number of the Target

For molecules, the $Z$ of the target is deined to be the $z$ of the first element in the molecular formula (e.g., for $\mathrm{H}_{2} \mathrm{O}$, $\mathrm{Z}$ is defined to be 1 , the $\mathrm{Z}$ for hydrogen). See Table 1 for the present table of compourids and special isotopes.

Field 2, (A) Atomic Weight of the Target

For naturally occurring elemental mixtures of isotopes $A$ is defined to be zero. For monoisotopic elements the mass number of the single isotope is used (e.g., Fluorine, $A=19$ ). For molecules $A$ is defined to be the molecular weight of the molecule, rounded to the nearest integer, plus 300, (e.g., for $\mathrm{H}_{2} \mathrm{U}$, A $=$ (molecular weight of $\left.\mathrm{H}_{2} \mathrm{O}\right)+300=318$ ). For isomers, the $A$ number of the longest lived level is defined to be the mass number (e.g., ${ }^{242 \mathrm{~m}} \mathrm{Am}, \mathrm{A}=242$ ). For the shorter lived level, the A number is defined to be the mass number plus 600

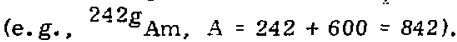
Radiolead is arbitrarily assigned the $A$ value of 999 . See Table 1 for a complete list of all compounds and special isotopes. General rules for $A$ are

- $A=0$ - Naturaily occurring elemental mixture.

- $1 \leq \mathrm{A} \leq 299$ - Individual isotofe.

- $300 \leq A \leq 599$ - Molecule.

- $600 \leq A \leq 998$ - Shor lived isomeric level.

- $A=999$ - Radiolead. 
Table 7. Field defiaitions for each numerical interaction wesignator (C) range.

\begin{tabular}{|c|c|c|c|c|c|c|c|c|c|c|c|c|}
\hline Card & & & & & & & & & & 3 & & \\
\hline fielit nunber. & 3 & a & $\therefore$ & + & $i$ & . & $y$ & 10 & 15 & 16 & 17 & 18 \\
\hline Contumns (nnetlosusei & $7-: ! \cdot$ & $10-11$ & $12-2-1$ & $21+3 I$ & $32-+1$ & $+2-i 3$ & $52-61$ & $62-i 1$ & $12-21$ & $22-31$ & $32=41$ & $+2+51$ \\
\hline Rowactio property & $r$ & $s^{2}$ & & & 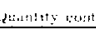 & ines: 6 ali : 11,1 & $3(10.31$ & & & & & \\
\hline 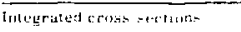 & $1-4:$ & & I: & $\triangle 1:$ & $\because 4$ & $2 c:$ & $x_{1}{ }^{11}$ & $\therefore$ & $x_{3}$ & $\lambda_{4}$ & $x_{3}$ & $x_{b}$ \\
\hline 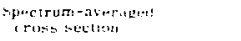 & ;1 - $-1: 4$ & & $r$ & $\doteq$ & $c^{2}$ & $\Delta 6 ':$ & $y$ & $s_{2}$ & $x_{i j}$ & $x_{4}$ & $x_{5}$ & $x_{t}$ \\
\hline Angular of =tritunions & $t+1-1 \cdot 1$ & & i: & $\Delta 1$ & ENint & c: & $\mathrm{sc}$ & $\therefore$ & $x_{2}$ & $x_{a}$ & $x_{4}$ & $x_{5}$ \\
\hline Entergy tistributum: & $2031-2+4$ & & $\cdot$ & $3:$ & $r$ & $21: 1$ & $c \rightarrow$ & $x,>$ & $i_{i}$ & $x_{2}$ & $x_{3}$ & $\therefore$ \\
\hline $\begin{array}{l}\text { Angular distributions } \\
\text { metegrated between fixed } \\
\text { antutiar limats }\end{array}$ & $2: i 1-24: 3$ & & $1:$ & $31:$ & (cositin & Icosit may; & $c, i$ & $s_{i} s$ & $x_{1}$ & $\therefore$ & $x_{i}$ & $x_{4}^{4}$ \\
\hline $\begin{array}{l}\text { Intioremitial energy-ungle } \\
\text { distribulionts }\end{array}$ & $30 !-34 ! !$ & & i: & $3:$ & $1:$ & anst & c:s & $.3 C_{1}$ & $\ddots_{1}$ & $x_{z}$ & $x_{y}$ & $x_{4}$ \\
\hline 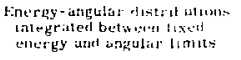 & $x+3 t-3 n+4$ & & I: & $\pm K$ & $F_{\text {man }}^{\prime}$ & $l_{m a x}$ & 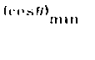 & $\left(\operatorname{Ln1} 5()_{\operatorname{trax}}\right.$ & 4,3 & $\Delta \mathrm{C}, \mathrm{s}$ & $x_{1}$ & $x_{2}$ \\
\hline 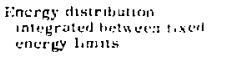 & $+111-1 ! 4 !$ & & I. & $31:$ & $r_{n=1 n}$ & $H_{\text {inits }}^{\prime}$ & c.s & $د C_{i} s$ & $x_{1}$ & $x_{2}$ & $x_{3}$ & $x_{t}$ \\
\hline 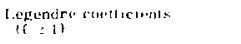 & $+1+1=151$ & & 1 & $د \mathrm{~B}$ & 1 & $\mathrm{Bi}^{\circ}$ & $3_{\text {in }}$ & $\mathrm{s}_{1}$ & $\mathrm{x}_{2}$ & $r_{3}$ & $x_{4}$ & $s_{5}$ \\
\hline Resonarice entegrat: & $50 \div-51 !$ & & $\because$ : & $F_{\text {mata }}$ & R.1. & si.l. & $\therefore$ & $x_{2}$ & $\lambda_{3}$ & $x_{4}$ & $x_{s}$ & $\lambda_{1}$ \\
\hline Pe,lanriadtesn & $\therefore 1-n+4$ & & l: & $31:$ & $c 11=11$ & $\mathbf{1}^{\prime}$ & Si & $x_{1}$ & $x_{2}$ & $x_{3}$ & $x_{4}$ & $\mathrm{~A}_{;}$ \\
\hline 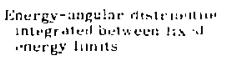 & $601-1,41$ & & 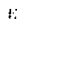 & $د:$ & $y_{m}^{\prime}$ & 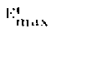 & cents & $c: s$ & $\Delta \mathrm{r}, \mathrm{si}$ & $\lambda_{1}$ & $x_{2}$ & $\therefore$ \\
\hline 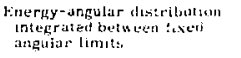 & $(1, \bar{x})-1+2+\cdots$ & & $\mathrm{r}$ & 21 & $\because$ & $(\cos [1)+1 x$ & $(\cos \theta)_{\mathrm{m} i \mathrm{i}}$ & $c_{i}$, & $\Delta \mathrm{C}, \mathrm{s}$ & $x_{2}$ & $\lambda_{3}$ & $x_{4}$ \\
\hline 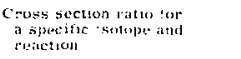 & $401-24 ! 1$ & & $\mathrm{I}:$ & $\Delta l:$ & R..1162 & 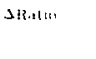 & $2 \lambda_{1}{ }^{4}$ & $c_{11}{ }^{2}$ & $x_{1}$ & $x_{2}$ & $\lambda_{3}$ & $x_{4}$ \\
\hline Nuclear netreperature & $5+40 t-i+10+4$ & & I & $\$ 1:$ & 1.1 & & ๆ & Iי & $\therefore$ & $x_{2}$ & $\lambda_{3}$ & $\lambda_{4}$ \\
\hline Thesmal sentlermér latu & mil & & .1 & S.i & or & d.x & $\therefore$ & $\Delta$ & $v$ & $\mathrm{~T}^{-}$ & $s_{1}$ & $\lambda_{2}$ \\
\hline 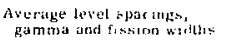 & {$[x+1)=5 ; i 4$} & & $1_{11:: 1}$ & tmax & Pitum & shuram & $\Delta_{1}{ }^{\prime}$ & $\mathrm{x}_{2}$ & $x_{3}$ & $x_{1}$ & $\lambda_{5}$ & $x_{i j}^{2}$ \\
\hline $\begin{array}{l}\text { Average teduced neut +ofl } \\
\text { uidibs atd stremgih } \\
\text { functions }\end{array}$ & $3+i-14 t$ & & $\mathrm{I}_{\mathrm{man}}$ & $V_{11 . .}$ & 1 & P.rum & DParitril & $x_{1}{ }^{\prime}$ & $x_{2}$ & $x_{j}$ & $x_{4}$ & $\lambda_{5}$ \\
\hline 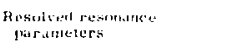 & $\because 51-1+4.014$ & & 1: & וا: & $1^{.1}$ & $\Delta \varepsilon^{x}$ & $x_{1}$ & $x_{2}$ & $\therefore$ & 4 & $\mathrm{~A}_{3}$ & $x_{1}$ \\
\hline
\end{tabular}

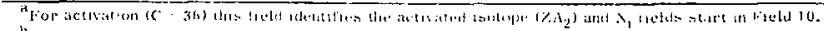

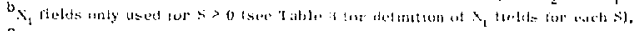

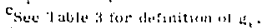

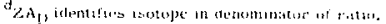

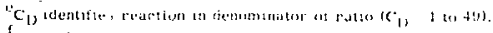

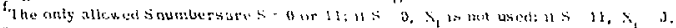

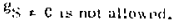

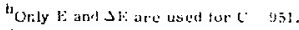

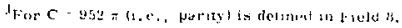


Field 3, (C) Interaction Designator

The interaction designator is the numerical sum of two numbers, the basic $C$ and the $C$ increment. The basic $C$ number describes the interaction (e.g. $l=$ total 2 = elastic, etc.), as cefined in Table 2. The $\mathrm{C}$ increment number describes the interaction property as defined in Table 3, e.g., from Table 2, $\left(n, n^{\prime}\right)$ is described by a basic $C=11$; the interaction designator for the $\left(n, n^{\prime}\right)$ cross section is $11,(11+0)$ whereas 311 $(11+300)$ indicates an $\left(n, n^{\prime}\right)$ secondary neutron energy spectrum).
A number of miscellanoous, usuadly derived quantities do not lend themselves to the scheme outlined above. These quantities have been assigned $C$ numbers in the range 200 to 999 and are all defined in Table 4. Table 7 defines the contents of each field for each range of the numerical interaction desigritor (C).

\section{Field 4 (S) Interaction Modifier}

All interaction modifiers are defined in Table 8. Relative distributions are indicated by $S+80$ (e.g., $C=22, S=0$ indicates a fission cross section (barn's);

Table 8. Interaction designator modifier (S number)."

\begin{tabular}{|c|c|c|c|c|}
\hline$S$ & Modifier & $\mathrm{x}_{\mathrm{i}}^{\mathrm{b}}$ field definition & Cuits & $\begin{array}{c}\text { Alluwed } \mathrm{Ai}_{\mathrm{i}}^{\mathrm{b}, \mathrm{c}} \\
\text { fields }\end{array}$ \\
\hline 1 & Level excitation & Energy of excited level & MeV & $1-6$ \\
\hline 2 & Isomer production & Half-Lile of isomer & Sec & $1-6$ \\
\hline 3 & lsomer production & Half-Life of isomer & Min & $1-6$ \\
\hline 4 & lsomer production & Half-Life of isomer & $\mathrm{Hr}$ & $1-6$ \\
\hline 5 & Isomer production & Halt-Life of isomer & Day & $1-6$ \\
\hline 6 & Isomer production & Half-Life of isomer & $Y \mathbf{r}$ & $1-6$ \\
\hline 7 & Photon production & Energy of photon & MeV & $1-6$ \\
\hline 8 & $\begin{array}{l}\text { Lnresolved level } \\
\text { excitation }\end{array}$ & $\begin{array}{l}\text { Lower }\left(x_{1}\right) \text { and upper } \\
\left(\mathrm{X}_{2}\right)\end{array}$ & MeV & 2 \\
\hline 9 & Material temperature & $\begin{array}{l}\text { Energs limits of } \\
\text { temputature levels }\end{array}$ & Kelvin & 1 \\
\hline 10 & $\begin{array}{l}\text { Lnresolved photon } \\
\text { excitation }\end{array}$ & $\begin{array}{l}\text { Lower }\left(X_{1}\right) \text { and upper } \\
\left(\mathrm{X}_{2}\right) \text { energy lirnits } \\
\text { of photons }\end{array}$ & $\mathrm{MeV}$ & $?$ \\
\hline 11 & Spin state & $\mathrm{J}$ & Dimensionless & 1 \\
\hline 12 & $\begin{array}{l}\text { Isotope bound in } \\
\text { material }\end{array}$ & $\begin{array}{l}Z_{A} A^{d} \text { of binding } \\
\text { material }\end{array}$ & Dimensionless & 1 \\
\hline 13 & Oriented caystal & Miller number & HKL & 1 \\
\hline 14 & Electron production & Energy of electron & $\mathrm{MeV}$ & $1-6$ \\
\hline 20 & $\begin{array}{l}\text { Transmission } \\
\text { measurements }\end{array}$ & Target thickness & Barn/Atom & i \\
\hline
\end{tabular}


$C=22, S=80$ indicates a relative fission cross section (dimensionless)l. $S=0$ or 80 indicates that onl $;$ the minimum number of fields are present, whereas all other $S$ values require one or more $x_{i}$ fields. See Table $\gamma$ for the position of $\mathrm{x}_{\mathrm{i}}$ fields for each range of the interactinn designator ( $C$ ), and Table 8 for the number of $X_{i}$ fields allowed for each $S$ value.

Fields $5-10\left(D_{1}-D_{6}\right)$ Experimentally Measured Components

Fields 5 10 of the first card (and fields 15- 18 of the second card if required) contain the actual results of the measurements. Table 7 defines the physical significance of each measured component for each range of the interaction designator (C). Conventions that have been adopted within the ECSlL system for handling or interpreting the measured components are:

- The energy is left blank for energydependent parameters (e.g., free atom cross section).

- A standard set of units (as opposed to arbitrary authul quoted units) is used. These units are: MeV, barn, steradian and Kelvin (e.g.. all level widths are in $\mathrm{MeV}$ ). An exception is that half-lives maj be expressed in seconds, minutes, hours, days or years (see Table 8).

- Only the latest cross section data are contained in the library. Superseded data are deleted from the library. Renormalized data are carried only in final form. Transmission data are not included in ECSIL, only derived cross sections.
- Uncertainties (e.g., cruss section error, energy resolution) are always expressed in the same units as the data with which they are associated (e.g., cross section and error both in barn, energy and error in $\mathrm{MeV}$ ).

- For spectrum-averaged cross sections no attempt is made to distinguish between thermal (Maxwellian) and thermal-reactor spectrum-averaged cross sections. Both are designated as spectrumaveraged cross sections at $0.025 \mathrm{eV}$. Similarly, fission-spectrumaveraged cross sections are entered with an equivalent energy of $2.0 \mathrm{Mel}$. Further differentiation is left to the annotations in the bibliographic library.

- Angular information for all two-body interactions are expressed in the center of mass system. Multibody reactions are naturally in the laboratory system.

- Legendre coefficier.ts are normalized (see Table 3), i, e, , $g_{0}=1$ and thus $g_{0}$ is never input.

- All resonance integrals include ine $1 / v$ cortribution.

- If for a resonance integral no upper energy limit is indicated, it is assigned a large value (e.g., 15 MeV).

- Spectrum-averaged $\alpha$ in the epithermal energy region is defined in the usual manner as the ratio of the capture resonance integral to that of fission. It is therefore assigned a $\mathrm{C}$ of 549 ( $\alpha$ resonance integral) rather than a $C$ of 99 (spectrum-averaged $\alpha$ ) 
- Parity $(C=952)$ is defined as +1.0 for + , or -1.0 for - .

- Fission widths may have either a + or - sign because they are assoniated with the interference term in a multilevel analysis.

Field 11 - Status Designator

The status indicates the current state or co.rdition of a data point. The three status categories and their numerical equivalents are listed in Table 9.

Table 9. Status designators.

\begin{tabular}{|c|c|}
\hline Dezignator & Status \\
\hline 0 (or blank), $5^{a}$ & $\begin{array}{l}\text { Data usable: without } \\
\text { restriction }\end{array}$ \\
\hline $1,6^{a}-$ & Prelìminary data \\
\hline $2,7^{a}$ & $\begin{array}{l}\text { Data not to be released } \\
\text { (usually at request } \\
\text { of author) }\end{array}$ \\
\hline
\end{tabular}

${ }^{a}$ For data points that require two input cards.

(Status designator +5 ) is used in the card format to indicate hat the data point is continued onto a second card. Fnr example a 1 in the status designaior field indicates a preliminary data point contained on one card. A 6 indicates a preliminary data point whose components are continued onto a second card. The status designator on the second card must be identical to that on the first."

Field i2 - Year

The last two digits of the year in which the data was published, or in the case of a private communication, the last two digits of the year in which the data was received (e.g., $1973 \Rightarrow 73$ ).

Field 13 - Reference Number

Seria! four digit reference number assigned when the reference is entered into the system. Reference numbers are never reassigned even after the data is deleted from the library.

Field 14 - Subreference Number

Designed ts lifierentiate between portions of the data from a given reference. Presently unused (i. e., always zero (0)).

\footnotetext{
"Regardiess of which set of numbers is used, the status sivred in the library will be 0,1 or 2 . This is important in planning programs ta manipulate date from the ECSIL library tapes. Any such program must reconstitute the original status designator in its output.
}

CARD 2

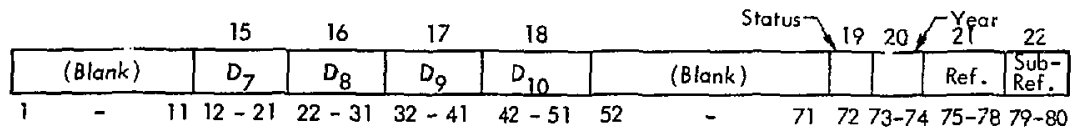


Card 2 is only present if over six experimentally measured components are required to describe a given data point. The presence of card 2, the continuation card, is indicated by a status of five or greater (see Field 11 ). The status, as well as year, reference, and subreference, must be identical on bein first and second cards. Columns $1-11$ (Z, A, C, S fields) on the second card must be blank.
Fields 15-18 - Experimentally Measured Components

See Fialds 5-10 of card 1 for all conventions associated with the measured components.

Fields 19-22 - The Status, Year, Reference Number and Sub-Reference Number

These items on the continuation card must be identical to the corresponding fields of the first card. See Fields 11-14 of card 1 for all conventions assnciated with these fields.

\section{ECSIL Numeric Data Library Format}

\section{LIBRARY ORGANIZATION}

- Although the following description of the ECSIL library discusses quantities that appear to be fixed point in nature ie.g., $Z A$, word counts), every word within the ECSIL numeric data library is stored in floating point.

- The data points within the ECSIL numeric data library are sorted into order according to the numerical equivalents used to describe the target $(Z, A)$, the interaction $(C, S)$, etc. Status, year, reference or sub-reference number are not used to sort the library.

- The oyerall uorting order of the information in the data file is as follows: all data are sorted first by the $Z A$ number $(1000 Z+A)$. With the exception of resolved resonance parameters (951 $\leq \mathrm{C} \leq 999$ ), the next sort is on $C$ number (see Tables 2, 3 and 4). Excluding all resonance parameters $(941 \leq \mathrm{C}$ $\leq 999$ ) this is followed by a sort on the $S$ numbers, along witli their pertinent data fields, $\mathrm{X}_{\mathrm{i}}$ (see Table 7). Subsequent sorting criteria depend upon the interaction property measured. Table 10 describes all sort criteria after $Z A$.

\section{LIBRARY FILE STRUCTURE}

Figure 1 displays the organization of the ECSIL data library.

- The numeric data library is divided into 12 files, each containing a range of $Z$ values. These files are always read from disk, as opposed to magnetic tape, and are identified as follows:

\begin{tabular}{lrrr} 
Filename & & \multicolumn{2}{c}{ range } \\
\cline { 1 - 1 } LIB001 & & $1-7$ \\
LIB002 & & $8-13$ \\
LIB003 & & $14-22$ \\
LIB004 & & $23-26$ \\
LIB005 & & $27-34$ \\
LIB006 & & $35-45$ \\
LIB007 & & $46-59$ \\
LIB008 & & $60-78$ \\
LIB009 & & $79-91$
\end{tabular}




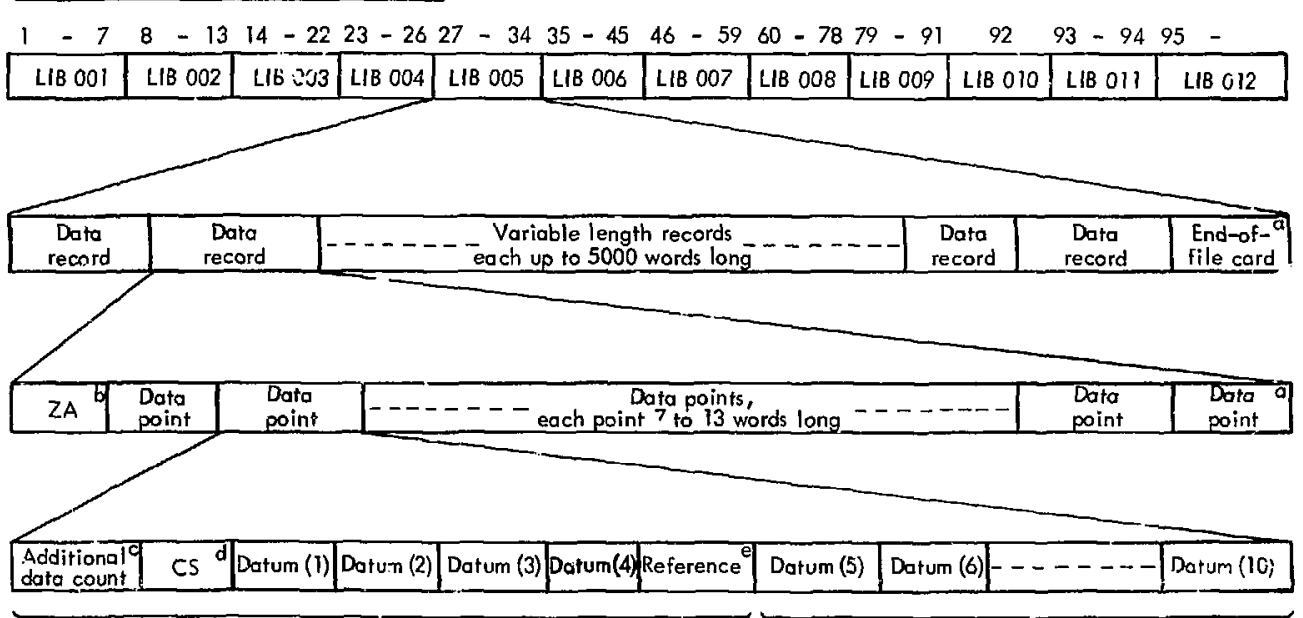

Minimum basic data point ( 7 words)

Additional data components ( 0 to 6 words)

a - End-of-file and record sentinels are no longer used.

b - $Z A=1000 Z+A$ - first word or each binary record - applied to all deta points in record.

c - Count of additional data components ( 0 to 6$)$.

(All words in ECSIL, including additional cota count, are floating point numbers.)

d- $C S=100 \mathrm{C}+5$.

e - Reference $=($ status number $) \times 10^{8}+($ yeor $) \times 10^{6}+($ reference No. $) \times 10^{2}+($ sub-reference numbei $)$. 


\begin{tabular}{|c|c|}
\hline Filename & $Z$ range \\
\hline LIB 010 & 92 \\
\hline LLBO 11 & $93-94$ \\
\hline LIB 022 & $95-$ \\
\hline
\end{tabular}

The division of the library into a number of relatively sma!l volumes, each with a separate $Z$ rarge, greatly simplifies updating and r.etrieval. Only those volumes affected need be present on the disks.

- Each of the 12 library volumes is composed of a number of variable length data records, each up to 5000 words long. The file is terminated by an end-of-file. This replaces the end-of-file sentinel used in earlier versions of $\mathrm{EC}^{\mathrm{er}} \mathrm{L}$.

Table 10. Sort order of ECSIL data library within a given ZA.

\begin{tabular}{|c|c|c|c|c|c|c|}
\hline \multirow[b]{2}{*}{ C range } & \multicolumn{6}{|c|}{ Sorting criteria } \\
\hline & 1 & 2 & 3 & 4 & 5 & 6 \\
\hline $1-99$ & C & $\mathrm{S}$ & $x_{i}^{a}$ & $E^{b}$ & & \\
\hline $101-149$ & & & & $\mathrm{E}$ & $\cos \theta$ & \\
\hline $201-249$ & & & & $\mathrm{E}$ & $\mathrm{E}^{\prime}$ & \\
\hline $251-299$ & & & & $\mathbf{E}$ & $(\cos \theta)_{\min }$ & \\
\hline $301-349$ & & & & $\mathrm{E}$ & $E^{\prime}$ & $\cos \theta$ \\
\hline $351-399$ & & & & $\mathrm{E}$ & $\mathbf{E}_{\min }^{\prime}$ & $(\cos \theta)_{\min }$ \\
\hline $401-449$ & & & & $E$ & $E_{\min }^{\prime}$ & \\
\hline $451-499$ & & & & $E$ & $\ell$ & \\
\hline $501-549$ & & & & $\mathrm{E}_{\min }$ & & \\
\hline $551-599$ & & & & $\mathrm{E}$ & $\cos \partial$ & \\
\hline $601-649$ & & & & $\mathbf{E}$ & $\mathrm{E}_{\mathrm{min}}^{\prime}$ & $\cos e$ \\
\hline $651-699$ & & & & E & $E^{\prime}$ & $(\cos \theta)_{\mathrm{min}}$ \\
\hline $801-849$ & & & & $\mathrm{ZA}_{\mathrm{D}}^{\mathrm{d}}$ & $C_{D}^{e}$ & $\mathbf{E}$ \\
\hline $900-904$ & & & & $\mathbf{E}$ & $\mathbf{E}_{\min }^{\mathbf{t}}$ & \\
\hline 911 & & 1 & l & $\mathrm{T}$ & $\alpha$ & $\beta$ \\
\hline $941-943$ & & $0^{\mathrm{C}}$ & 0 & $E_{\min }$ & $\mathrm{J}^{\mathrm{f}}$ & \\
\hline $944-946$ & $\varphi$ & 0 & 0 & $\mathrm{E}_{\mathrm{min}}$ & $\ell$ & $\mathrm{J}^{\mathrm{f}}$ \\
\hline $951-999$ & 951 & 0 & 0 & $\mathrm{E}$ & $c$ & \\
\hline
\end{tabular}

$\vec{a}_{\text {lf }} \mathrm{S}=0$, sort key defines $\mathrm{x}_{\mathrm{i}}=-1.0 ; \mathrm{i}=1,0$.

${ }^{b}$ Activation $(C=36)$ is a special case. The sorting criterion is iirst $Z_{2}$, the $Z A$ of the activation product, and then $E$.

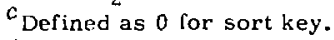

${ }^{d} Z A_{D}$ identifies isotope in denominator of ratio.

${ }^{e} C_{D}$ identifies reaction in denominator of ratio $\left(C_{D}=1\right.$ to 49$)$.

${ }^{f}$ Defined as -1.0 for sort key if $\mathrm{J}$ not given $(S=0)$. 
- A given variable length data $r$ ecord only applies to a single ZA. However, for a given $Z A$; there may be as many data records as are required to hold all of the data points associated with the $\mathrm{ZA}$, each record 5000 words or less in length. The ZA only appears once in each data record, as the first word, (in floating point). The remainder of the data record is made up of a series of data points. Since the data records are of variable length, no end-of-record sentinel is used as in earlier versions of ECSIL.
- Each data point is composed of from 7 to 13 words. The first seven words contain the minimum information associated with a data point: C, S, status, year, reference number, sub-reference number, four measured compositions and a count of the extra number word ( 0 to 6 -in. floating point). The remaining zere to six words contain additional measured compositions, as outlined in the description of the numeric data card format. The contents of the first seven words are:

1 - Additional word count (0 to 6$)^{\text {* }}$

$2-$ Combined $\mathrm{CS}^{* *}=100 \mathrm{C}+\mathrm{S}$

3 - Measured quantity (1)

4 - Measured quantity (2)

5 - Measured quantity (3)

6 - Measured quantity (4)

7 - Combined reference ${ }^{*}=$ status $\times 10^{8}+$ year $\times 10^{6}+$ (Ref. No.) $\times 10^{2}+$ (sub. Ref. No.). (Status is always storeo as 0,1 or 2.)

The contents of the remaining fields are:

$$
\begin{aligned}
& 8-\text { Measured quantity (5) } \\
& 9-\text { Measured quantity (6) } \\
& 10-\text { Measured quantity (7) } \\
& 11-\text { Measured quantity (8) } \\
& 12-\text { Measured quantity (9) } \\
& 13-\text { Measured quantity (10) }
\end{aligned}
$$

See Table 7 for definition for each range of $C$ values.
See Tables 7 and 8 for definition for each value of $S$ and range of $C$ values.

All words in library are floating point. 
- Each data point is immediately

followed by another until the end of

the variable length data record is

reached, The record address of

the first point is the reccrd is

always the second word (immediately

following $Z A$ ). If $P_{i}$ is the record address of the first word of the $i^{\text {th }}$ data point on the record and $\mathrm{N}_{\mathbf{i}}$ is the corresponding additional word count, the record address of the first word of the $(i+1)^{\text {th }}$ data point is $P_{i+1}=P_{i}+7 N_{i}$ (i.e., $7+N_{i}$ words from the start of the $i^{\text {th }}$ data point).

\section{ECSIL Bibliographic Information Format}

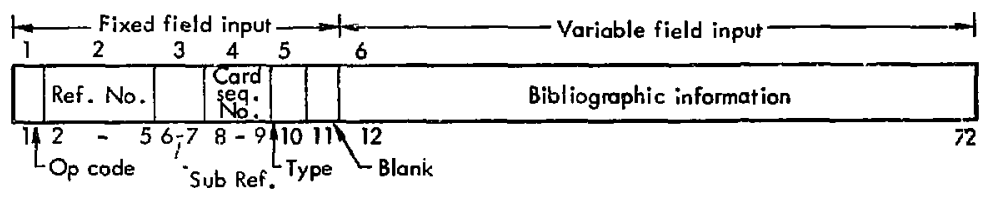

A card image format is used throughout the ECSIL bibliographic information system: for preparation of new information, for storage, and for retrieval.

\section{FIXED FIELDINPUT}

\section{Field 1 - Operation Code}

For the vast majority of the references in the bibliography file this field is blank. The exceptions to this rule are alternate corms for the reference, usually conferences. For example there are a number of references from the conference "Nucl. React. w/Light Nucli/Nucli. Struct. Rossendorf (1967)." However references from this conference may also be listed under: "Proc. 2nd Conf. Nucl.
React. w/Iight N-N Struct, Rossendorf (1967)." Reference number 2917 was used to enter the later title and to indicate that in lieu of this title the user should look under the former title. Such alternate references are the only reference numbers not associated with data in the numeric data file. The operation code minus ( - ) is used in this case to indicate that the reference number is merely an alternate form.

The only operation codes iounc in the library are blank or ainus (-). Fcwever this column is used during uptiate or retrieval runs to indicate retrieval (R) or deletion (D) of the reference number that appears : field 2, col.2-5. Therefore a complete list of operation codes is: $\left.\begin{array}{cl}\text { Blank } & - \text { Normal reference } \\ - & - \text { Alternate form lor refe. encts } \\ \mathrm{R} & - \text { Retrieve reference numiser in field } 2 \\ \mathrm{D} & - \text { Delete reference number in field } 2\end{array}\right\}$
Only fields 1 and 2 are used on cards that have these operation codes. 
Field 2 - Reference Number

This field is blank on all cards but the first nard of each reference number. The reference number is a unique four digit integer that must be assigned to each primary reference entered into the bibliography library.

Field 3 - Subreference Number

This field is designed to differentiate between portions of the data from a given reference. Presently unused (i.e., field is always blank).

Field 4 - Card Sequence Number

An integer, beginning with one (1) on the first card of each reference number arr requentially increasing on successive cards of the reference number. If there are over 99 cards for a givan reference number the sequence may be repeated from 1 to 99 as many times as required.

Field 5 - Card Type

Each card of a reference number must he designated as type 1,2 or 3 to indicate: (1) Reference information, (2) Commentary or (3) Cross reference information.

\section{VARLABLE FIELD INPUT}

Columns 12 through 72 of the bibliographic information cards contain reference information of which the field boundaries are determined by the punctuation rather than fixed column limits. Spaces are ignored except as noted. Information should follow in the order indicated.

The contents of a bibliographic information card depends on the card type (see field 5, above). The following sec- tion describes each of the three card types.

\section{Type 1}

Type 1 cards describe the primary reference by giving the journal or report series title, qualifying information (e.g. , part, section, series, etc.), volume, page, and/or report number, followed by the year, a list of lithors, and linally the institution. Any number of type 1 cards may be used. There are four distinct lields that may appear on a type 1 card: referancs, date, authors, and institution. Conventions associated with these fields are:

Reference - The repori or publication title must appear on the first card of any reference number and cannot be continued onto subsequent cards. The reference is considered to extend from column 12 up to the date. Acceptable abbreviations should be used whenever possible. (See the current alphabetically ordered bibliographic ist. ${ }^{5}$,

- Maximum reference length is 55 characters

- Publications are divided into three types that require different coding conventions:

1. Periodicals

- journal Name - Use accepted abbreviations whenever possible. (See the current alphabetically ordered bibliographic list. ${ }^{5}$ )

- Qualifying information - Optional further description of journal name but not actually part of it (e.g., series, section, part). If present this field must begin with a comrna. 
- Volume - Must be numeric and end with a comma.

- Page - Must be numeric.

2. Reports

- Report Series - Use accepted abbreviations whenever possible. (See the current alphabetically ordered bibliographic list. ${ }^{5}$ )

- Report Number - Must be numeric and immediately preceded by a hyphen.

- Qualifying information - Optional further description of report name but not actually part of it (e.g., series, section, part). All information between the last numeric characters of the report number and the date is considered to be qualifying information.

3. Other publications

- Name or Title of Publication Use accepted abbreviations when. ever possible, (See the currert alphabetically ordered bibliographic list. ${ }^{5}$ )

- Qualifying Information - Optional further description of publication name but not actually part of it (e.g., series, section, part). If present this field must begin with a comna.

Date - Must follow the reference and must also be on the first card. The date must be given as a four digit integer enclosed in parenthesis in the form (19XX) or, if the dacument is undated (0000). The date should be the year of the publication or private communication and is always six characters long.

Authors - Names may follow the date, either immediately on the first card or on following cards.
- Maximum author's name length is 28 characters.

- Any number of authors may be listed.

- An author's name may never be continued onto a subsequent card. (i. e., must be wholly on one card).

- Any number of authors may appear on a card.

- Any number of cards may be used to list authors.

Punctuation rules that allow individual author's names to be recognized and manipulated by a computer are:

- Initials (if preserit) must prerede the last name.

- Eacr initial may contain more than one letter, but each initial must be followed by a period (e.g., Yu. S. Zamyatnin).

- Commas le g. . H. E. Montgomery, Jr. ) and single blanks (e.g., T.W. De Witt are allowed.

- The end of an author's name is indicated by a comma followed by a blank if another author's name follows, 〈e.g., R. K. Smith, F.. L. Henkel). In the case of the last author, follow with two bla lks or a blank followea iy a parenthesis (e.g., T. S. Green (AWRE)).

- An author's name may not contain a comma followed by a blank, two blanks, or a blank followed by $a$ parenthesis.

lnstitution - If present, the institution name should follow the last author's name and be enclosed in parenthesis (e.g. T. S. Greene (AWRE)). The institution refers to the place where the 
work was donc, not an author's place of employment.

\section{Type 2}

Commer $r_{2}$ ts consistit:g of a'phanumeric lext may be input as desired in the variable field part of type 2 cards (columns 12-72). This information may be used to describe the experiment or the data. Any number of comment cards may be used, all identified as type 2 .

\section{Type 3}

Cross reference information in exactly the same format as type 1 cards appear on type ${ }^{3}$ cards. The following conventions replace those used in earlier versions of ECSIL.
- Cross zeferences of the form "SEF. ALSO REFERENCE XXXX," wher $\mathrm{X} \times \mathrm{XX}$ may be any reference num $r$ in the library, may appear only is a comment, type 2, card.

- For stataments such as "SEE ALSO" followed by a reference name, "SEF. ALSO" should bo on a comment, type 2, card and the reference name on the following, type 3 , s.

- Each cross reference must appear on a new card.

- There is no limit to the number of cross references per reference number.

\section{ECSIL Program System}

\section{OVERVIEW}

The programs that are used to maintain ano edit the ECSIL library are all written in FORTRAN-IV and are presently implemented on the Lawrence Livermore Laboratory CDC -7600 computers and IEM-1360 photostore. These programs are summarized in Table 11.

The ECSIL numeric data system includes a complete set of file maintenance programs capable of sort/merge, update, delete and retrieval operations. These programs also supply editing capabilities and prepare index listings, ${ }^{4}$ interpreted listings, and graphical displays. 1,2 There are also many programs for iranslating experimental data to the ECSIL format or for performing calculations and evaluation based upon data retrieved from the library. This volume, however, will describe only the file mainienance and editing programs.

The entire system of programs is optimized both from the viewpoint of the user and computer. The programe are optimized for the user by proviting similar input format for all programs. by minimizing input options and ou!put lines, and by using a common set of filenames to reference the required information. These features mais program oparation easy to learn and $t_{0}$ remeinber.

The programs are optimized for the CDC-7600 computer by minmizing the core and execution tims si the proginams. In particular the smi:'l core memo:y (SCM) requirements of each program is ils the range $20-35 \mathrm{~K}_{10}$, mininum ase is made of tha large core mersory (i.CM), in no case exceding $20 \mathrm{~K}_{10}$, and extarsive 
Table 11. ECSIL program sunmary.

\begin{tabular}{|c|c|c|c|c|c|c|c|c|c|c|}
\hline \multirow[b]{2}{*}{ Prugram } & \multirow[b]{2}{*}{ Function } & \multirow{2}{*}{$\begin{array}{c}\text { sized } \\
\text { (SCHisn) }\end{array}$} & \multirow{2}{*}{ 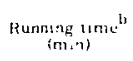 } & \multicolumn{3}{|r|}{ Input } & \multirow{2}{*}{$\begin{array}{l}\text { Detault } \\
\text { uption }\end{array}$} & \multirow[b]{2}{*}{ l. 1103 in } & \multirow{2}{*}{\multicolumn{2}{|c|}{ Files unt }} \\
\hline & & & & $C: \mathbf{r} r$ & Col + . & [escruption & & & & \\
\hline ECSBIB & $\begin{array}{l}\text { Retriese from or } \\
\text { update bibliographic } \\
\text { librury (merge, } \\
\text { delete, retreves }\end{array}$ & is & 0.2 & $i$ & $\begin{array}{l}i-5 \\
6-10\end{array}$ & 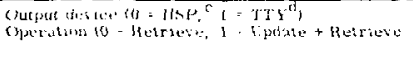 & $\begin{array}{l}0 \\
0\end{array}$ & $\begin{array}{l}\text { BIBLIB } \\
\text { BIBLDI }\end{array}$ & 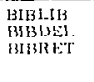 & (131 JaOH D \\
\hline ECsCEN & $\begin{array}{l}\text { Check data library, } \\
\text { report un points } \\
\text { per } 7 . A \text { in library }\end{array}$ & $21+$ & 1.8 & 1 & $\begin{array}{l}1-5 \\
\vdots-10 \\
1,-10 \\
11-1 \\
16-20\end{array}$ & 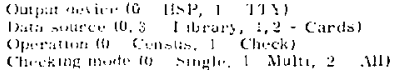 & $\begin{array}{l}0 \\
0 \\
0 \\
0\end{array}$ & $\begin{array}{l}\text { 1.1BOU1 } \\
- \\
1.15012\end{array}$ & & \\
\hline ECSCHK & Check cári turmat & 134 & 0.5 & 1 & $1-5$ & 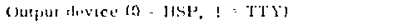 & $\theta$ & LSSORT & & \\
\hline ECSIJEL & $\begin{array}{l}\text { Delete data from } \\
\text { datu library }\end{array}$ & $26,6 j$ & $? .0$ & $\frac{1}{2-2}$ & $\begin{array}{l}1-\overline{3} \\
610 \\
1-80\end{array}$ & 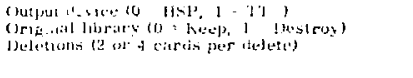 & Aluort & $\begin{array}{l}\text { 1.1 } \\
+ \\
1.13001 \\
\end{array}$ & $\begin{array}{l}1.13001 \\
1.113012\end{array}$ & 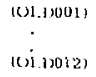 \\
\hline ECsisex & $\begin{array}{l}\text { Create indexes t: } \\
\text { data libr. } \mathrm{y}\end{array}$ & $25 \mathfrak{b}$ & 3.8 & 1 & $\begin{array}{r}1-5 \\
7-7 \\
13-10 \\
12-15\end{array}$ & 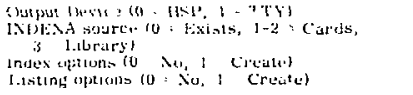 & $\begin{array}{l}0 \\
3 \\
111 \\
1111\end{array}$ & 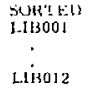 & 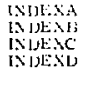 & 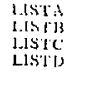 \\
\hline ECSMRG & $\begin{array}{l}\text { Merue surted } \\
\text { card files }\end{array}$ & $18 \cdot 8$ & 0.7 & 1 & $\begin{array}{l}i-5 \\
i-10\end{array}$ & 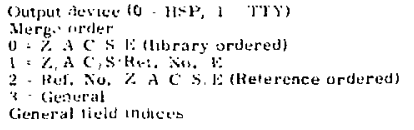 & $\begin{array}{l}0 \\
0\end{array}$ & $\begin{array}{l}\text { SOTYODOS } \\
\text { SOHTOOL } \\
: \\
:\end{array}$ & SORTED & \\
\hline ECSORT & Sort card filt: & $28 ; 16$ & 1.2 & 1 & $\begin{array}{l}1-13 \\
0-10 \\
13-20\end{array}$ & 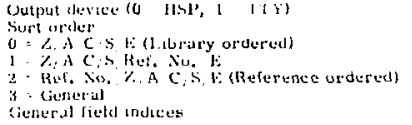 & $\begin{array}{l}0 \\
\text { D }\end{array}$ & Lxsont & 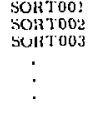 & \\
\hline
\end{tabular}

\section{Continued cn next page.}


Table 11. (continued)

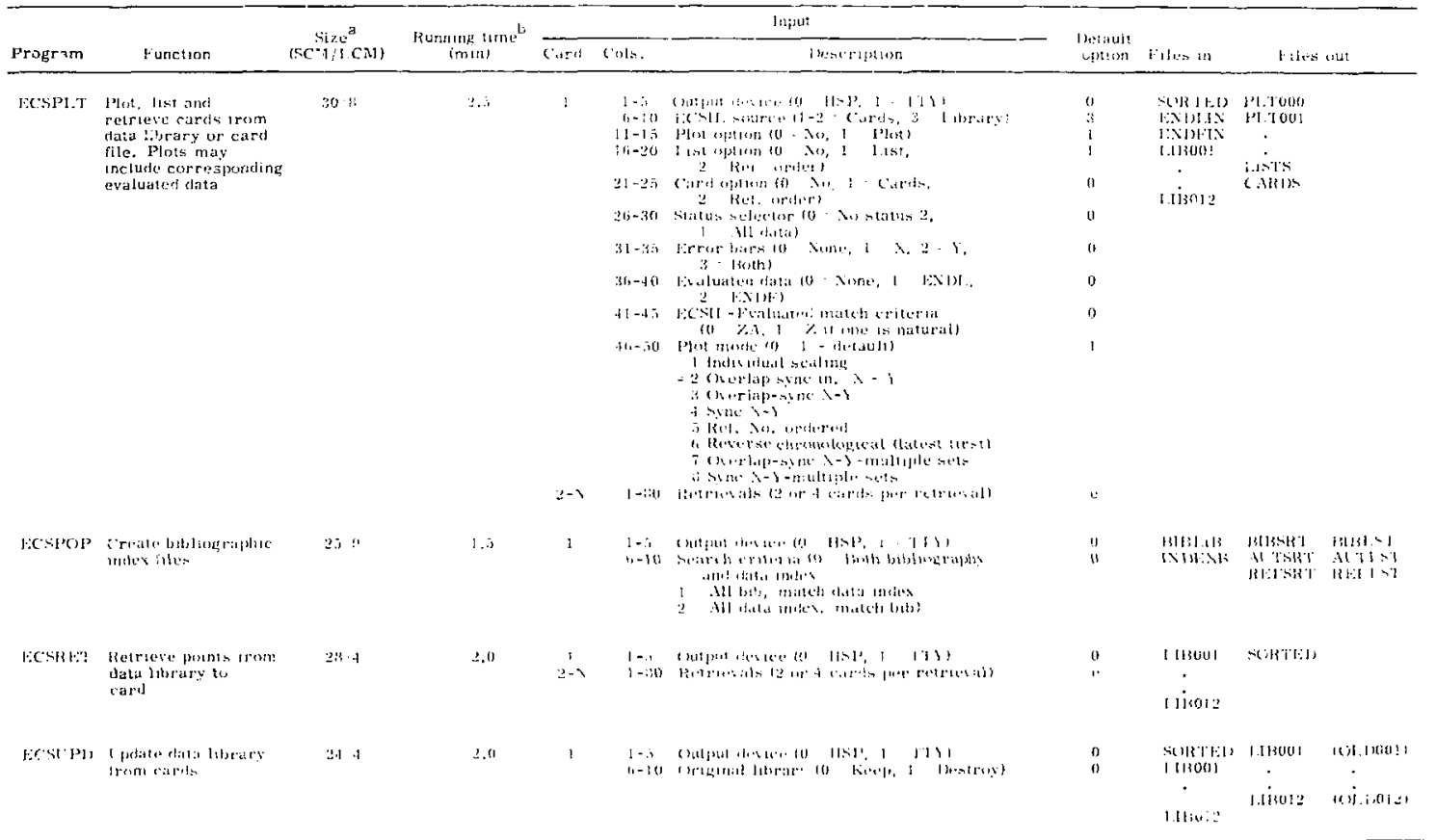

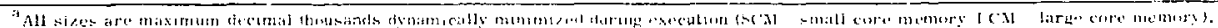

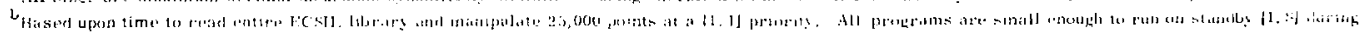
the slay.
}

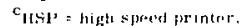

d.TY = teletypr.

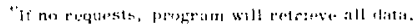


use is made of scratch disk files. This combination of features allows all of the programs to be operated in standby priority $[1,5]$ during the day to minimize computer charges and yet still maintain good response time.

COMMON DESIGN FEATURES

There are three features of the system of programs that are common to all programs and that greatly simplify the process of learning and remembering how to operate the programs. These features are minimum input/output and common filenames.

\section{Input Cards}

Ajl of the programs are designed to read input parameters from the INPUT file. However, if there is no INPUT file present they will execute with a standard set of default options (see Table 11). The default options are desig jed to facilitate operations perfor $\mathrm{m} \leadsto \mathrm{d}$ during normal file mainterance and editing procedures. Therefore, the TNPUT file is only equired if one wishes to periorm a special operation.

Even when the INPUT file is present, the number of parameters that must be supplied by the user is minimum. All proglams read only one parameter card that specifies program options. Several programs then read additional cards that describe the data to be retrieved, deleted, plotted, etc.

General rules that apply to the parsmeter card are:

- All input is integer and in I5 format whenever possible.
- Arrays of yes/no type choices will be right adjusted into series of 5 or 10 columns (e.g., 1X, 411 ; $3 X, 7 I 1)$.

- Yes (or do it) is always indicated by a one (1) (or $>0$ ), and no (or Jon't) is always indicated by a zero $(0)$ (or $\leq 0)$.

- Columns 1-5 always indicate the output listing device $10=$ high speed printing (hSP), 1 - teletype (TTY)). High speed printer is always the default option, if INPUT file is not present. General rules that apply to all cards, if any, following the parameters card are:

- All cards are in the ECSIL card image format and specify data requests (e.g., retrieve, delete, plot, list).

- Each data request is specified by one or, if "ards are continued, two pairs of cards; the former of each pair giving the lower limit of each field and the latter giving the upper limit.

- Limits may be specified for any or all of the 18 fields described in the card format.

c A blank (not zero) field indicates "no limit," whereas a zerc field irdicates a zero (0) limit (e.g., blank A (atomic weight) field limits indicates the whole gamut, including all isotopes and comfounds of the element, whereas zero field limits indicate only the elemental mixture $(A=0))$.

- The end of the input cards is indicated by an end of file.

- For programs that expect data requests, the default option (no 
IN PUT file, or no requests on the input file) is to request everything (e.g., retrieve, plot, list everything). Delete everything has no meaning and program will simply terminate.

\section{Output Listings}

The output listing provided by every program is designed to provide enough information to properly document and simply check the operation of any program or series of programs. The information supplied by all programs includes:

- Indentification of the program, computer and date.

- Interpretation of all input parameters, or list of default options if no input file).

- Interpretation of all data requests (always on high speed printer).

- Statistics of all data points and/or cards read and/or written by the program. These statistics are designed to monitor not only the size of the library and card files, but also program operation. They insure point and card "conservation" during any sort/merge, update, delete and/or editing operation. Each statistic can be independently obtained from at leant two programs fe.g., the number of points in each library volume is defined during an update and may be verified during a data index creation).

Unless the program encounters an error condition, this is the only output listing information supplied. An update operation, for instance normally has only 14 lines of information output: identification of program, computer and date, one line of statistics for each of the 12 library volumes and finally statistics for the library as a whole. This output information is in a form that can be retained to document each version of the library.

\section{Filenames}

A feature of the ECSIL system of programs that has greatly simplified the input and made disk files easily recognizable is the use of standard filenames. All output files are left on disk to facilitate storage in the photcstore and allo:" as many copies as required to be made. Standard fiienames are defined below.

Binary Library - The existing 12 volumes of the ECSIL binary data library are referred to by the filenames: LIB001, LIB002, . . LIB0 11 and LIB012 respectively. Turing a library update or deletion the altered volumes of the library are defined as temporary files: TMPOD1, TMP002, ... TMP011 and TMP0:2 respectively. At the conclusion of the library update or deletion the uriginal volumes (if altered) are renamed as a backup version as: OLD001, OLD002, ... OLD011 and OLD012 respectively. The new altered volumes become: LIB001, LIB002 ... LIB011 and LIB012 respectively. Therefore following an update or deletion the current library will still be LIB001-LIB012. 'The replaced volumes will be OLDOD1-OLD012 (only those replaced), and the temporary files TMP001-TMP012 will have disappeared. In summary:

- LIBONN (NN = Di-12) Current ECSIL binary cata files.

- OLDONN (NN = 01-12) Penultimate ECSIL binary data filles.

- TMPONN (NN = 01-12) Temporary files. 
Numeric Data Cards - Data card files are considered to be either sorted or unsorted and are referred to by the filenames: SORTED or UNSORT respectively. If there is a conflict to this convention, such as a program reading and writing a sorted card file, the input file is called SORTED and the output file is called CARDS. Multiple SORTED files that are to be merged togethor to form a single sorted file are called SORT001, SORT002, ... SORTONN (as many as required) and the merged output file will be called SORTED. In summary:

- SORTED - sorted ECSIL numeric data card images.

- UNSORT - unsorted ECSIL numeric data card images.

- CARDS - sorted ECSIL numeric data card images (program already using filename: SORTED.)

- SORTONN (NN = 01 to 99) - individually sarted files to be merged.

Evaliated Cross Sections - The Livermore Evaluated Nuclear Data Library (ENDL) and the Evaluated Nuclear Data File/version B (ENDF/B) are read using the filenames (ENDLIN and ENDFIN respectively. In summary:

- ENDLIN - evaluated nuclear data library (ENDL)

- ENDFIN - evaluated nuclear data file (ENDF/B)

Numeric Data Listing, Plotting and Index Files - Interpreted data listing files are always named LISTS, and plotting files are a series of files called PI TO01, PLT002,... PLTONN (as many as kequired.' The plotting files are normally $t_{1}$ en processed through the program FROG ${ }^{6}$ to obtain $35 \mathrm{~mm}$ film, microfiche, printer, etc. hardcopy. Reaction indexes are made in four sort orders: (a) Z/A/C/S/E (Library order), (b) Ref. No. $/ Z / A / C / S / E$ (Reference number order), (c) C/S/Z/A/E (Interaction number order) (d) Basic $C / C$ Increment/S/Z/A/E (Basic interaction number order: Both machine readable and interpreted listing files are made for each sort order. The machine readable files are named: INDEXA, INDEXB, INDEXC and INDEXD, while the interpreted listings are named: LISTA, LISTB, LISTC and LISTD respectively. In summary:

- LISTS - Interpreted data listing file.

- PLTONN (NN = 01 to 99) - Plotted data files (UCRL-50400, Vols. 7-8).

- INDEXN (N = A to D) - Machine readable reaction index files.

- LISTN (N = A to D) - Interpreted reaction index files (UCRL-50400, Vol. 3).

Bibliographic Card Image Files - The current bibliographic library is named BIBLIB and the penultimate version is named BIEOLD. Tirece additional bibliographic filenames have been defined. BIBUPD contains all new bibliographic information for inclusion in the library as well as deletion and retrieval requests. BIBRET contains bibliographic information retrieved from the library. BLBDEL contains bibliographic information deleted from the library. In summary

- BIBLIB - current bibliographic library file.

- BIBOLD - penultimate bibliographic library file. 
- BIBUPD - update (new bibliographic information), deletion and retrieval request file.

- EIBRET - retrieved bibliographic card file.

- BIBDEL - deleted bibliographic card file,

Bibliographic Listing and Index Files Three bibliographic listing and index orders are routinely prepared: (1) a reference number ordered, combined bibliographic and data index, (2) an alphabeticnlly ordered listing of all references, (3) an alphabetically ordered listing of all author citations. For each ordering a machine readable file and an interpreted listing are made. In summary

- BIBSRT - machine readable, reference number ordered, combined bibliography and data index.

- REFSRT - machine readable, alphabetically ordered references.

- AUTSRT - machine readable, alphabetically ordered author citations.

- BIBLST - interpreted combined bibliography and data index."
- REFLST - interpreted alphabetically ordered references.

- AUTLST - interpreted alphabetically ordered author citations.

Scratch Files- Scratch files, as many as are required, are named SCR1, SCR2, etc. all scratch fil:s are destroyed at the end of the program.

\section{PROGRAM OPERATION}

The following section describes each - of the ECSIL programs in turn in the order in which they are normally used to first check and enter numeric data into the library, to delete or retrieve data, to create listings, plots, and indexes of the data. Then the programs used to update the bibliography and create listings and indexes of the bibliography are described. This is followed by a summary of the program in alphabetic order.

\section{Program Names}

The programs will be discussed in the following order.

\footnotetext{
UCBL-50400, Vol. 2
} 


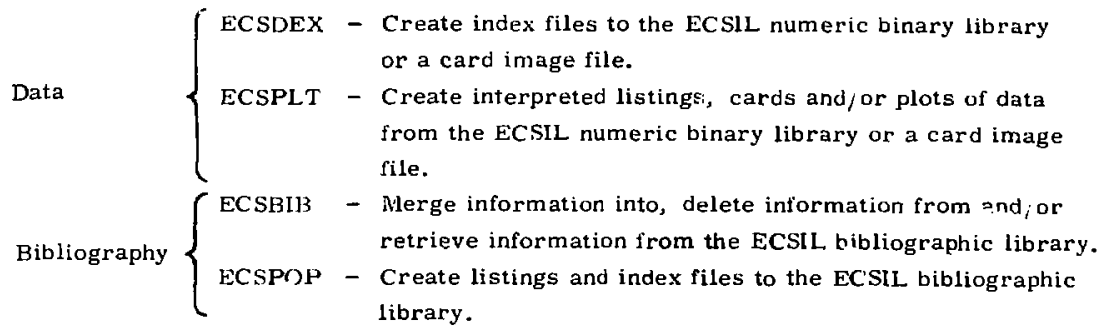

Program Availability

All ECSIL programs have been compiled, loaded and are ready for execution. They may be obtained from the IBM-1360 photostore, where they are stored under the name of the program in the. $\Gamma: E C S I L$ directory of user 193025 (e.g., ELF RDS $.193025:$ FCSIL: ECSPLT / 1 I will retrieye the ECSIL listings and plotting code ECSPLT, ready for immediate execution).

\section{Library Availability}

The current ECSIL numeric and bibliographic files are available from the IBM-1360 photostore, where they are stored under the same of the file in the . T:LIBE directory of user 394800 (e.g. , ELF RDS. . 394800:LIBE:BIBLST / 11 will retrieve the listing of the reference number ordered, combinsd bibliography and Jata indexes). The following files are always available under . T:IIBE

LIBONN (NN $=01$ to 12) - Current ECSIL data library. BIBI.IB - Current ECSIL bibliographic library. INDEXN ( $N$ = A to [) ) - Machine readable indexes to ECSIL data library. LISTN $(N=A$ to $D$ ) - Interpreted indexes to ECSIL data library (UCRL-50400, Vol. 3). BIBLST - Interpreted, reference number ordered, combined bibiiography and data indexes.

REFLST - Interpreted, alphabetically ordered references. AUTLST - Interpreted, alphabetically ordered authors. 


\section{ECSCHK}

Purpose

ECSCHK checks the format and contents of numeric data in the ECSIL rard image format.

Limitations

None.

Core

$$
\mathrm{SCM}-13 \mathrm{~K}_{10} \mathrm{LCM}-4 \mathrm{~K}_{10}
$$

Time

$0.5 \mathrm{~min} / 25,000$ cards chec'red.

Files In

UNSORT - riumeric data in ECSIL card image format.

Files Out

(None)

input Parameters

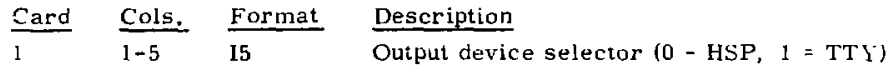

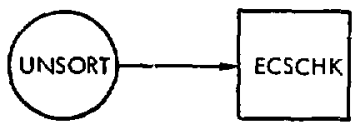

ECSCHK operation diagram. 


\section{ECSORT}

\section{Purpose}

ECSORT sorts numeric data in the ECSIL card image format into one of three standard orders, or into a generalized sort based upon any combination of reven fields. The standard orders available are:

(1) Z/A/C/S/E - Library order.

(2) $Z / A / C / S / R e f$. No. /E - Reaction/Reference Number order.

(3) Ref. No./Z/A/C/S/E - Reference Number order.

The sort continues according to the order outlined under ECSIL library organization for each $\mathrm{C}$ rarge.

The generalized sort is any ordering of from one to seven of the following fields:

(1) Z

(2) A

(3) $\mathrm{C}$

(4) $\mathrm{S}$

(5) Status

(6) Year

(7) Reference Number

The sort order is indicated by using the above indexes $i: i$ the order desired. For example the three standard sorts correspond to:

(1) $Z / A / C / S / E-1234$

(2) $2 / A / C / S / R e f . ~ N o . / E-12347$

(3) Ref. No./Z/A/C/S/E - 71234 .

An example of a chronologically ordered file is:

Year/Z/A/C/S,E-61234.

\section{Limitations}

There is no limit to the number of cards sorted by ECSIL. The program will create a series of sorted files each up to 16,000 cards in length. If there is more than one file they are not merged together, and ECSMRG must be used to merge them.

\section{Core}

$S C M-28 K_{10} / 1 . C M-16 K_{10}$.

Time

$1.2 \mathrm{~min} / 25,000$ cards sorted.

Files ln

UNSORT - Numeric date to be sorted in ECSIL card image format. 
- SORT001 - Sorted card files, each file up to 16,000 cards, as many liles as required.

SORT002

\section{Input Parameters}

$$
\begin{aligned}
& \text { Card Cols, Format Description } \\
& 1 \text { 1-5 I5 Output device selector }(0=\mathrm{HSP}, 1=\text { TTY) } \\
& \text { 6-10 I5 Sort order } \\
& =0-Z / A / C / S / E(L i b r a r y) \\
& =1-Z / A / C / S / R e f \text {. No. }: E \text { (Reaction 'Reference) } \\
& =2-\text { Ref. No. } / Z / A / C ; S / E \text { (Reierence) } \\
& =3 \text { - Cieneral }
\end{aligned}
$$

13-20 711 General sort index used for general sort order only. Use any of the 7 available columns: e.g., 1231000 is considered identical to $000123 \frac{1}{4}$ or 1020304 .

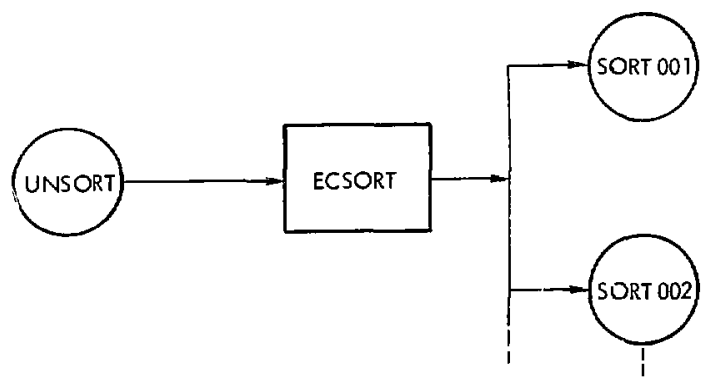

ECSORT operation diagram. 


\section{Purpose}

ECSMRG merges sorted cards into one of three standard orders, or a generalized merge based upon any combination of seven fields. The merge orders are identical to those used by ECSORT, as are the input parameters (INPUT file) and names of files to be merged. See ECSORT for a description of available merge orders. The program determines which files to merge by opening them in order, SORT001, SORT002, etc., until it cannot locate? file.

Limitations

From 1 to 10 sorted files may be merged together. If only one file is present it is simply renamed from SORT001 to SORTED and execution is terminated.

Core

SCM $-18 \mathrm{~K}_{10^{2}} / \mathrm{LCM}-8 \mathrm{~K}_{10^{\circ}}$

Time

$0.7 \mathrm{~min} / 25,000$ cards merged.

Files In

- SORT001 - Sorted card files, of any length, from 1 to 10 files. SORTO02

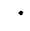

SORT010

Files Out

- SORTED - Merged card file.

Input Parameters

\begin{tabular}{|c|c|c|c|}
\hline Card & Cols. & Format & Description \\
\hline 1 & $1-5$ & 15 & Output device selector $(0=\mathrm{HSP}, 1=\mathrm{TTY})$. \\
\hline & $6-10$ & 15 & $\begin{array}{l}\text { Merge order } \\
=0-\mathrm{Z} / \mathrm{A} / \mathrm{C} / \mathrm{S} / \mathrm{E} \text { (Library) } \\
=1-\mathrm{Z} / \mathrm{A} / \mathrm{C} / \mathrm{S} / \text { Ref. No. } / \mathrm{E} \text { (Reaction / Library) } \\
=2-\text { Ref. No. } / \mathrm{Z} / \mathrm{A} / \mathrm{C} / \mathrm{S}, \mathrm{E} \text { (Reference) } \\
=3-\text { General }\end{array}$ \\
\hline
\end{tabular}

13-20 711 General merge index (used for general merge order only). Use any of the 7 available columns: e.g., 1234000 is considered identical to 0001234 or 1020304. See: ECSORT for general index definitions. 


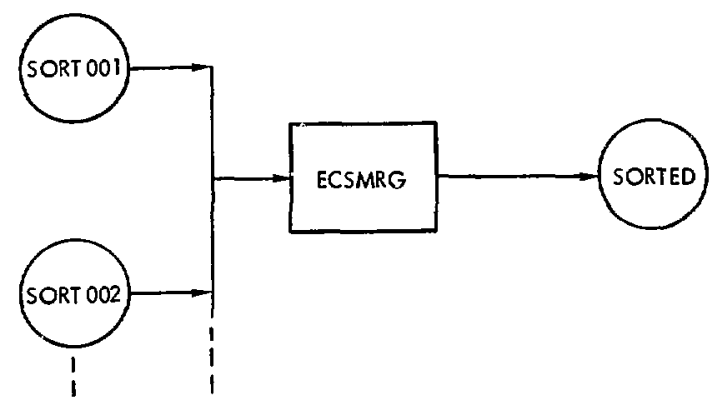

ECSMRG operation diagram. 


\section{ECSU PD}

Purpose

ECSUPD uprates the ECSIL numeric data binary library by reading data points in the ECSIL. card inage format and merging them into the library. Deletions are not performed by the ripdate program (see ECSDEL).

\section{Limitations}

The cards must be sorted into library order (see ECSORT and ECSMRG).

Core

$\mathrm{SCM}-24 \mathrm{~K}_{10} / \mathrm{LCM}-4 \mathrm{~K}_{10}$

Time

2.0 min to read entire library and merge 25,000 points.

Files In

SORTED - Data in ECSIL card image format, sorted into library order.

LIB001 - Current ECSIL binary library volumes (only those iibrary volumes

LIB002 affected by the update need be present, e.g., to add U-235 fission data to library, only LIB010 need be present). See description of

- ECSIL library file structure to define the $Z$ range for each library

LIJ3012 volume.

Files Out

OLD001 - Penultimate ECSIL binary library volumes (only those library

OLDO02 volumes affected by the update). These are the original library volumes beiore update.

OLD012

I.IB001 - New current ECSIL binary library volumes conly thrse library

I.13002 volumes affected by the update will differ from th.e original library volumes).

L.I I3012

Input Parameters

$$
\begin{aligned}
& \text { Card Cols. Format Description } \\
& 1 \text { I5 } \quad \text { Output device }(0=\text { HSP, } 1=\text { TTY). } \\
& \text { 6-10 I5 Disposition of outmoded library volumes } \\
& =0 \text { - Leave on disk as OLD001, OLD002, etc. } \\
& =1 \text { - Destroy (minimize disk storage requirements). } \\
& -32-
\end{aligned}
$$




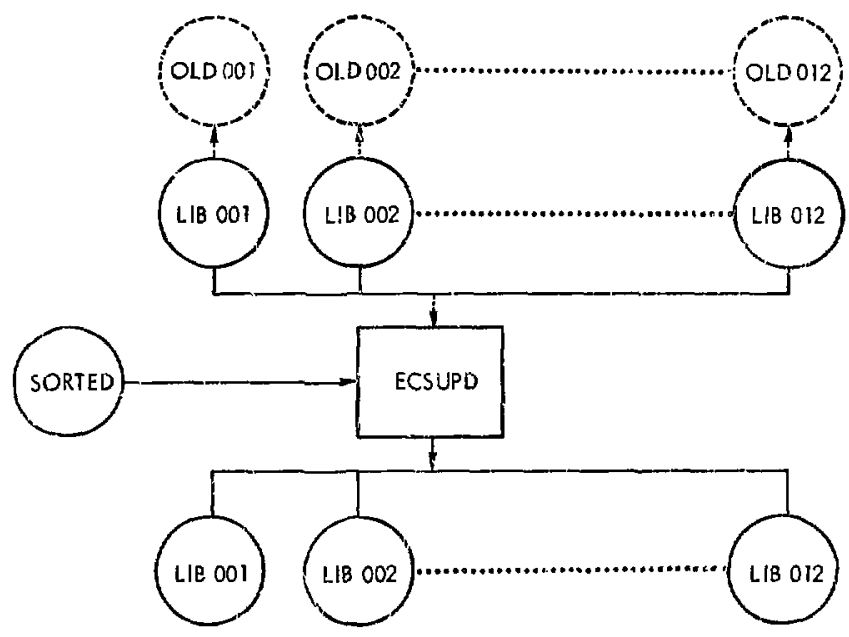

ECSUPD operation diagram. 
ECSDEL

\section{Purpose}

ECSDEI, exists to delete data points from the ECSIL numeric data binary library based upon a series of deletion requests. All deleted data points are written in the SORTED file in the ECSIL card image format. Lach deletion request is in the ECSII data card format and is composed of one or, in the case of continuation cards, lwo pairs of cards. The first card of each pair specifies a lower limit for each of the 18 fields described in tive card tormat. The second card specifies an upper limit for the corresponding "ields. A blank field indicates no limit, whereas a zer $(0)$ means a zero limit. For example, leaving the $A$ (atomic weight) field blank indicates not only the elemental mixture $(A=0)$ but also all the element's isotopes and compounds. A zero in the $A$ field indicates the elemental mixture $(A=0)$ only.

\section{Limitations}

Deletions may be in any order. There is a maximum of 100 deletio. requests (i.e., 200, or 400 , cards). The operation of the program can be greatly expedited by specifying a $Z$ range for each request. This makes it possible to examine only certain volumes and data records, not the entire library.

\section{Core}

$$
\text { SCM }-26 \mathrm{~K}_{10}{ }^{\prime} \mathrm{LCM}-6 \mathrm{~K}_{10^{\circ}}
$$

$\underline{\text { Time }}$

2.0 min to read entire library and delete $2 j, 000$ points.

Files In

1.13001 - Current ECSIL binary library volumes (only those library volumes

i.lB002 affected by the deletion need be present, e.g., to delete a set of Li-235 fission data from the library, only LlB010 need be present).

- See description of ECSIL library file structure to defint: the $Z$ range

LlBol2 for each library volume.

\section{Files Out}

SORTED - Deleted data points in the ECSIL card image format.

OI.D001 - Penultimate ECSIL binary library volumes (only those library

Ot.1 vo02 volumes affected by the deletion). These are the original library volumes before deletion.

OI.10012 
I.HBO01 - New current ECSIL binary Library volumes (only those library

L.I 3002 volumes affected by the deletion will differ from the uriginal library volumes).

I_IBO 12

Input Parameters

\begin{tabular}{|c|c|c|c|}
\hline Card & Cols. & Format & Description \\
\hline \multirow[t]{2}{*}{1} & $1-5$ & 5 & Output device $(0=\mathrm{HSP}, 1-\mathrm{TTY})$ \\
\hline & $6-10$ & I5 & $\begin{array}{l}\text { Disposition of outmoded library volumes } \\
=n \text { - Leeve on disk as OLDO01, OLD002, etc, } \\
=1 \text { - Destroy (minimize disk storage requirements). }\end{array}$ \\
\hline $2-\mathrm{N}$ & $1-80$ & & $\begin{array}{l}\text { Deletions in the ECSIL data card format. Each } \\
\text { request is composed of one or twr. pairs of cards, } \\
\text { the former of each pair specifying a lower and the } \\
\text { latter specifying an upper limit for each of the } \\
18 \text { inelds defined in the format. A blank field } \\
\text { indicates no limit. }\end{array}$ \\
\hline
\end{tabular}

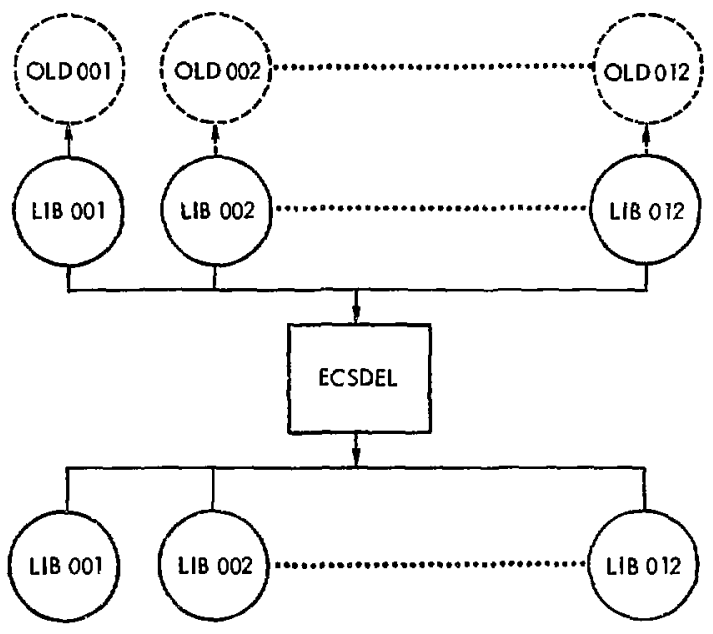

ECSDEL operation diagram. 
Purpose

ECSRET retrieves data points from the ECSIL numeric data binary library based upon a series of retrieval requests. All retrieved data points are written in the SORTEL file in the ECSII card image format. Each retrieval request is in the ECSLL data card format and is composed of one or, in the case of continuation cards, two pairs of cards. The first card of each pair specifies a lower limit for each of the 18 fields deseribed in the card format. The second card specifies an upper limit for the corresponding fields. A blank field indicates no limit, whereas a zerolo) means a zero limit (e.g., the limit indicated by blank A (atomic weight) field includes the elemental mixture $(A=0)$, all isotopes, and all compounds. A zero field limit indicates the elemental mixture $(A=0)$ exclusively.

\section{Limitations}

Requests may be in any order, with up to 100 requests (i.e., 200 or $400 \approx a$ ards). 'The operation of the program can be greatly expedited by specifying a $Z$ range for each request. This makes it possible to examine only certain volumes and data records, nat the entire library. Retrieved data point are always in library order; use ECSORT and ECSMRG to obtain other orderings.

\section{Core}

$$
\operatorname{SCM}-28 \mathrm{~K}_{10^{1}} / \mathrm{LCM}-4 \mathrm{~K}_{10^{*}}
$$

Time

2.0 min to read entire library and retrieve 25,000 points.

\section{Files In}

LIBO0I - Current ECSIL binary library volumes fonly those library volumes LIB002 affected by the deletion need be present, e.g., to retrieve a set of U-235 fission data from the library, only LIB010 need be present). See description of ECSIL library file structure to define the $Z$ range

LIB012 lor each libral volume.

\section{Files Out}

SORTED - Retrieved data points in the ECSIL card image format.

lnput Paraneter's

\begin{tabular}{|c|c|c|c|}
\hline Card & Cols. & Format & Description \\
\hline I & $1-5$ & I5 & Output device $(0=$ HSP, $1=, \because !$ \\
\hline $2-N$ & $1-80$ & & $\begin{array}{l}\text { Retrievals in the ECSIL data caro format. Each } \\
\text { request is composed of one or two pairs of cards }\end{array}$ \\
\hline
\end{tabular}


Cormer of each pair specifying a lower and the latter specifying an upper limit for each of the 18 fields defined in the format. A blank field indicates no limit.

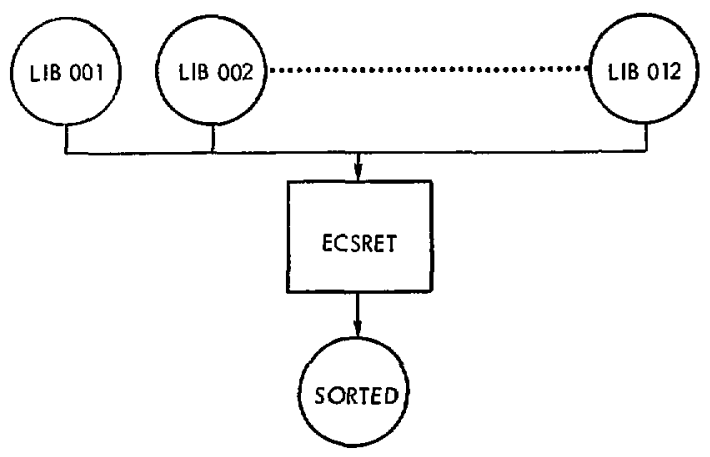

ECSRET operation diagram. 


\section{Purpose}

ECSEN counts the data points per ZA and $Z$ (census) or checks either the ECSIL numeric data binary library or a card image file. The census also defines total point and camputer word counts for each volume and for the library as a whole. In addition to tests normally performed by ECSCHK to check the consistency of isdividual data points, ECSEN performs tests based upon the relative position of data points within the library (e.g., duplicate points, similar points etc.).

\section{Limitations}

None

Core

$\mathrm{SCM}-21 \mathrm{~K}_{10} ; \mathrm{LCM}-4 \mathrm{~K}_{10}$.

Time

$1.8 \mathrm{~min}$ to read entire library and create census of check.

Files In

SORTED - Data in ECSIL card image format, either sorted or unsorted.

LIB001 - C.2rrent ECSIL binary library volumes fonly those volumes present

LIB002 will be used, missing volumes will be skipped and will not cause program to abort).

LIB 3012

Files Out

(None)

Input Parameters

\begin{tabular}{|c|c|c|c|}
\hline Card & Cols. & Format & Description \\
\hline \multirow[t]{11}{*}{1} & $1-5$ & I5 & Output device $(0=$ HSP, $1=$ TTY $)$. \\
\hline & $6-10$ & I5 & Source of data to check \\
\hline & & & $0=$ Library \\
\hline & & & $1=$ Sorted (no sort order checks) \\
\hline & & & 2 = Sorted (perform sort order checks) \\
\hline & & & $3=$ Library \\
\hline & $11-15$ & 15 & Operation $(0=$ CENSUS, $1=$ CHECK $)$ \\
\hline & $16-20$ & I5 & Checking mode \\
\hline & & & $0=$ One error :nessage per $Z, A, C, S$, Hef. \\
\hline & & & $1=$ One error message of each type per $Z, A, C, S$, Ref. \\
\hline & & & $\begin{array}{l}2=\text { All error messages } \\
\quad-38-\end{array}$ \\
\hline
\end{tabular}




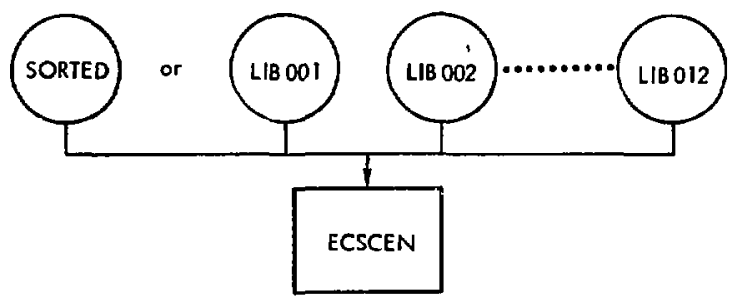

ECSCEN operation diagram. 


\section{ECSDEX}

Purpose

ECSDEX creates index files to either the ECSIL numeric binary library or a card image file. Index files may be created in any or all of four sort orders: (a) $Z / A, C / S / E$ (library order) (b) Ref. No./Z/A/C/S/E (reference number order), (c) $C_{i} S_{2} Z / A, E$ (interaction number order), (d) Basic $C / C$ Increment $/ S / Z ; A ; E$ (basic interaction number order). Both mackine readable and interpreted listing iiles may be made for each sort order.

\section{Limitations}

If index riles are to be made from a card image file, the card image file must be sorted in the library order (see ECSORT). The file INDEXA is used to make the files INDEXB, INDEXC and/or INDEXD. The files LIS'TA-D are then made from the corresponding file INDEXA. Therefore to make INDEXB-D, INDEXA must first exist or be made from cards or the library. Similarly to make LISTA-D the corresponding file INDEXA-D must exist or be made during execution.

\section{Core}

SCM $-29 \mathrm{~K}_{10^{\prime L C M}} / 6 \mathrm{~K}_{10^{\circ}}$

\section{Time}

2.2 min to read entire library and create all index files.

Files In

INDEXA - Z/A/C/S/E ordered machine readuble index (if col. $7=0$ ).

or

SORTED - Card image file (if col. $7=1$ or 2 ).

or

LIBO01 - Current ECSIL binary library volumes (if col. $7=3$ ). (Only those

LIB002 volumes present will be used. Missing rolumes will te skipped and will not cause program to abort.)

\section{LIBOL2}

\footnotetext{
Refers to columns of input card.
} 


\begin{tabular}{|c|c|c|}
\hline IN JUEXA & $-Z_{i} A_{i} C_{i} S / E$ order (if col. $7>0$ ) & \\
\hline INDEXB & $\begin{aligned}- & \text { Ref. No. } / Z / A / C / S / E \text { order } \\
& (\text { if col. } 8>0)\end{aligned}$ & $\begin{array}{c}\text { Machine read } \\
\text { index }\end{array}$ \\
\hline INDEXC & $-\mathrm{C} / \mathrm{S} / \mathrm{Z} / \mathrm{A} / \mathrm{E}$ order (if col. $9>0$ ) & files \\
\hline IN DEXD & $\begin{array}{l}\text { - Basic C/C Increment/S/Z/A/E } \\
\text { order (if col. } 10>0 \text { ) }\end{array}$ & \\
\hline LISTA & $-2 / A / C / S / E$ order (if col. $12>0$ ) & \\
\hline LISTB & $\begin{aligned}- & \text { Ref. No. } / Z / A / C / S / E \text { order } \\
& (\text { if col. } 13>0 \text { ) }\end{aligned}$ & $\begin{array}{l}\text { Interpreted } \\
\quad \text { index }\end{array}$ \\
\hline ILISTC & $-C / S / Z / A / E$ order (if col. $14>0$ ) & \\
\hline LISTD & $\begin{aligned}- & \text { Basic } C / C \text { Increments/S/Z/A/E } \\
& \text { order (if col. } 15>0 \text { ) }\end{aligned}$ & \\
\hline
\end{tabular}

\section{Input Parameters}

\begin{tabular}{|c|c|c|c|}
\hline Card & Cols. & Format & Description \\
\hline \multirow[t]{9}{*}{1} & $1-5$ & 15 & Output device $(0=\mathrm{HSP}, 1=\mathrm{TTY})$ \\
\hline & 7 & 11 & $\begin{array}{l}\text { Source of INDEXA }(0=\text { it exisis, } 1 \text { or } 2=\text { cards, } \\
3=\text { library) }\end{array}$ \\
\hline & 8 & I 1 & INDEXB option ( $0=$ no, $1=$ create $)$ \\
\hline & $\mathrm{g}$ & I1 & INDEXC option ( $0=$ no, $1=$ create) \\
\hline & 10 & 11 & IN DEXD option (0 = no, $1=$ create $)$ \\
\hline & 12 & $\mathrm{~J} 1$ & LIST $A$ option $(0=$ no, $1=$ create $)$ \\
\hline & 13 & 11 & LISTB option ( $0=$ no, $1=$ create $)$ \\
\hline & 14 & 11 & LISTC option ( $0=$ no, $1=$ create $)$ \\
\hline & 15 & I1 & I.IST D option ( $0=$ no, $1=$ create $)$ \\
\hline
\end{tabular}

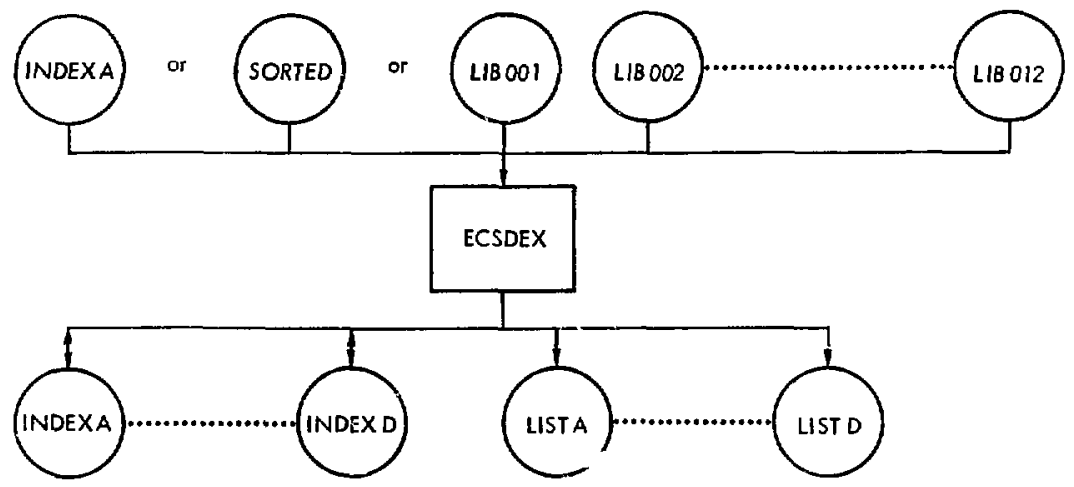

ECSDEX operation diagram. 


\section{ECSPLT}

\section{Purpose}

ECSPLT exists to create intepreted listings, cards and/or plots of data from the ECSIL numeric binary library or a card image file. Plots of the data may have evaluated data from either the evaluated nuclear data library (ENDL) ${ }^{7}$ or the evaluated nuclear data file version $\mathrm{B}(\mathrm{ENDF} / \mathrm{B})^{8}$ overlayed on the plots. To facilitate comparison of experimental data physically comparable data sets may also be presented, either sn separate plots with similar scaling or on the same plot.

\section{Limitations}

If a card image file is used it must be library ordered. Requests may be in any order. There is a maximum of 100 requests (i.e., 200 or 400 cards). The operation of the program can be greatly expedited by specifying a $\mathbf{Z}$ range for each request. This makes it possible to examine only certain volumes and data records, not the entire library.

Core

$$
\mathrm{SCM}-30 \mathrm{~K}_{10} / \mathrm{LCM}-8 \mathrm{~K}_{10}
$$

Time

$2.5 \mathrm{~min}$ to read entire library and plot 25,000 points ( 400 plots).

Files in

SORTEI - Card inıge file.

or

LIB001 - Current ECSLL binary library volumes (only those library volumes

LIB002 affected by the requests need be present, e.g., to plot the U-235 fission cross sections from the library, only LIBDI0 need be • present). See description of ECSIL library file structure to define

LIB 012 the $Z$ range for each library volume.

ENDLIN - Evaluated nuclear data library (ENDL) data in card image format ${ }^{3}$ (required only if ENDL comparison requested).

ENDFIN - Evaluated nuclear data file (ENDF/B) data in card image format ${ }^{B}$ (required only if ENDF/B comparison requested).

\section{Files Qut}

- PLT000 - Plot files (present only if plots are requested) which may be PLT001 prosessed by FROG ${ }^{6}$ to obtain $35 \mathrm{~mm}$ film, microfiche, printer etc. hardcopy. 
- LISTS - Internreted listings of data (present only if listing is requested).

- CARDS - Data points in ECSIL card image format (present only if cards are requested).

Input Parameters

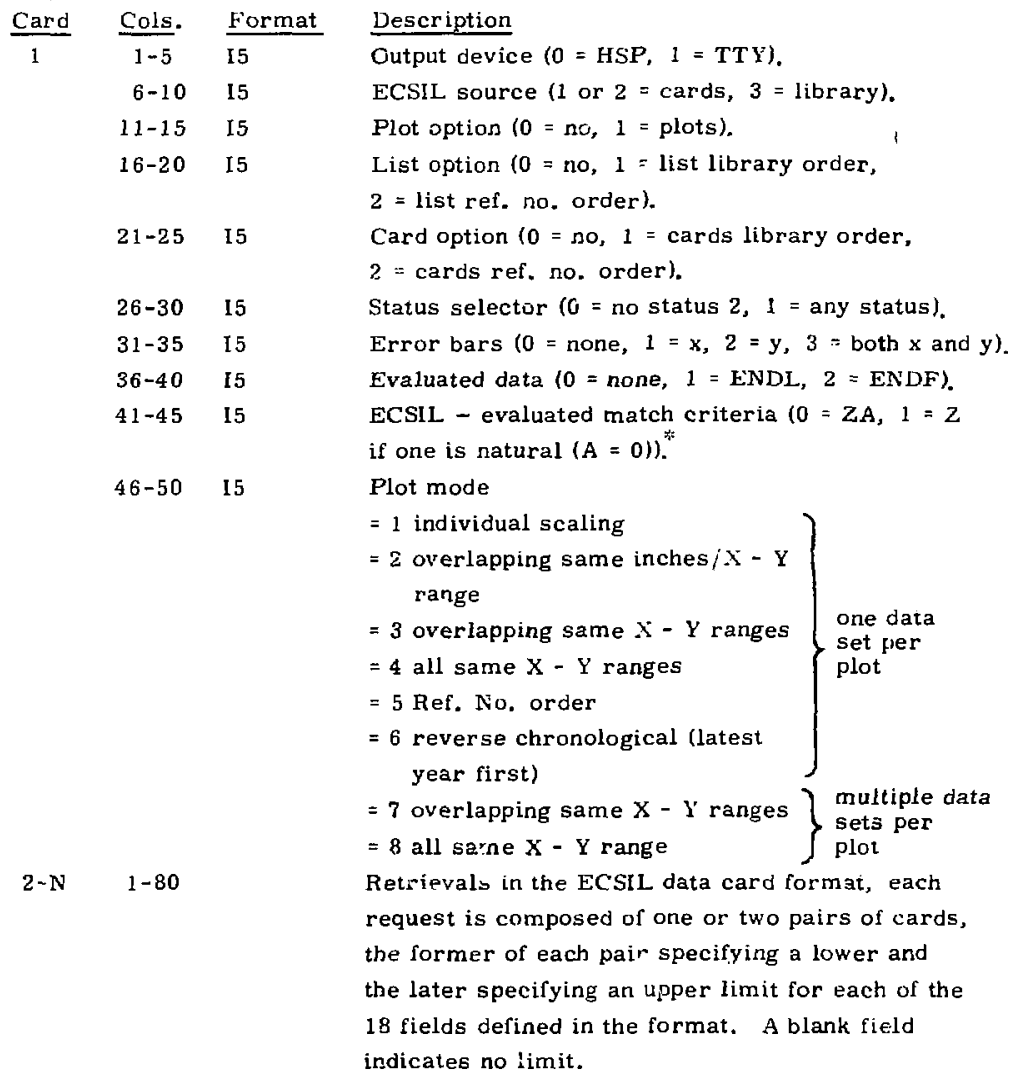

\footnotetext{
The ECSIL ano evaluated data are normally considered to be physically comparable if both are for the same reaction and isotope (ZA). When ECSIL and evaluated data are not both available for a given isotope (ZA), this option may be used to compare isotopic data from one library to elemental (same $Z, A=0$ ) data from the other library (e.g., compare an oxygen-16 evaluation to natural oxygen experimental data).
} 


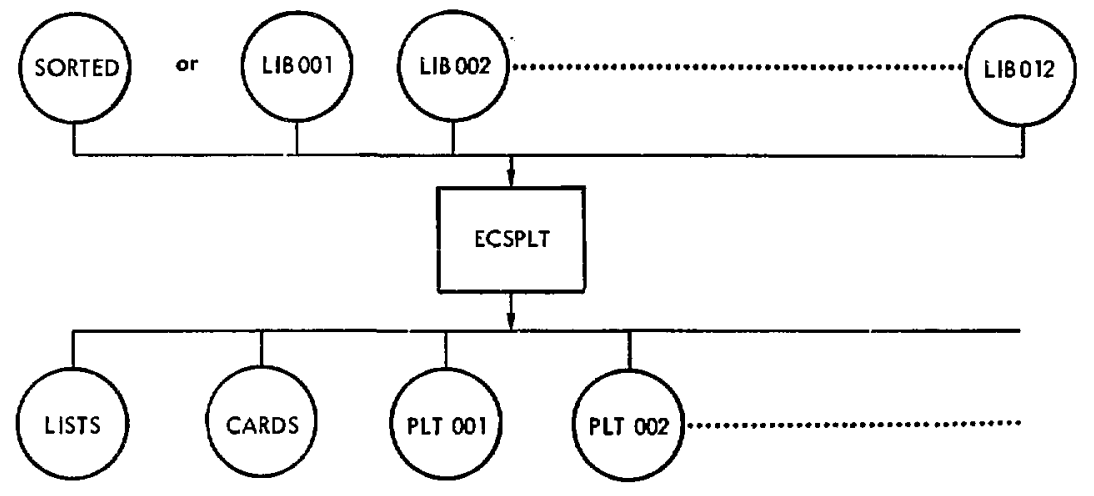

ECSPLT operation diagram. 
ECSIBIB

\section{Purpose}

ECSBIB merges information into, deletes information from, and retrieves inlormation irom the ECSI 1 bibliographic ibeary. Information to be merged is in the iCSII bibliographic card image lormat. Intornation to be deleted or retrieved is indicated by using the operation kode (col, 1$)$ and reference number (col. 2-5) fields. The operation code for detetion is 1 , that for retrieval is 5.

\section{Limitations}

'I he information to be merged and requests tor deletion or retrieral need nut be in rel'erence number order. There is no limit to the number of bibliugraphic cards to be merged, deleted or retrieved. For simple retrieval (i.e. no changes to library) the operation of the program can be expedited by indicating retrieval only un the input card (e.g. col. $10=0$ ).

\section{Core}

$$
S C M-6 K_{10}: \text { L.CM }-7 \mathrm{~K}_{10^{\circ}}
$$

Time

0.2 min to read entire bibliography and merge, delete or retrieve 300 reference numbers.

Files In

B313L_13 - Current version of the ECSIL bibliographic file.

BII3LPD - Bibliographic information to be merged, deleted or retries'ed.

Files Out

BIBOLD - Penultimate version of the ECSIL biblicgraphic file. This was current hibliographic file before update con!y usetin merge ditete mode of program).

BIB].LB - New current version of the ECSLL bibliographic ille.

BIBI]EL. - Bibliographic informaticn that was deleted from the library (only used if a deletion occurs).

BIHRET - Bibliographic information that was reteieved from the library (only used if a retrieval occurs).

Input Parameters

\begin{tabular}{|c|c|c|c|}
\hline \multirow{3}{*}{$\frac{\text { Card }}{1}$} & Cols. & Iormal & Description \\
\hline & $1-5$ & I5 & Output device $(0=$ HSP, $1-\mathrm{Y} T Y)$. \\
\hline & $6-10$ & I5 & $\begin{array}{l}\text { Operating mode }(0=\text { retrieval, } 1=\text { any combination } \\
\text { of Merge, Delete and Retrieve). }\end{array}$ \\
\hline
\end{tabular}




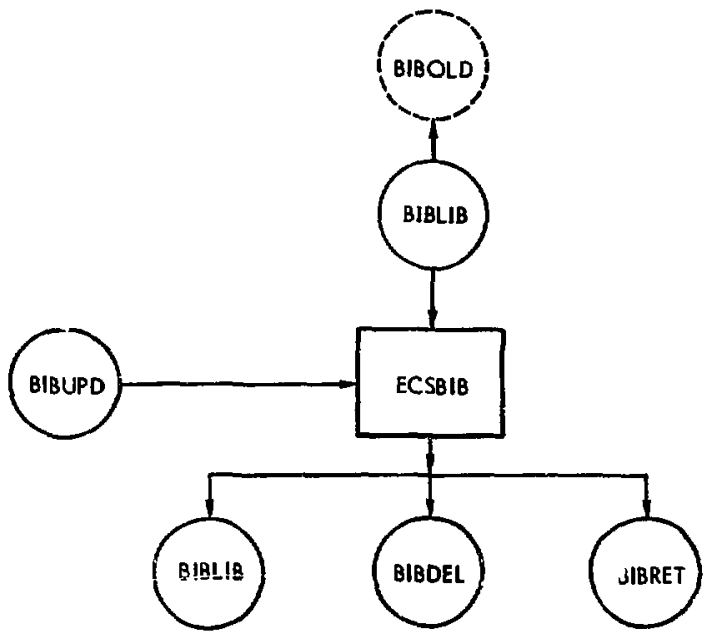

ECSBIB operation diagram. 


\section{ECSPOP}

\section{Purpose}

ECSPOP creates listings and index files to the ECSIL bibliographic system. Three listings and index files are created: (1) combined complete bibliography aad data index, (2) alphabetic reference index, (3) alphabetic author citation index. Each of these files is created in two forms, machine readakle and interpreted listings. ${ }^{5}$

The listings may be based upon the entire bibliographic file and reference number order data index (see ECSDEX). Alternatively the lisings maj be based upon all bibliographic information, and on! $j$ the corresponding data indexes (e.g., determine what was measured for any set of reference numbers), or on all data indexes, and only the corresponding bibliographic information (e.g., define the bibliographic information for any set of data indexes).

\section{Limitations}

If a minibibliographic lihrary is used to determine the corresponding data indexes, the bibliographic information must be ascending reference number order. If either the bibliographic file (BIEIIB), or the data inde: file (INDEXB) is not present on the disk the program will process the other file. If both are missing the program will abort.

Core

$$
\mathrm{SCM}-25 \mathrm{~K}_{10^{1}} / \mathrm{LCM}-9 \mathrm{~K}_{10^{\circ}}
$$

Time

1.5 min to read all files and create all listings and index files.

Fi.les In

BIBLIB - current bibliographic information library.

INDEXB - Ref. No. $Z$ Z/A $/ C_{i} /$ S E ordered data index (see ECSDEX).

Files Out

\begin{tabular}{|c|c|c|}
\hline BIBSRT & - combined bibliography and data index & \\
\hline REFSRT & - alphabetic reference index & machine readable \\
\hline AUTSRT & - alphabetic author citation index & \\
\hline BLBLST & - combined bibliography and dat $z$ index & \\
\hline REFLST & - alphabetic reference index & interpreted listings \\
\hline 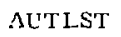 & - alphabetic author citation index & \\
\hline
\end{tabular}


Input Parameters

$\frac{\text { Card }}{1} \quad \frac{\text { Cols. }}{1-5} \quad \frac{\text { Format }}{15} \quad \frac{\text { Description }}{\text { Output device }}$

6-10 $15 \quad$ Search criteria

$=0$ - All bibliography and data indexes.

$=1$ - All bibliography, corresponding data indexes.

= 2 - All data indexes, corresponding bibliography.

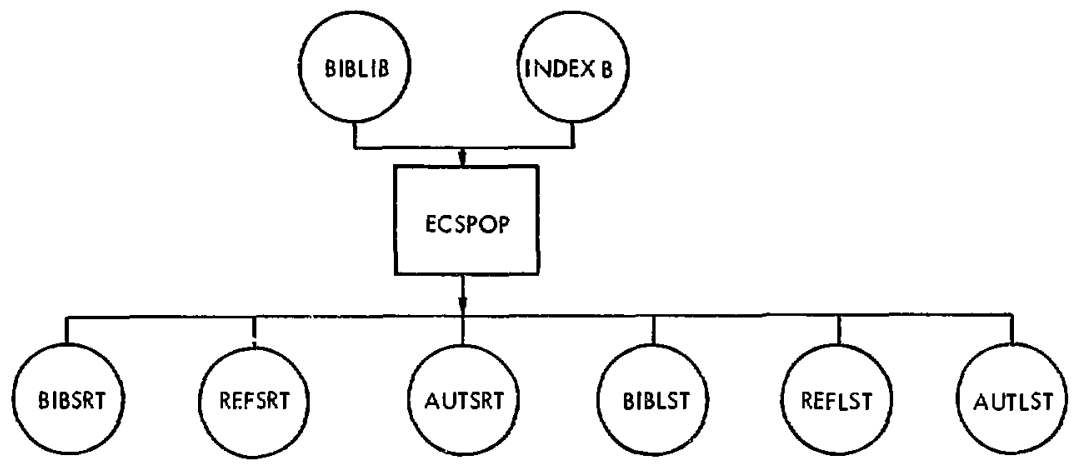

ECSPOP operation diagram. 


\section{Extended ECSIL Conventions}

The extended ECSIL conventions still describe experimental neutron-induced cross sections by target, interaction, interaction property and interaction modifier. However the interaction and the interaction property, formeriy the basic $\mathrm{C}$ and $\mathrm{C}$ increment, are now referred to simply as the $C$ and the $I$ and are separate fields. The data is further described by indicaing the incident and outgoing particles.

Incident Particle

A numerical equivalent (reierred to as $\mathrm{Y}_{\mathbf{i}}$ ) is assigned for each incident particle of interest, see Table 12. This allows the system to handle incident charged particles, photons, etc.

\section{Outgoing Particle}

A numerical equivalent (referreo to as $\mathrm{Y}_{\mathrm{o}}$ ) is assigned for each outgoing particle of interest, see Table 12 , to allow the system to describe angular distributions, energy distributions, etc. for charged particles, photons, etc.
Table 12. Designators of incident or outgoing particles.

\begin{tabular}{cl}
\hline $\begin{array}{c}\text { Particle } \\
\text { designato }\end{array}$ & Particle \\
\hline 0 & None $^{2}$ \\
1 & Neutron \\
2 & Proton \\
3 & Deuteron \\
4 & Triton \\
5 & 3 He \\
6 & 4 He \\
7 & Photon \\
8 & Beta plus \\
9 & Beta minus \\
\hline
\end{tabular}

A secondary particle is designated only if a property of the secondary particle is being described (e.g., $\sigma\left(p, p^{\prime}\right)$ cross section has $Y_{O}=0$, while the $\sigma\left(p, p^{\prime}\right)$ angular distribution of the proton has $\mathrm{Y}_{\mathrm{O}}=2$ ).

At present the system is designed to handle only light $\mathrm{Y}_{\mathbf{i}}$ and $\mathrm{Y}_{0^{\circ}}$. The assignment of numerical equivalents is not systematic and may be extended as needed.

\section{Extended ECSIL Data Card Format}

The extended EC'SIL system uses a completely new numeric data card image format, but requires minimum changes to the binary library and no changes to the bibliographic format. The new numeric data card image format uses the same conventions for continuation on to a second card, to allow up to 10 measured quantities, as well as the same conventions for all fields defined in the original ECSIL numeric data card image format. The new format is diagrammed below. 


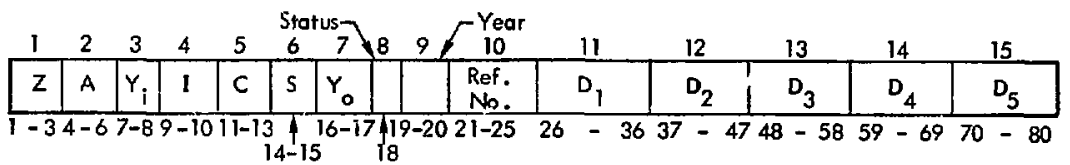

Field 1 (Z) Atomic Number

Identical to original ECSIL conventions.

Field 2 (A) Atomic Weight

Identical to original ECSIL conventions.

Field $3\left(Y_{i}\right)$ Incident Particle

Table 12 presents conventions for $\mathrm{Y}_{\mathrm{i}}$. More will be defined as required.

Field 4 (I) Interaction Property

Similar to $C$ increment in original ECSIL conventions, see Tuthle 3 . Presently directly derivable from the $C$ increment as $I=(C$ increment $) / 50$.

Field 5 (C) Interaction

Identical to basic $\mathrm{C}$ in original ECSIL, see Table 2 .

Field 6 (S) Irteraction Modifier

Identical to interaction modifier in original ECSLL, see Table 7.

\section{Field 7 (Y o ) Outgoing Particle}

Uses same conventions as $Y_{i}$, field 3 above, and Table 12. More will be defined as required. Outgoing particle is defined as $\mathrm{Y}_{0}=0$ for $\mathrm{I}=0$ or 1 lenergy dependent or energy average cross sections) where the interaction, not the outgoing particle, is being described.

Field 8 - Status

Identical to status in origina!. ECSIL, including use for continuatic...

\section{Field 9- Year}

Identical to year in original ECSIL.

Field 10 - Reference Number

Identical in cortent to original ECSIL, except now five digits long. Note the sub-reference number is no longer used.

Fields 11-15

Similar to $D_{1}$ through $D_{5}$ of original ECSIL, only now in E11.4 format. (Note: The new format contains only five measured quantities on the first card compared to six in the old format. However over $97 \%$ of the data points in the library are described by five or fewer measured quantities. Therefore the new format will not appreciably increase the number of cards for inputting or retrieving data).

\section{CARD 2}

\begin{tabular}{|l|l|l|l|l|l|l|l|l|l|}
\hline & \multicolumn{1}{c}{$\begin{array}{l}\text { Sear } \\
\text { (Blatus) }\end{array}$} \\
\hline 1 & & & $\begin{array}{l}\text { Ref. } \\
\text { No. }\end{array}$ & $D_{6}$ & $D_{7}$ & $D_{8}$ & $D_{9}$ & $D_{10}$ \\
\hline
\end{tabular}


Card 2 is present only if over five measured quantities are required to describe the data point. The presence of card 2, the continuation card, is indicated as in the original ECSIL system by a status of 5 or greeter. The status, as well as year and reference must be identical on both first and second cards. As before, the status will be stored in the library as 0 , 1 , or 2 ano reconstituted on output as required.
Fields 16-18

The status, year and reference number on the continuation card must be identical to the corresponding fields on the pirst card.

Fields 19-23

Sirnilar to $D_{6}$ through $D_{12}$ of original ECSIL, only $\mathrm{D}_{6}$ is now on second card and all are in E11.4 format.

\section{Extended ECSIL Data Library Organization and Format}

The organization of the extended ECSIL binary library is similar to that of the original ECSIL, except that instead of sorting each $Z A$ into $C, S, X$, etc, order it is sorted into: $Y_{i}, I, C, S, X_{i}, Y_{0^{\prime}}$ etc. order. For a given $\mathrm{ZA}$ all data due to incident neutrons precedes that for incident protons, etc. For a given $\mathrm{ZA}$ the angular distributions for an $\sigma\left(n, n^{\prime} p\right)$ interaction will have the angular distri butions for the neutron and proton grouped together, with the neutron angular distribution preceding the proton asijular distribution.

The library file structure of the extended ECSIL system is idenrical to the file structure of the original ECSIL system down to the date point level (see Fig. 1). The only differences between the original data point format and the extended data point format are in the second and seventh words of each data point. The second words which contained the combined $\mathrm{C}$ and $\mathrm{S}$ in the form $\mathrm{C} \times 10^{2}$ $+S$, now contains the combined $Y_{i}, C$, $S$ and $Y_{0}$ in the form

$Y_{i} \times 10^{7}+C \times 10^{4}+S \times 10^{2}+Y_{0}$

The seventh word has been adjusted to drop the subreference number and to allow for a five digit reference number. It stores the combined reference in the form Status $\times 10^{7}+$ year $\times 10^{5}+$ (reference No.).

Adoption of these conventions allows the current library size to be maintained. Conversion to the new system only requires the data points within each $Z A$ to be converted to the new format where for all present points $Y_{i}=1$ and $Y_{0}=1$ or $0(\mathrm{I}=0$ or 1$)$. The library need not be re-sorted; the present neutron data is already in the correct sort orier for the extended LCSII system. 


\section{References}

1. D. E. Cullen, R. C. Haight, R. J. Howerton, M. H. MacGregor, and S. T. Perkins, Graphical Experimental Data for Major Neutron-Induced Interactions,

Lawrence l.ivermore Laboratory, Rept. UCRL-50400, Vol. 7, (1974).

z. D. F Cullan, R. C. Haight, R. J. Howerton, M. H. MacGregor, and S. T. Pe. ns, Graphical Experimental Data for Supplemental Neutron-Induced Interactions, Lawrence Livermore Laboratory, Rept. UCRL-50400, Vol. 8, tu be published.

3. S. T. Perkins, 13. E. Cullen, R. C. Haight, R. J. Howerton, and M. H. MacGregor, Tabulated Experimental Data for Neutron-Induced Interactions, Lawrence I.ivermore Laboratory, Rept. UCRL-50400, Vol. 10, (1974).

4. S. T. Perkins, D. E. Cullen, R. C. Haight, R. J. Howerton and M. H. MacGregor, An Index of the Experimental Data of Neutron-Induced Interactions, Lawrence Livermore Laboratory, Rept. UCHL-50400, Vol. 3, (1974).

5. S. T. Perkins, D. E. Cullen, R. C. Haight, R. J. Howerton and M. H. MacGregor, A Bibliography of the Experimental Data of Neutron-Induced Interactions, Lawrence Livermore Laboratory, Rept. UCRL-50400, Vol. 2, (1974).

6. C. R. Hunt, EROG, Lawrence Livermore Laboratory, Internal Document DC-606 (1973). Readeis outside the Laboratory who desire further information on LIL. internal documents should address their inquiries to the Technical Information Department, Lawrence Livermore Laboratory, Livermore, California 94550.

7. R. J. Howerton, R. J. Doyas, T. C. Michels, S, T. Perkins, Evaluatea Nuclear Cross Section Library, Lawrence Livermore Laboratory, Rept. UCRL-50400, Vol, 4, (1971).

8. M. K. Drake, Dati Formats and Procedures for the ENDF Neutron Cross Section Library, Brookhaven National Laboratory, BNL-50274 (T-601), FNDF-102 (1970). 


\section{Appendix A \\ Example Reference}

The soibwing figures illustrate a typical reference, how it is prepared for inclusion in ECSII, ard how the reference appears in the listings, plots and indexes normally obtained after each library update.

For illustrative purposes consider the ${ }^{232}$ Th and ${ }^{238} \mathrm{U}$ prompt $\bar{\nu}$ measurements of B. D. Kuz'minov, published in Soviet Progress in Neutron Physics, page 177 (1961).

Figure A-1 illustrates the data transcribed onto the standard data coding sheet. The reference has been assigned the Ref. No. 1079 and the prompt $\bar{\nu}$ numerical equivalent $C=46$ has been defined.

Figure A-2 illustrates the bibliographic information transcribed onto the standard bibliographic code sheet. The bibliographic information and the data (Fig. A-1) are now linked through the use of Ref. No. 1079.

After the data and bibliographic intormation have been checked they are merged into the ECSIL system. The reference will appear in subsequent listings an! indexes to the libraries. These listings and indexes are prepared after each library update and are period ically published. The following figures illustrate where Ref. No, 1079 appears within the various publications associated with ECSIL.

Figures $A-3 a, A-3 b$ and $A-3 c$ illustrate how the data appears in UCRL-50400, Vol. 7. The ${ }^{232}$ Th and $238 \mathrm{~V}$ prompt $\bar{\nu}$ now appear separately under the correct isotope and energy ordered with all other prompt $\bar{\nu}$ for the respective isotopes.

Figures $A-4 a$ and $A-4 b$ illustrate how the $Z A$ ordered reaction index to Ref. 1079 appears in the first section of CCRL-50400, vol. 3. The reaction index is here in Z, A/C/S,E-low order (e.g. all prompt $\bar{\nu}$ date for ${ }^{232}$ Th together, in energy order'.

Figures $A-5 a$ and $A-5 b$ illustrate how the reaction number (C) ordered reaction index to Ret. 1079 appears in the second section of LCRL-50400, Vol. 3. The reaction index is here in $C / Z / A ; C$ /S! $E-$ low order (e.g. all prompt $\vec{\nu}$ data together, in ZA and energy order

Figure $A-6$ illustrates how the refererce nurn: er ordered reaction inciex to Ref. 1079 appears in the third section of UCRL-50400, VoI. 3. The reaction index is here in Ref. No, $Z / A / C ; S / E$-low order (e.g., all reaction indexes to Ref. 1079 , in $\mathrm{ZA}$ order).

Figure A-7 illustrates how the autior cilation to Kuz'minov, B. D. for Ref. 1079 appears in the first secticn of JCRL50400 , Vol. 2. Kuz'minov, B. D. is indicated to be the lirst author by the asterisk following the reference number (i.e. $1079 \%$ ).

Figure A-8 illustrates how the alphabetically ordered reference to Ref. 1079 appears in the second section of LCRL50400, Vol. 2. Following a sort on the alphabetic portion of the reference the references are sorted into volume, section, page, elc. order.

Figures A-9a and A-9b illustrate how the combined bibliographic information and reaction indexes to Ref. $1079 \mathrm{app}$. $3 \mathrm{r}$ in the third section of UCRL-50400, Vol. 2. There is now no limit to the amount of bibliographic information that may be associated with a given reference. 


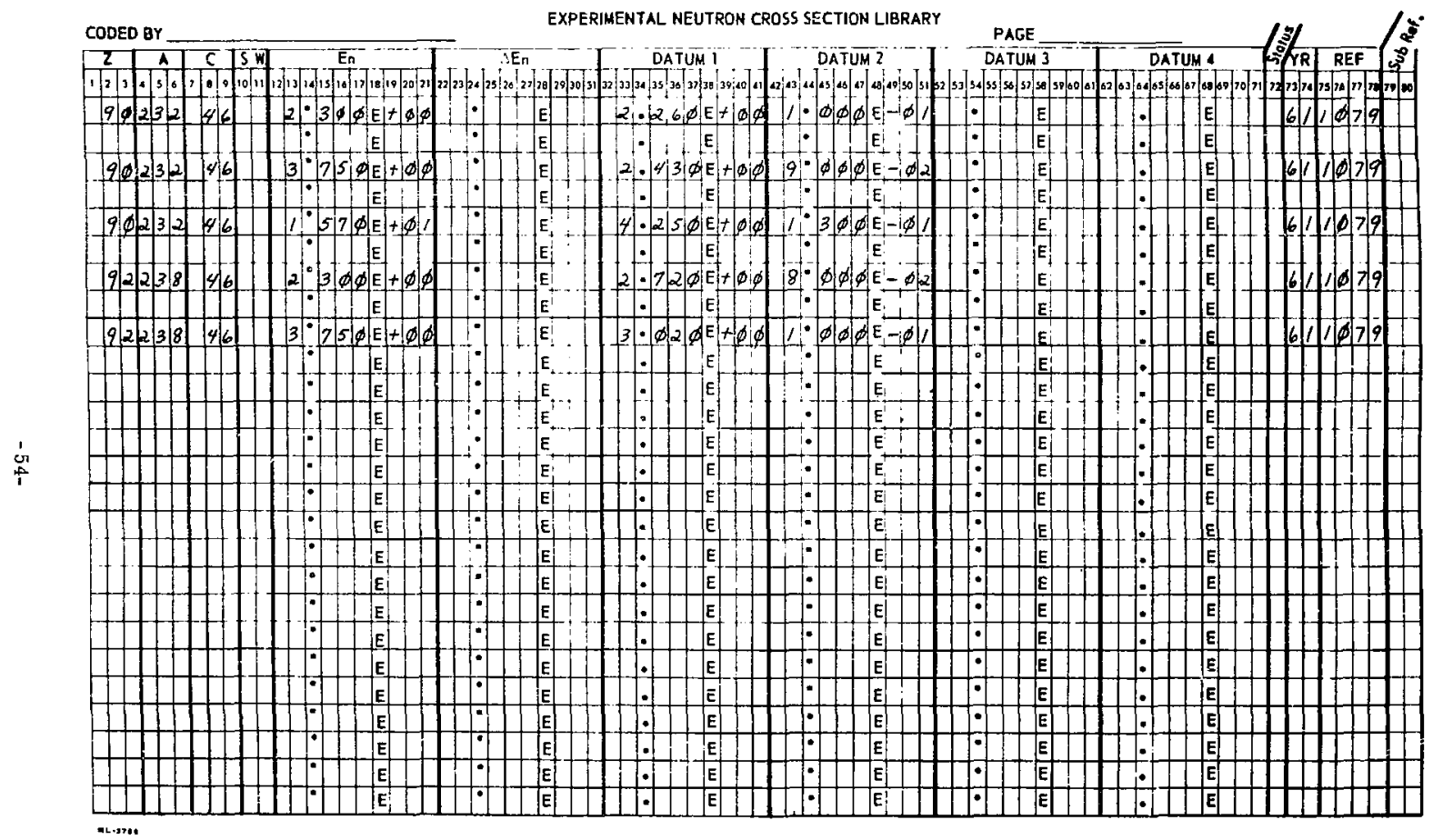

Fig. A-1. Data from Ref, 1079, transcribed onto an input coding sheet. 


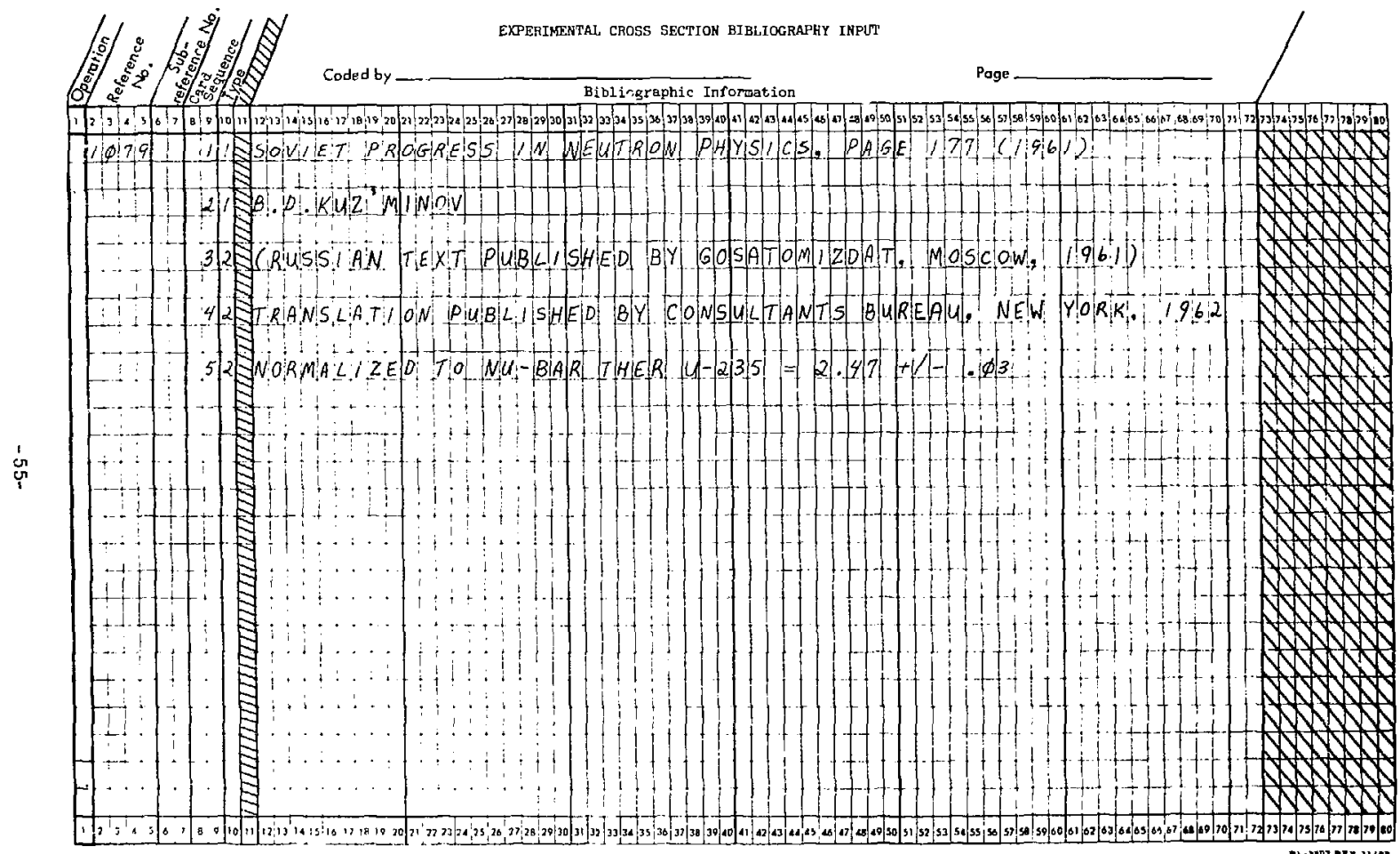

Fig. A-2. Bibliographic data for Ref. 1079 transcribed onto an input coding sheet. 
CROSS SECTION

\begin{tabular}{|c|c|c|c|c|c|c|c|c|c|c|}
\hline \multirow{2}{*}{\multicolumn{2}{|c|}{ REFERENCE }} & ENERGY & DEL TA & $x-\operatorname{SEC}$ & DELTA & REFERENCE & ENERGY & DELTA & $x-\operatorname{SEC}$ & OELIA \\
\hline & & MEV & MEV & BARN5 & GARN5 & & MEV & MEV & ZARNS & BARNS \\
\hline 65 & 949 & $1.4400-6$ & & $1.3280+1$ & $6.0000-?$ & 233 & $.8400+1$ & & $5.4910+0$ & $3.4000-1$ \\
\hline 52 & B! & $1.4000+1$ & & $5.69 ! 0+0$ & $1.1000-1$ & 281 & $1.2000+1$ & $1.0000 * 0$ & $5.0310+0$ & $07.0010-$ \\
\hline
\end{tabular}

\begin{tabular}{|c|c|c|c|c|c|c|c|c|c|}
\hline $03 / 01 /$ & & & & EL & & & & $90-$ & -232 \\
\hline REFERENCE & $\begin{array}{r}\text { ENERGY } \\
\text { MEV }\end{array}$ & $\begin{array}{r}\text { OEL TA } \\
\text { MEV }\end{array}$ & $\begin{array}{l}X-5 E C \\
\text { BARNS }\end{array}$ & $\begin{array}{l}\text { DEL IA } \\
\text { BARN5 }\end{array}$ & REFERENCE & $\begin{array}{r}\text { ENERGY } \\
\text { MEY }\end{array}$ & $\begin{array}{l}\text { :JL TA } \\
\text { MEV }\end{array}$ & $\begin{array}{l}X \text { X-SEC } \\
\text { EARNIS }\end{array}$ & $\begin{array}{l}\text { OELTA } \\
\text { QAAR:IE }\end{array}$ \\
\hline
\end{tabular}
\begin{tabular}{llll|rr}
54 & $1031.0000+0$ & $3.0000-25.3000+0$ & $7.9500-1$ & $618463.1000+0$ & $3.7000+01.0000-1$
\end{tabular} $6515092.0000+05.0000-25.0000+0$

\begin{tabular}{|c|c|c|c|c|c|c|c|c|c|}
\hline \multicolumn{2}{|c|}{$03 / 01 / 74$} & \multicolumn{5}{|c|}{ FISSION } & \multicolumn{3}{|c|}{$90-T H-232$} \\
\hline GEFERENCE & $\begin{array}{r}\text { ENERG } Y \\
\text { ME } Y\end{array}$ & $\begin{array}{r}\text { DELLTA } \\
\text { MEV }\end{array}$ & $\begin{array}{l}x \text {-SEC } \\
\text { BARNS }\end{array}$ & $\begin{array}{l}\text { OELTA } \\
\text { BARNS }\end{array}$ & REFERENCE & $\begin{array}{r}\text { ENERGY } \\
\text { MEY }\end{array}$ & $\begin{array}{r}\text { DELIA } \\
\text { MEV }\end{array}$ & $\begin{array}{l}X \text {-SEC } \\
\text { BARNS }\end{array}$ & $\begin{array}{l}\text { OELIAA } \\
\text { BARNS }\end{array}$ \\
\hline 69 21 & $1.2000+0$ & $2.0000 \cdots$ & $3.5000-3$ & $3.0000-4$ & 692354 & $1.4600+1$ & $2.0000-1$ & $14.5000-1$ & $4.0000-2$ \\
\hline $69 \quad 2192$ & $1.4000+0$ & $2.0000-$ & $5.5400-2$ & $3.7000-3$ & E9 2354 & $1.4600+1$ & $2.0000-1$ & $15.6000-1$ & $1.4000=$ \\
\hline 68 रा & $1.6000+0$ & $2.0000-2$ & $1.780-1$ & $7.0000-3$ & $5860 \mathrm{~B}$ & $1.4600+1$ & & $3.7000-$ & 2.0000 \\
\hline 501413 & $1.4000+1$ & & $3.4000-1$ & $1.0000-2$ & 528 & $1.4600+1$ & & $3.5000-1$ & $2.0000-$ \\
\hline $56 \quad 771$ & $1.4100+1$ & & $3.4700-1$ & $1.9000-2$ & 461 & $3.6000+2$ & & $9.0000-i$ & \\
\hline
\end{tabular}

\begin{tabular}{|c|c|c|c|c|c|c|c|c|c|c|c|c|}
\hline \multicolumn{4}{|c|}{$03 / 01 / 74$} & \multicolumn{4}{|c|}{ N. GAMMA } & \multicolumn{5}{|c|}{$90-T H-232$} \\
\hline REFERENI & NCE & ENERG $r$ & DEL LA & $\begin{array}{l}X-5 E C \\
\text { BARNS }\end{array}$ & OELTAA & REFERE & ENCE & ENERO & & DELTA & $x-\operatorname{SEC}$ & $\begin{array}{l}\text { DEL IA } \\
\text { BAFNS }\end{array}$ \\
\hline 57 & 537 & $.5300-8$ & & $7.6000+0$ & $1.6000-1$ & 58 & 363 & $.0000-$ & & $.5000-2$ & $2.1700-1$ & $11.1000-2$ \\
\hline 55 & 191 & $2.5300-8$ & & $7.3100+0$ & $1.2000-1$ & 58 & 363 & $.0000-$ & $t$ & & $2.1000-1$ & $14.0000=$ \\
\hline 65 & 867 & $2.4000-2$ & & $4.8000-i$ & $5.0000-2$ & 60 & 633 & $2.2000-$ & & $.0000-2$ & $2.1300-1$ & 15.0000 \\
\hline 57 & 305 & $0-2$ & $100-3$ & $5.0000-1$ & $1.0000-1$ & 57 & 521 & $.4500+$ & & & $5.2010-3$ & 38.0010 \\
\hline
\end{tabular}

03/01/74 PROMPT NEUTRONS/FISSION 90-TH-232

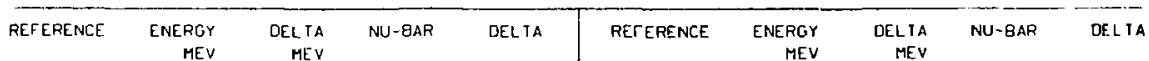

$591151+4000+$

(5) $10792.3000+0$

ME'V

5. $5600+02.0000-1$

$5.2600+01.0000$

$6110793.7500+0$

$2.4300+59.0000-2$

Fig. A-3a. Data from Rel. 1079, as it appears in UCRL-50400, Vol. 7. 
PROMPT

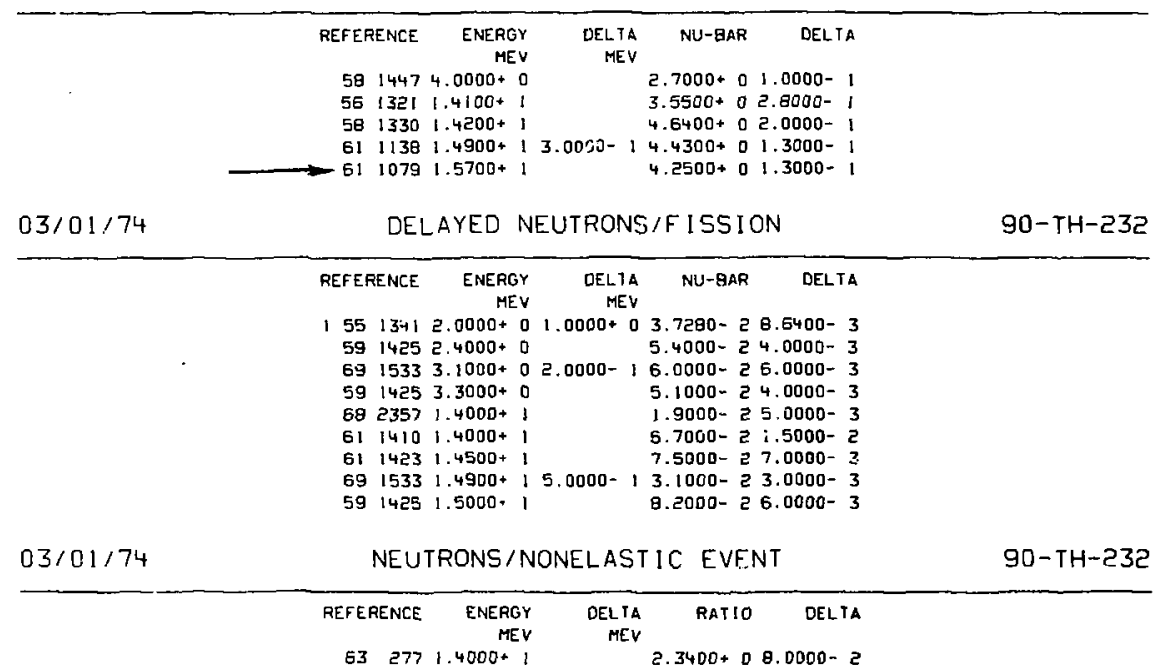

Fig. A-3b. Data from Ref, 1079, as it appears in UCRL-50400, Vol, 7 
CROSS SECTION

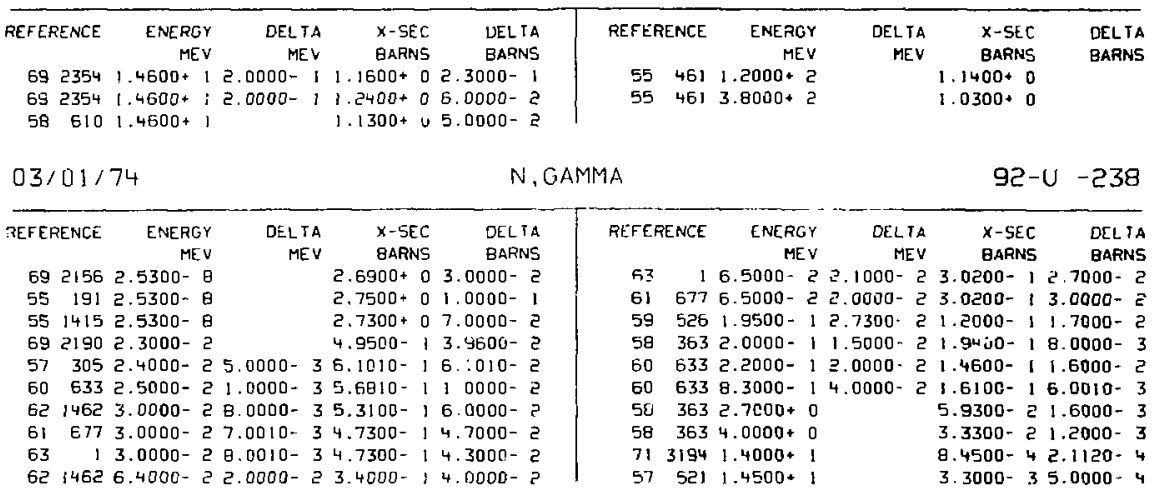

$03 / 01 / 74$

PROMPT NEUTRONS/FISSION

$25-U-238$

\begin{tabular}{|c|c|c|c|c|c|c|c|c|c|}
\hline REFERENCE & $\begin{array}{l}\text { ENERG } \\
\text { MEV }\end{array}$ & $\begin{array}{r}\text { DELTA } \\
\text { MEV }\end{array}$ & NU-BAP & OELTA & REFERENCE & $\begin{array}{l}\text { ENERGY } \\
\text { ME }\end{array}$ & $\begin{array}{r}\text { DELTA } \\
\text { MEV }\end{array}$ & NU-BAF & DEL T \\
\hline 571190 & $1.5000+0$ & & $2.5500+0$ & $09.0000-2$ & 631126 & $1.4000+1$ & & $4.3600+0$ & $03.4000-$ \\
\hline 611334 & $1.5800+0$ & & $2.5600 \cdot 0$ & $03.0000-2$ & $56 \quad 1321$ & $14100+1$ & & $4.1300+0$ & $02.5000-$ \\
\hline-611079 & $2.3000+0$ & & $2.7200+0$ & $08.0000-2$ & $58 \quad 1330$ & 1.4200 .1 & & $4.5500+0$ & $01.5000-$ \\
\hline $56 \quad 1321$ & $2.5000+0$ & & $2.3500+0$ & $01.8000-1$ & $58 \quad 1134$ & 1. $4200 *$ & $i$ & $4.4400+0$ & 02.0000 \\
\hline 611138 & $3.6000+$ & $03.0000=1$ & $2.7900+0$ & $09.0000-2$ & 611068 & $1.4200 \cdot 1$ & 1 & $4.4400 \cdot 0$ & 01.2000. \\
\hline-611079 & $3.7500+$ & 0 & $3.0200+0$ & $01.0000-1$ & $60 \quad 1325$ & $1.4300+1$ & 1 & $4.2800+0$ & 03.0000 . \\
\hline $55 \quad 1383$ & $4.5000+$ & o & $3.1000 \cdot 0$ & $04.0000-1$ & 611138 & $1.4900 \cdot 1$ & $13.0000-1$ & $14.7500 \cdot 0$ & $01.2000-$ \\
\hline $58 \quad 1324$ & $1,4000+1$ & 1 & $4.4600+0$ & $03.2000-1$ & & & & & \\
\hline
\end{tabular}

Fig. A-3c. Data from Ref. 1079, as it appears in UCRL-50400, Vol. 7. 


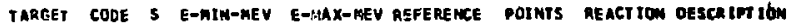

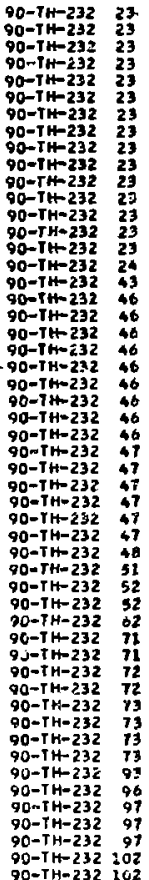

\begin{tabular}{|c|c|c|}
\hline 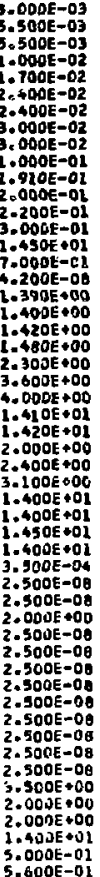 & 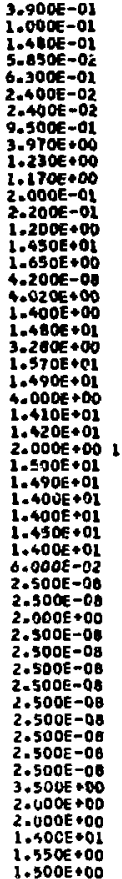 & $\begin{array}{l}60 \\
63 \\
63 \\
64 \\
57 \\
57 \\
65 \\
61 \\
61 \\
59 \\
63 \\
54 \\
60 \\
59 \\
57 \\
61 \\
62 \\
65 \\
59 \\
63 \\
81 \\
61 \\
61 \\
59 \\
56 \\
50 \\
55 \\
50 \\
69 \\
61 \\
60 \\
61 \\
63 \\
61 \\
51 \\
51 \\
50 \\
55 \\
57 \\
59 \\
\end{array}$ \\
\hline
\end{tabular}

\begin{tabular}{|c|c|}
\hline & 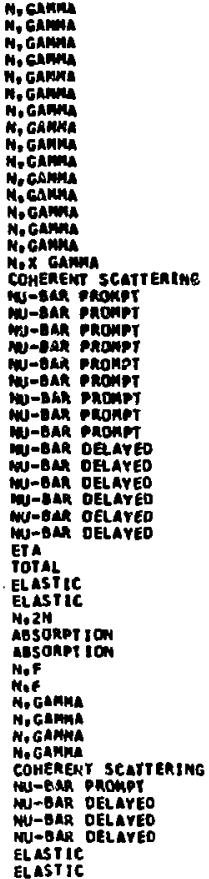 \\
\hline
\end{tabular}

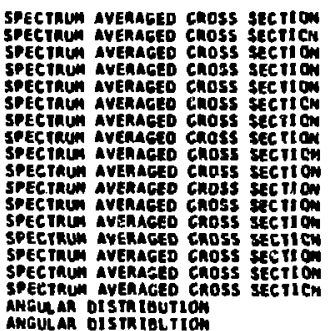

Fig, A-4a. Reaction index to Ref. 1079, as it appears in UCRI.-50400, Vol. 3, Sec, 1. 
TARGET CODE S E-MIN-MEV E-MAX-MEV REFERENCE POINTS REACIION OESCRIPIION

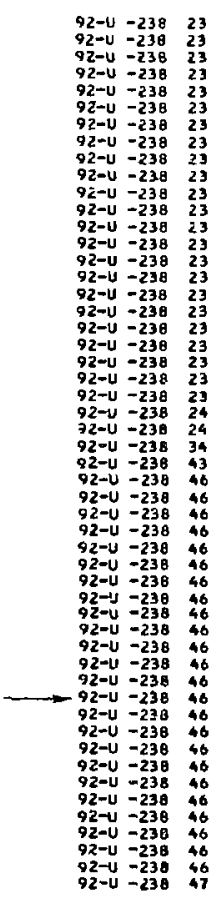

\begin{tabular}{|c|c|c|c|c|c|c|}
\hline $\begin{array}{l}000 E-03 \\
000 E-03 \\
000 E-03 \\
050 E-03 \\
00 B E-02 \\
300 E-02 \\
800 E-02 \\
300 E-02 \\
400 E-02 \\
440 E-02 \\
500 E-02 \\
900 E-02 \\
000 E-02 \\
000 E-02 \\
000 E-02 \\
000 E-02 \\
270 E-01 \\
750 E-01 \\
950 E-01 \\
000 E-01 \\
000 E-01 \\
4 C 0 E+01 \\
450 E+01 \\
090 E+00 \\
000 E-01 \\
450 E+01\end{array}$ & $\begin{array}{l}2.000 E-03 \\
2.200 E-01 \\
5.900 E+00 \\
9.700 E-02 \\
5.835 E-02 \\
1.700 E-01 \\
3.000 E=01 \\
2.300 E-02 \\
2.400 E-02 \\
5.030 E-01 \\
6.300 E-01 \\
6.400 E-01 \\
6.400 E-02 \\
6.500 E-02 \\
6.500 E-02 \\
9.000 E-01 \\
7.600 E+00 \\
2.000 E+00 \\
1.950 E-01 \\
4.000 E+00 \\
3.000 E+00 \\
1.400 E+01 \\
1.450 E+01 \\
1.480 E+01 \\
1.700 E+00 \\
1.450 E+01 \\
0 . \\
-6.140 E+00 \\
-6.140 E+00 \\
-6.140 E+00 \\
-6 .+140 E+00 \\
-6.140 E+00 \\
=6.140 E+00 \\
-6.140 E+00 \\
-6.140 E+00 \\
1.479 E+01 \\
6.020 E+00 \\
1.400 E+01 \\
1.500 E+00 \\
1.580 E+00 \\
3.750 E+00 \\
1.410 E+01 \\
1.490 E+01 \\
4.500 E+00 \\
0.000 E+00 \\
1.400 E+01 \\
1.400 E+01 \\
1.42 .0 E+01 \\
1.420 E+01 \\
1.420 E+01 \\
1.430 E+01 \\
2.000 E+00 \\
\end{array}$ & $\begin{array}{l}69 \\
60 \\
46 \\
63 \\
64 \\
63 \\
62 \\
09 \\
57 \\
68 \\
60 \\
59 \\
62 \\
61 \\
63 \\
69 \\
64 \\
60 \\
59 \\
58 \\
45 \\
75 \\
5,7 \\
66 \\
61 \\
59 \\
55 \\
71 \\
52 \\
54 \\
57 \\
59 \\
60 \\
60 \\
63 \\
67 \\
65 \\
64 \\
57 \\
61 \\
61 \\
56 \\
61 \\
55 \\
69 \\
58 \\
63 \\
58 \\
50 \\
61 \\
60 \\
55\end{array}$ & $\begin{array}{r}2096 \\
727 \\
313 \\
1830 \\
454 \\
1438 \\
1407 \\
2190 \\
305 \\
1547 \\
633 \\
1402 \\
1462 \\
677 \\
1 \\
2523 \\
1401 \\
674 \\
526 \\
363 \\
1403 \\
3194 \\
521 \\
1027 \\
11 \\
550 \\
902 \\
2509 \\
1366 \\
1128 \\
1370 \\
1157 \\
1133 \\
1454 \\
1075 \\
211 \\
1074 \\
1379 \\
1190 \\
1334 \\
1079 \\
1328 \\
1138 \\
1383 \\
2092 \\
1324 \\
1126 \\
1134 \\
1330 \\
1060 \\
1324 \\
1341\end{array}$ & $\begin{array}{r}17 \\
17 \\
14 \\
92 \\
126 \\
10 \\
8 \\
1 \\
1 \\
9 \\
3 \\
10 \\
2 \\
2 \\
2 \\
4 \\
13 \\
7 \\
1 \\
3 \\
5 \\
1 \\
1 \\
6 \\
135 \\
1 \\
1 \\
1 \\
1 \\
1 \\
1 \\
1 \\
1 \\
1 \\
1 \\
21 \\
4 \\
1 \\
1 \\
1 \\
2 \\
2 \\
2 \\
1 \\
2 \\
1 \\
1 \\
1 \\
1 \\
1 \\
1\end{array}$ & 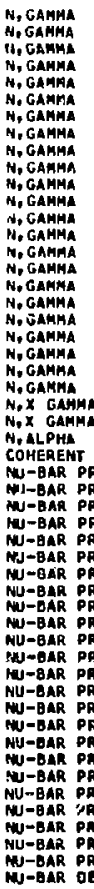 & 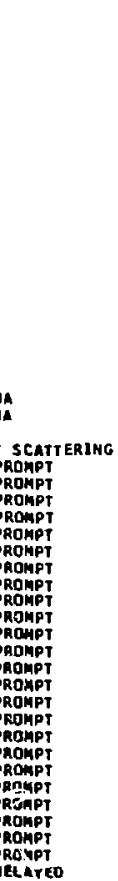 \\
\hline
\end{tabular}

Fig. A-4b. Reaction inde $x$ to Rer, 1079, as it appears in UCRL-50400, Vol. 3, Sec. 1. 
TAREE: CODE 5 E-MIN-MEV E-MAX-MEV REFEREIJCE POINTS REACTION OESCRIPTION

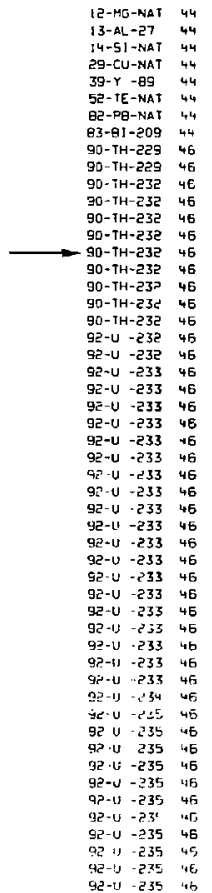

\begin{tabular}{|c|c|c|c|c|c|c|}
\hline C.5SUL-U日 & 2.530E-0Q & 57 & 2833 & $!$ & INCOHERE,NT & SCATTER. \\
\hline e.530E-0日 & C.530E- $0 \mathrm{~g}$ & 63 & 2663 & 1 & INCOHERENT & SCAT TER. \\
\hline 9. $420 E-06$ & $9.420 E-06$ & EE & 1759 & 1 & INCOHERE NT & SCATTER. \\
\hline & 0 . & 58 & 404 & 1 & [HCOHERENT & SCATTER. \\
\hline $2.530 E-00$ & $2.530 E-08$ & 65 & $211 \theta$ & i & INCOHERENT & SCATTER. \\
\hline $2.500 \mathrm{E}-0 \mathrm{~B}$ & $2.500 E-00$ & 51 & 2398 & $\mathrm{i}$ & INEOHERENT & SCATTER. \\
\hline $9.420 E-06$ & 9. $420 E-06$ & 66 & 1759 & 1 & INCOHERENT & SCATTER. \\
\hline $2.530 \mathrm{OE}-0 \mathrm{~B}$ & $2.530 \mathrm{E}-0 \mathrm{~B}$ & 63 & 2663 & $i$ & JNCOHERENT & SCATTEA. \\
\hline $2.530 E-0 \mathrm{E}$ & 2. $530 E \cdot 09$ & 58 & 1156 & I & NU-BAR PROH & MPT \\
\hline $2.530 \mathrm{E}-0 \mathrm{\theta}$ & $2.530 \mathrm{E}-0 \mathrm{~B}$ & 61 & 1088 & 1 & NU-BAR PRO & \\
\hline $1.390 E+00$ & $4020 E+00$ & 65 & 1074 & 4 & NU-BQR PROM & \\
\hline $1.400 E+00$ & $1.400 \mathrm{E}+00$ & 59 & 1151 & 1 & $\mathrm{NU} U$-BAR PROM & MFT \\
\hline $1.420 E+00$ & $1.480 E+01$ & 65 & 1378 & 7 & NU-BAR PROH & \\
\hline $1.4 \mathrm{BOE}+00$ & $3.280 E+00$ & 66 & 219 & 7 & NJ-BAR FROM & \\
\hline $2.300 E+00$ & $1.570 E+01$ & 61 & 1079 & 3 & NU-BAR F FOH & MPI \\
\hline $3.500 E+00$ & $1.490 E+01$ & 61 & 1138 & 2 & NU-BAR PROM & \\
\hline $4.000 E+00$ & $4.000 c+00$ & 50 & 1447 & $i$ & NU-BAR PROM & MPT \\
\hline $1.410 E+01$ & $1.410 E+01$ & 56 & 1321 & 1 & NU-BAR PROM & MPT \\
\hline $1.420 E * 01$ & $1.420 E+01$ & 50 & 1330 & 1 & HU-BAF PROH & \\
\hline $2.530 \mathrm{OE}-0 \mathrm{~B}$ & c. $530 \mathrm{E}-0 \mathrm{~B}$ & 61 & 1080 & i & NU-PAR PROK & \\
\hline $2.530 \mathrm{E}-0 \mathrm{~g}$ & 2. $530 E-09$ & 69 & 1912 & $i$ & NU-GAR PROH & \\
\hline $2.530 \mathrm{E}-0 \mathrm{~B}$ & 2. $530 \mathrm{E}-0 \mathrm{~B}$ & 46 & 1313 & 1 & NU-OAR PROM & \\
\hline $2.52=-09$ & $2.530 E-08$ & 55 & 1097 & 1 & NU-GAR PFOM & \\
\hline $2.530 E-08$ & $2.530 \mathrm{E}-0 \mathrm{~B}$ & 55 & 1098 & $i$ & NU-BAR PROH & HFT \\
\hline $2.530 \mathrm{E}-0 \mathrm{~g}$ & 2. $د 30 E-08$ & 55 & 1099 & 1 & NU-BAR PROH & \\
\hline $2.530 \mathrm{E}-0 \mathrm{~B}$ & 2. $530 E-0 B$ & 56 & 1065 & 1 & NU-BAR PRGS & MPT \\
\hline e. $530 \mathrm{E}-\mathrm{Cg}$ & 2. $530 \mathrm{E}-0 \mathrm{O}$ & 59 & 1063 & $i$ & NIS-GAR PROH & \\
\hline $2.530 E-O_{B}$ & 2. $530 \mathrm{E}-0 \mathrm{~B}$ & 58 & 1172 & $i$ & NU-BAR PROH & \\
\hline $2.530 E-0 B$ & e. $530 \mathrm{E}-0 \mathrm{~B}$ & 59 & 1092 & i & NU-BAF PAOM & $M P T$ \\
\hline $2.5305-00$ & $2.5300-00$ & 65 & 1085 & 1 & NU-BAR PPOH & \\
\hline $2.530[-0 \mathrm{~B}$ & 2. $5300-00$ & 66 & 1336 & $i$ & NU-GAR PROH & API \\
\hline 2. $530 \mathrm{E}-\mathrm{OQ}$ & 2. $530 \mathrm{E}-0 \mathrm{~g}$ & 67 & 1417 & $i$ & NU-BAR PPOH & \\
\hline $2.530 E-08$ & $3930 E+00$ & 63 & 1073 & 6 & MU-GAF PROH & \\
\hline$P .530 \mathrm{D}-0 \mathrm{\theta}$ & $\because 000 E+00$ & 65 & 1074 & 5 & MJ-EAR PROH & TPT \\
\hline 9.000E-02 & B. $000 E-02$ & 56 & 1145 & i & NU-BAR PFOH & \\
\hline $8.000 E-02$ & 7. O00E-01 & 87 & 226 & 7 & NU-BAR PROP & \\
\hline $4.000 E \cdot 70$ & $1,500 E+01$ & 50 & 1121 & $a$ & NU-BLR PROM & MPI \\
\hline$. .400 E+0 !$ & $1.400 E \cdot 01$ & 61 & 1269 & 1 & MU-BAR PROM & \\
\hline $1.410 E+01$ & $1 .+10 E+01$ & 56 & 13?!: & i & NU-BAR PPOY & MPT \\
\hline $1.480 E+01$ & $1480 \mathrm{O}+01$ & 58 & 1122 & 1 & NU-BAR PROH & IAP T \\
\hline $9.900 \varepsilon-0 i$ & $4 \quad \mathrm{E}: 20 \mathrm{CE}+0 \mathrm{O}$ & 65 & 1074 & 4 & MU-BAP' PROM & MPI \\
\hline $2.53 v_{i}-U_{H}$ & $\bar{r}, 53 \overline{v e}-\bar{v} \bar{a}$ & in, & i 316 & $i$ & MU-BAR PPOM & IPT \\
\hline $2.520 \mathrm{C}-9 \mathrm{~A}$ & 2. $530 \mathrm{OF}-0 \mathrm{~B}$ & 55 & 1097 & $i$ & NU-bar Prom & \\
\hline$c^{3} .530 \mathrm{E}-\mathrm{Q} \theta \mathrm{\theta}$ & ?. 530E-08 & 56 & 1065 & 1 & NU- $\theta \propto R$ PRON & IPI \\
\hline$-530 \mathrm{E}-0 \mathrm{~B}$ & $2.530 \mathrm{DE}-\mathrm{00}$ & 58 & 1320 & i & MU-GA: PROM & IMP: \\
\hline $2.530 \mathrm{E}-0 \mathrm{\theta}$ & $2.530 E-00$ & 66 & $j a>1$ & $i$ & :NU. HAR FROM & MPT \\
\hline $2.530 \mathrm{E}-0 \mathrm{~g}$ & ¿ $530 E-09$ & E6 & 1323 & 1 & NU-GAR PROM & PT \\
\hline ? $530 \mathrm{CE} \cdot 0 \mathrm{~B}$ & P 5,3 तก - م & 65 & 1336 & 1 & Nu-gaH P & \\
\hline $2.530 \mathrm{E}-\mathrm{Dg}$ & $2.530 E-139$ & 67 & 1417 & 1 & $\mathrm{NU}-\mathrm{\theta AP}$ PROM & IMPI \\
\hline 2.5300 QB & 1. $900 E+60$ & 70 & 3278 & 15 & MU-BAR PROM & IMP I \\
\hline 2. $5306-$ - & 2.07et.00 & 65 & 1085 & 10 & NU-BAR PR2 & IMP T \\
\hline $53 \cap E-\square \theta$ & $7.960 E+00$ & 54 & 1155 & 19 & NAJ-gAR PROM & IMPT \\
\hline
\end{tabular}

Fig. A-5a, Reaction index to Rel. 1079, as it appears in UCRI-50400, Vol, 3, Sec. 2. 
TAHGE COOE 5 E-MIN-HEV E-HAX-MEV REFERENCE POINTS REACTION DESCRIPTIOA

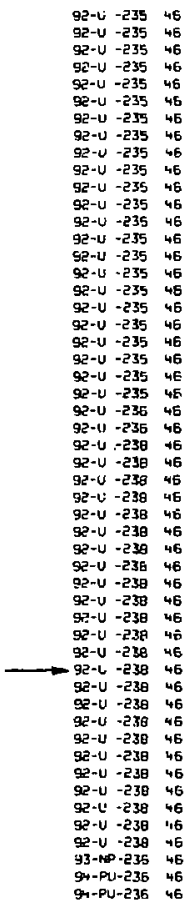

\begin{tabular}{|c|c|c|c|}
\hline $2.530 \mathrm{E}-0 \mathrm{~B}$ & $1.45 G E+01$ & & \\
\hline 2. $530 E-00$ & $1 \quad 480 E \cdot 01$ & 65 & 1319 \\
\hline $\begin{array}{l}\text { 3. } 000 E-05 \\
\text { 3.900E }-05\end{array}$ & 1, 760E • O0 & 02 & 1154 \\
\hline & $1.000 E \cdot 00$ & 66 & 1327 \\
\hline 7.500E-02 & $1.420 E=01$ & 51 & 1068 \\
\hline 8. 000E-02 & 6.000E-02 & & $111: 5$ \\
\hline B. $000 E-0 \tilde{z}$ & $7.000 E \cdot 01$ & 67 & 226 \\
\hline 9. 000E-02 & 9.900E-0I & 64 & 1326 \\
\hline 2. $100 E-01$ & 1. $58 D E \cdot 0 D$ & 51 & 1334 \\
\hline 3. $700 \mathrm{E}-01$ & $2,130 E \cdot 00$ & 89 & 3थे। \\
\hline 3. $7000-01$ & 3. $250 E \cdot 00$ & 66 & 219 \\
\hline 7. $000 E-01$ & $7.000 E-01$ & 55 & 1374 \\
\hline $1.000 E+00$ & I $\quad \mathrm{OOOE}+00$ & 59 & 1373 \\
\hline $1.1506 \cdot 05$ & $6500 E+C O$ & & \\
\hline $1.250 E-00$ & $4.600 E \cdot 00$ & 57 & 1190 \\
\hline 1. $360 E+00$ & $1.4795+01$ & 67 & 211 \\
\hline $2.500 E+00$ & $1,410 E \cdot 01$ & 56 & 1321 \\
\hline $\begin{array}{l}4.000 E+00 \\
4.000[\cdot 00\end{array}$ & $\begin{array}{l}4.500 E+00 \\
1.500 k+01\end{array}$ & & $\begin{array}{l}1383 \\
1121\end{array}$ \\
\hline $4.000[\cdot 00$ & $1.500 \mathrm{~L}+01$ & & \\
\hline $7.000[+00$ & $8.000 E \cdot 00$ & & 2092 \\
\hline $1,400 E+01$ & $1.400 E+01$ & & 1324 \\
\hline $1.430 E+01$ & $1.430 E * 01$ & 60 & 1325 \\
\hline $1.480 E+01$ & $1.480 E+01$ & 38 & 1322 \\
\hline$-6.400[+00$ & $-6.400 E \cdot 00$ & 69 & ¿309 \\
\hline $7.700 \mathrm{E}-01$ & 6. $700 E \cdot 00$ & & 2509 \\
\hline$-6.14 \mathrm{fzet}+50$ & $-6.140 E \cdot 00$ & & 1365 \\
\hline$-6.140 E+20$ & $-6,140 E+00$ & 54 & 1128 \\
\hline$-6.140 E+00$ & $-6.14 G E+00$ & 57 & 1370 \\
\hline$-6.140 \Sigma+00$ & $-6.140 E+00$ & 53 & 1157 \\
\hline$-6.140[+70$ & $-6.140 E+00$ & 60 & 1133 \\
\hline$-6.140[+00$ & $-6.140 E+00$ & 60 & 1454 \\
\hline$-E .140 E+00$ & $-6.140 E+00$ & 63 & 1075 \\
\hline$-6.140 E+00$ & $-6.140 E+00$ & & \\
\hline $1.360 E+00$ & $1.479 \mathrm{E}+8 !$ & 57 & 211 \\
\hline $1.410 E+00$ & $4.020 E+00$ & 55 & 1074 \\
\hline $1.490 E+00$ & $1,480 E \cdot 01$ & 54 & 1379 \\
\hline $1.500 E+00$ & $1.500 E \cdot 90$ & & 1190 \\
\hline $3.580 L+100$ & $1.580 E \cdot 00$ & & 1334 \\
\hline $2.3000+00$ & $3.750 \varepsilon \cdot 00$ & & 1079 \\
\hline $2.500 E \cdot 00$ & $1.4100+01$ & 56 & 1321 \\
\hline $3.600 E+00$ & $1.490 \mathrm{E}+01$ & 61 & 1138 \\
\hline $4.500 c \cdot 00$ & $4.500 E+00$ & & 1383 \\
\hline $7.000 E \cdot 00$ & $8.000 E+00$ & 69 & 2092 \\
\hline $1.400 \mathrm{E}+01$ & $1.400 E+01$ & & 1324 \\
\hline $1,400[+01$ & $1.400 E+[01$ & 63 & I1265 \\
\hline $1.420 E+01$ & $1.420 E+01$ & & 1134 \\
\hline $1.420 E+01$ & $1.420 E \times 01$ & 58 & 1330 \\
\hline $1.420 E+01$ & $1.42 \pi \mathrm{E} \cdot 01$ & 61 & 1060 \\
\hline 1. $40 \mathrm{E}+0 \mathrm{C} !$ & $1.430 E=01$ & & 1325 \\
\hline $2.5305-08$ & $2.530 E-0 B$ & bl & 1088 \\
\hline & $-7350 E \div 00$ & & \\
\hline
\end{tabular}

7 N-BAF PROTPT

3 NU-GAR PROHPT

6 MU-BAR PROMP

16 MU-GLA PROHF

3 NU-BNR PROMPT

- MU-EAA PROMPT

7 Nu-gaR Prompt

12 NU-FAR PROMPT

4 MU-GAR PROMPI

21 NU-TAR PROMPT

14 MU-BAR PROHPT

1 NU-BAR FROMPI

1 NU-BAR PROMP

2 NU-BAR PRONP

1. NU-GAR PROEPT

1 NU-BAR PRCAPT

21 NU BAR PROR

NJ-GAR PROPPI

I NU-BAR PRDOPI

NU-GAR PROTPT

I NU-GRR PROTP I

NU-Ear OPOPI

1 NU-BaR paor

27)

- Nu-gar prompr

- Nu-gaR PROMPI

I NU-BAR PROMP

l NU-Bar PROMP

2 NU-BAR POOHPI

2 NU-OAR PROTPI

2 NU-BAR PPOTP

2. NU BaR Prom?

- NU Bar porom

1 NU-EAR PRONT

NU Bap PRor

MU BAR PROMPI

NU-BAR PRDTP

i nu-gar prompi

- mu-bar paoto

1 NU-BAR PROAP

NU-BAR PROTPT

l nu-gar promer

Fig. A-5b. Reacion index to Ref. 1079 , as it appears in UCRL-50400, Vol. 3, Sec. 2. 


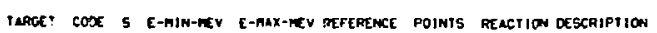

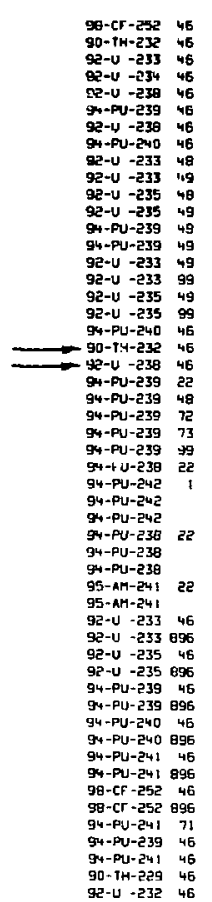

\begin{tabular}{|c|c|c|c|}
\hline $6.500=00$ & $-5.350[.00$ & & \\
\hline $1.3905 \cdot 00$ & $4.020 E+00$ & 65 & 1074 \\
\hline $2.530 t-00$ & & & 1074 \\
\hline $9.900 t-01$ & $4,0200+00$ & 65 & 1074 \\
\hline $\begin{array}{l}1.410 E+00 \\
2.530 E-00\end{array}$ & $\begin{array}{l}4.020 \varepsilon+00 \\
4.020 \varepsilon+00\end{array}$ & 65 & $\begin{array}{l}1074 \\
1074\end{array}$ \\
\hline$=6.140 E \cdot 00$ & $-6.140 E \cdot 00$ & 83 & 1075 \\
\hline $\begin{array}{r}-6.680 E+00 \\
2.500 E=00\end{array}$ & $\begin{array}{r}-6.600 E+00 \\
5.200 E-00\end{array}$ & 63 & $\begin{array}{l}1075 \\
1076\end{array}$ \\
\hline 2.500E-09 & 5. $700 \mathrm{E}-00$ & 65 & 1076 \\
\hline $\begin{array}{l}2.500 \mathrm{E}-\mathrm{OE} \\
2.500 \mathrm{E}-0 \mathrm{~B}\end{array}$ & $\begin{array}{l}2.500 E-00 \\
2.500 E-00\end{array}$ & 65 & $\begin{array}{l}1076 \\
1076\end{array}$ \\
\hline $2.500 \varepsilon-00$ & 5. $700 E-08$ & 65 & 1076 \\
\hline & & & \\
\hline $2.530 E-00$ & $2.530 E=08$ & 66 & 1077 \\
\hline & $2,5000-00$ & 66 & 1077 \\
\hline $2.530 E-00$ & 2. $530 \%-00$ & & \\
\hline $2.500 E-00$ & 2. $500 E-00$ & 66 & 1077 \\
\hline $3.6005+00$ & $1.500 \mathrm{E}+01$ & 61 & 1078 \\
\hline 2. $300 \mathrm{C}+00$ & $! .570 E \cdot 01$ & & 1079 \\
\hline $2.300 E+00$ & 3. $750 E \circ 00$ & 61 & 1079 \\
\hline $1.000 E-04$ & 2. $993 \mathrm{E}-02$ & & Ineo \\
\hline $1.000 E-04$ & $2.993 \mathrm{E}-02$ & 68 & 1080 \\
\hline $1.500 E-04$ & 2.5O0E-02 & 68 & 1000 \\
\hline 1.500E-04 & 2.500E-02 & & 1060 \\
\hline $1.500 E-04$ & $2.500 E-C 2$ & & 1000 \\
\hline $1.400 E-01$ & $1.740 E+00$ & 63 & 1081 \\
\hline 2. $500 \mathrm{E}-00$ & 3. $682 t-0$ & 56 & 1082 \\
\hline 2.000E-0B & $4,000 E-04$ & 66 & 1082 \\
\hline 2. $640 \mathrm{E}-06$ & $3.860 E-04$ & & 1082 \\
\hline $2.090[-06$ & 2. $.992 E-04$ & 66 & 1083 \\
\hline ᄅ. $900 E-G E$ & $2.600[-04$ & 66 & 1003 \\
\hline $1.5100 \cdot 04$ & $2.600[\cdot 04$ & 66 & 1083 \\
\hline 3.2IOE-00 & 9. $000 E-04$ & 65 & 1084 \\
\hline 3. $1008-07$ & 1. $504 E-05$ & & 1084 \\
\hline $2.530 \mathrm{E}-08$ & $2.530 E-08$ & 65 & 1085 \\
\hline $2.500 E-00$ & ¿.500E-0日 & 65 & 1085 \\
\hline Z. $530 E-00$ & $P .572 E+00$ & & 1085 \\
\hline $1.010 E-01$ & $2.572 E+00$ & 65 & 1005 \\
\hline $2.530 \mathrm{E}-0 \mathrm{~B}$ & 2. $530 \mathrm{E}-0 \mathrm{O}$ & & \\
\hline $2.500 E-00$ & C. BOOE -00 & 65 & 1085 \\
\hline$-6.6800+00$ & $-6.6800+00$ & 65 & 1085 \\
\hline $6.6800+00$ & $-6.680 \mathrm{0} \cdot 00$ & 65 & 1085 \\
\hline 2. $5308-08$ & E. $530[-00$ & 65 & 1085 \\
\hline & $2.500 \mathrm{E}-0 \mathrm{~B}$ & & 1085 \\
\hline & $-6.350 E$ & & \\
\hline$-6,350 E+00$ & $-6.350 E=00$ & & 1005 \\
\hline & $4.585 E-03$ & 65 & 1086 \\
\hline & I $480 E \cdot 0$, & 60 & 1087 \\
\hline 5. $200 E-01$ & $1.480 E+(11)$ & & 1087 \\
\hline & & & \\
\hline $2.5300-00$ & $2.530 E-00$ & 61 & 1080 \\
\hline
\end{tabular}

\section{MU-BNR PEOPTT}

5 IN-BAB PRONTI

I NU-BAR PRONP

LU-BLP Promet

ETa

a Alpar

ETA

ILPAA

z) ETA

2 ALPHA

1 ALPHA

1. ALPHA

1. ALPHa

5 NU-BAR PROMPI

3 NU-BAR PROAPI

2 NU-BAR PROAPI

5293 N.F

Segs ETA

59 N,F

50 ALPHA

75 N.F

189 10TAL

1. average pesonahice paraitetefs

16 RESONANCE PARAHE TERS

$217 \mathrm{Nar}$

aVERAGE RESONANCE PaRAMETERS

6 RESOTIANCE PARAHETERS

470 N.T

\section{6 resohance parametefs}

1 NU-GAR PRDMPI

NU-GAR PROMPI

NU-BAP PNOTPI

NU-BAP PROTPY

NU-GAR PROHPI

NU-GAR PROHPI

NUEAAR PROHP)

NU-BAR PROHI

NU-BAR PRONOP

NU-BAR PROHPI

1 NU-BAR PROMP

7 ABSOAPTION

5 MU-BAA PROAPI

5 MN-GAR PROMPI

1 NU-BAA PROTPI
SPECTRIMA AVERAGEO CROSS SECTION

SPECTFIA AVERACEO CROSS SECTION

SPECTRUA AVERAGEO CROSS SECTION SPECTRUH AVERAGEO CROSS SECTION

\author{
CROSS SECTION RATIO \\ CAOSS SECIIOA RAITO \\ CROSS SECTION RA: to \\ CROSS SECTION RATIO \\ CROSS SECIION RATIO \\ SROSS SECTION RATIO

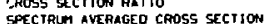

Fig. A-6. Reaction index to Rer, 1079, as it appears in UCRL-50400, Vol, 3, Sec. 3. 
AUTHOR

KREGEA. W.E

KREISLER, TN.

Kay ZMANSEY, L.

KFOGUKSKI. I.

KROAN, $v$.E.

KROPP, 2 .

MRUCER.

KRUER. $R$.

Khuger. F.G

KuCH, $Y, J, M$

cuciovin. $F$

Kumavadze, $\mathrm{G}$.

KU. ABUKHOV, YU.5.

TLLISIC.

Kurveneres, $H$

KUO. L.G.

KuFOOA, P.K

XUSCH, H.

KuSHEFIIUK, S.A

KuTikoY, $1 . \mathrm{E}$.

KUTSAEVA. L.j.

\begin{tabular}{|c|c|c|c|c|}
\hline CITATIO & ONS & & & - aUTHDR \\
\hline 495 & 031. & & & - lake. R.o. \\
\hline $1948^{\circ}$ & 2350 & 3100 & & - \\
\hline 2193 & 2363 & & & - LAMG. J. \\
\hline $\begin{array}{l}2235 \\
2312\end{array}$ & & & & : Langknu, $\mathrm{R}$ \\
\hline $1691^{\circ}$ & $2600^{\circ}$ & & & - lakosoori .ja a a.s. \\
\hline $\begin{array}{l}-2517 \\
2734\end{array}$ & 3091 & 3329 & & : \\
\hline $\begin{array}{l}1629 \\
1587\end{array}$ & 1694 & & & : \\
\hline 412. & & & & - \\
\hline $\begin{array}{l}3043 \\
2351 .\end{array}$ & & & & $\because$ LANGSFORD. $A$. \\
\hline $1414=$ & 1490 & 2196 & 2226 & - LANNING. O.D. \\
\hline $\begin{array}{l}2235 \\
1908\end{array}$ & 2247 & P362 & 2684 & $\begin{array}{l}\text { : LANIZ. P. } \\
\text { LANTZ, F.M. }\end{array}$ \\
\hline 1975. & 2036 . & $2326 \cdot$ & & - \\
\hline $\begin{array}{l}474 \text {. } \\
667 \%\end{array}$ & $535^{\circ}$ & 537. & $630^{\circ}$ & $\begin{array}{l}\text { * LAPS. R.E. } \\
\text { : LARCE. R.S. }\end{array}$ \\
\hline $\begin{array}{r}3180 \\
986\end{array}$ & & & & 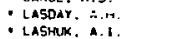 \\
\hline 1945 & 2314 & 2707 & 3150 & - \\
\hline 1890 & & & & - LASINGEH. V.F. \\
\hline 1386 & 2915 & & & - lathay. J.h. \\
\hline 148 & -1158 & 1360 & & ILvHad. X.A. \\
\hline IIEI & 1157 & 1198 & 1447 & - Latrsher. o.d. \\
\hline $\begin{array}{l}1078 . \\
1447\end{array}$ & 1079. & 1157. & $1190^{\circ}$ & $\begin{array}{l}\text { : Laueer, } \\
\text { - laurat. i. }\end{array}$ \\
\hline 225 & $13 \pm 6$ & & & - \\
\hline 2891. & $\begin{array}{l}3070 . \\
720\end{array}$ & 3275 & & - lavalle, D.E. \\
\hline 3123 & & & & - HAVGESCHIK, Y.N. \\
\hline-1061 & & & & - LuAPENCE. G.P. \\
\hline ell & & & & - LAZAR, M. \\
\hline $\begin{array}{l}2034= \\
2762\end{array}$ & & & & $\begin{array}{l}\text { - LAZAR, N.H. } \\
+ \text { LEOV, A.A. }\end{array}$ \\
\hline 3195. & & & & - LE cOD, G. \\
\hline $\begin{array}{l}1613 \\
1622 .\end{array}$ & 1975 & 2036 & & $\begin{array}{l}\text { - LE PIPTC. C. } \\
\text { - LE POI'IEVIN, } 0 .\end{array}$ \\
\hline $\begin{array}{r}-3146 \\
3297\end{array}$ & 3154 & & & i le higoleua, c.o. \\
\hline $\begin{array}{l}132 . \\
15294\end{array}$ & $152^{\circ}$ & $268^{*}$ & a93. & $\begin{array}{l}\text { : LEACHFEH, R.B. } \\
\text { - LEARY, J.A. }\end{array}$ \\
\hline 64 & 183. & & & - LEECDEV. P.P. \\
\hline $32.59^{\circ}$ & & & & : LEEECEV. Y.I. \\
\hline 497. & 1057 & $11390^{\circ}$ & 2025. & $\cdot-20$ \\
\hline $\begin{array}{l}-5299 . \\
-3440 \\
3034 .\end{array}$ & $\begin{array}{l}2327 \\
2441 .\end{array}$ & $\begin{array}{l}2395 \circ \\
2893\end{array}$ & $\begin{array}{l}2432 \\
2502 .\end{array}$ & 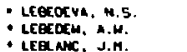 \\
\hline $3287 \cdot$ & & & & \\
\hline $\begin{array}{l}40 \\
231\end{array}$ & $571^{\circ}$ & 665 & 807. & $\begin{array}{l}\text { LEBONITZ. J. } \\
\text { LEONITZ, J.m. }\end{array}$ \\
\hline
\end{tabular}

CIIATJOAS

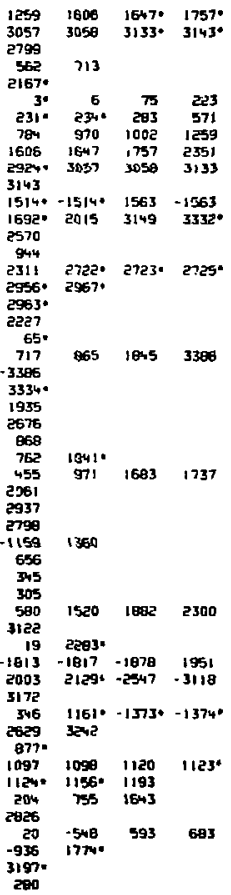

Fig. A-7. Author citation to Ref, 1079, as it appears in UCRL-50400, Vol. 2, Sec, 1. 


\section{OEF-N RETEREMCE}

1079 SOVIET PAOCAESS IN MEUTRON PHYSITS. P. 177 D76 SOVIET PAOGRESS IN MEUTRON PATSICS,P, 181

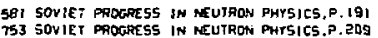

754 SOVIET PhOGRESS IN MEUTRON PuYSICS.P. 211

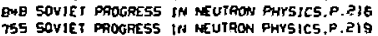

Q46 SOVIET PROEAESS IN NEUTRON PHYSICS.P. 226 35 SOVIE PROCAESS IN NEUTPOA PAYSICS P. 250 650 SOVIE? PROGAESS IN NEUTRON PHYSICS. 241

T6O STANFORD UNIVERSITY THESIS

2050 SUAP-69-2

-2569 5YHPOSIUT PILE O5EIL MEAS. NEUT. ABSOAP. BUCHARE ST,P. 553 1042 TEXAS MULLLAR CORPORATION REPORT

172 TEXAS MELEAR CORPORATION REPORT

1725 TEXAS MULLEAR CORPOAAIION REPORT

1728 TEKAS NUELEA CORPORATION AEPORT

1730 IEXAS NUCLEAR CORPORATIC REPORT

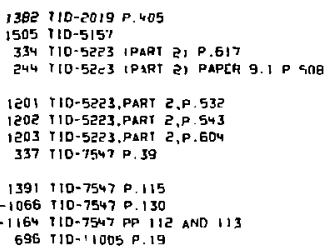

\section{YR AUTMOA}

6) Kuz'ntwov. 6.0.

61 KUZ MINOV, 8.0

EI MIKHALLINA, K, m.

TIKtomions $f, a$,

EI AVERCHENXOV. Y.TA

kture

v. ASFaxo, V.P.

G1 ARDRECY. Y.H.

G) LOVCHIKOVA. G.N.

61 MOROzOV. Y.H.

61 POPOV, $v, 1$.

6i stavissxil. Wu. ya

61 TOLSTIKOV, V.A.

G) MeFEDov, V.V.

YAZVE fGXI1. Yu. 5.

63 MLAFIS. K.K.

GRRDESA, O.O.

65 Mathur, 5.6

MORG 1 N, $l . L$

ASHE. J.B.

MOHGAN, J.L.

Ge ASHE. J.8.

HeNDEASON. J.o.

Mel is, 0.0 .

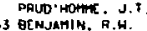

63 GENJAHIN. R.h.

MORGAN. 1.1.

PARKER. C.V.

64 MUOSON.JR., O 7

HATHAA. S.C.

MORGAN, $1 \mathrm{~L}$

MELLIS. D.O

55 JNACY.

53 WAL $T$. H,

52 HAGEMANA, $T$.

STUDIER. H.H.

52 Jarfer, A.H.

52 KATZIN. $t .1$

50 JAFFEY. A.H.

StGaARGifux, $C$.

57 LEONAPE $R$... R.

57 KEEPIN. G.R.

EO GAL!. OHAY, III, L.A. autmat

Nonor $120 V, A, A$

Tastov. K.

rastov. K.D.

crar iss, $Y . t$

GAirs, ru.A.

SAL NIKOX: O.A.

LeBeCEYa. N. 5 .

SHAPAR'. A.V

STAVISEKII, YU. Ya

PoFov, $\left.V_{1}\right]$

SHLarpicelo, it.

Buchatran. I 5

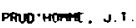

gemiatin. A.h

motian, $1 . \mathrm{L}$

PRELEIT, R.L

ERNAAHIN. A.W.

HOSON, NA, O, M.

MELLIS. D O

AStE. 3.8.

TUCKER. H.E.

EUCHANAN, P.

Fucker. H

A5S J.Q

EENJAHIN. R.h

GHIOnso. A.

Grof. $i *$.

Hacemana, $r$.

VAN HINELE, 0 .

JoL $Y$, $P$

Fig. A-8. Alphabetically ordered listing of Ref. 107\%, as it appears in ICRl-50400, Vol, 2, Sec. 2. 
1071 GORON PILE.

EANOC (UK) - G45 11966 )

1072 J. NUCLEAR ENERGY, PARTS A/8, 19, 423 (1965) J.L.PERK IN P.H.HHITE. P.FIELDHOUSE

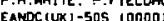

NEUTROA FLUX DETERHINEO BY THGEE INOEPENDENT ABSOLUTE FLAT

RESPONISE OETECTOPS

1073 NUCLEAR PHYS. 48. 433 119631 J.C. HOPKINS. B.C.DIVEN RELATIVE TO SPONTANEOUS TISSION NU BAR OF CF - 252 . SEE ALSO PWTS. OF FASI AND INTERTFE. REACTORS, VIENYA, SH-18/56/19611 FOR PRELIHIMARY RESULTS.

1074 MUCLEAR PHYS. 65. 149119651 D.5. MATHEF. P.FIELDHOUSE, A. HOA

LALRE) SCINTILLATOR COUNTER

EANDC (UK) - 495 (0000)

RELATIVE TO CFZSE SPONTANEOUS FISSION NU-BAP $P=3.782+.024$

1075 NUCLEAR SCIENCE AND ENGINEERINO 15, 213119631

1. ASPLUND-NILSSON, H. CONDE, N, STARFEL

RELATIYE TO NU FOR SPONTANEOUS FISSION OF CF-252 (3.80).

LIOUID SCINTTLLATOR

ID76 EULL. AH. PHYS. 5OC, to. 1099 I/9651 J.R.SM!TH. S.D.REEDER. R. G.FLUHARTY (PHILLIPS)

CONF. ON MEUTRON CIS TECHNOLOGY, HASH.D.C., P.9/Y (1966)

J.R. SHITH, E.FAST

100-1 3140 PAGE $30 \div 1965$

MIF CAYSTAL SPECTROHETER. HE HAVE DETERMINED ALPHA HERE GY

TAK ING NU $=2.494 .2 .430$ ANO 2.871 FOR U233. U235. AND PU239. RESPECTIUELY

1077 AMERICAN CHEMICAL SOCIETY MEETING. PITTSBURGM IIS66। F.L.LISHAN. H.J.MAECK. J.E.REIN

ICONF-650303 B00K a PHYSICS TID-4500,

COAT. ON HEUTROA CIS TECHAOLOOX. HASH.O.C., 9.919419651 J.R.SHITH. E.TAST

CITS

1079 SOYIET PROGRESS IN NEUTAON PHY5ICS. PAGE 191119611 Q.D.KUZ' MINOY

'RUSSIAN TEKT PUBLISHED gY GOSATOMIZOAT, MOSCOW, 196!

RAASLATION PUBLISHED QY CONSULIANTS BUREAU, NEH YORK, 1962;

c39. $2.9+1-.04$

AEC - TR $-4710 ; 1960$

1079 SOVIET PROGRESS IN NEUTRON PHYSICS, PAGE 177 (1961,
92-U $-233 \quad 2.40-02$ 2.40-05 92-U -235 2.40-02 $2.40-02$ g.2-U -235 2.40-02 $2.40-0$ 93-4⿴囗-537 $\quad 2.40-02 \quad 5.40-03$ g. 94-PU-240 $2.40-02 \quad 2.40-00$ GM-PU-Z41 2.40-02 $2.40-02$

$95-4-233 \quad 2.53-00 \quad 3.93 \cdot 00$

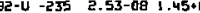
$94-P U]-239 \quad 2.53-061.45 \cdot 01$ $24-P U=240-6.68+00-6.68 \cdot 00$ $88-C F-252-6.35+00-6.35+00$

90-7H-232 $\quad 1.39+00 \quad 4.02+00$ 92-U -233 2.53-68 $4.00+00$ 92.U $-234 \quad 9.90-014.02+00$ Se-U $-230 \quad 1.41+004.02+00$ 94-FU-239 $2.53-00 \quad 4.02+00$

95-10 $-538-6.14+00-8.14+00$ $24-8 U-540-6.68+00-6.68+00$

1 N.F IS5

1 N,Fiss

I N,Fiss

I N.FISS

I N,Fiss

1 N.FISS

6 M-PRAT

7 MU-PFist

7 NW-PRAT

1 MU-PFAT

I Nu-Prit

4 NU-PFIT

5 MU-PANT

4 KU-PFit

4 NU-PFit

5 NU-PRAT

1 MU-PFin

i NU-PFerI

97-1) $-233 \quad 2.50-00$ 5.70-08 92-U -233 2.50-08 5.70-09 92-U $-235 \quad 2.50-00$ 2.50-00 32-U - $235 \quad 2.50-002.50-00$ 94.

a ETA

a AlPHA

1 ETA

1 ALPHA

a)

g2-U -233 5.53-00 2.53-08 2.0 - $2.50-00$ 2.50-08

$92-4-235$ 2.53-08 2.53-08 I ALPFA

I ALPHA

I ALPHA SPECT.AY.

SPRet.av.

$94-P U-240 \quad 3.60+00 \quad 1.50+01 \quad 2 \mathrm{MU}-\mathrm{PR}+1$

90-TH-232 $2.30 * 00 \quad 1.57 \times 01 \quad 3 \mathrm{MU}-\mathrm{PF}+1$

Fig. A-9a. Bibjiographic information for Ref, 1079, as it appears in [CRR-50400, Vol. 2, Sec. 3. 


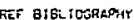

1079 B.D.KUZ'MINOH

IRUSSIAN TEXT PUBI ISHED GY COSATOHI20AT, HOSCOW, 1961 TRANELATION PUOR ISHED GY CONSULTANTS GUREAU, NEN YOFX, 1962, NDRTALIZED TO NU-BAR THER U-235 $=2.47+1-.03$

1080 EANOC (UK) -GSAL 1/968Y B.H.PATRICK. M.G.SOHERGY, M.G.SHOMEEAS (AERE)

AERE-PRINP- 14 PAGE II (1968)

IAEA COAF. ON MUELEAR DATA. PARIS, PAPER CH-23/30 11965S Q.H, PATR:CK, H.G.SCHOMEERG, M.G.SOHERBY, J.E. JOL.LY TIIIE OF FLIGHT REASUAEMENT OF ETA. ALPHA AND MLUTRON CROSS SECTIONS. MLPHA MERE IS THE RATIO OF THE AVERACE CAPIUPE CROSS SECTION TO THE AVERAGE FISSION CROSS SECTION

1081 GURL. AH. PHYS. SOC. G, 369 I1953) O.K. BUTLER, R.K. SJOBLOH (ANR) GAS SEINITLLATIOA COUNTER. RELATIVE TO U-235 SIGMA F. DATA TAKEN FROM

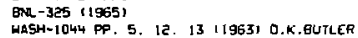

I0BR PHYS. FEV. 146. 840 I1966) G.F.AUEHAMPAUG, C.D.BOHMAN, H.S. COOPS. S.C.FULTZ LLRL TITE OF FLIGHT TECHNIOUE. CROSS SECTION DATA OBIAINED FROM

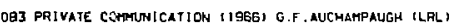
TINE OF FLIGHT TECHNIQUE. ThL. PHY $50 \mathrm{CO} 10.109911965$ VCAL-70033 (1966)

aREa analysis. fesonatce parateters geloh 150 EV reported IN REFEHENCE 1252.

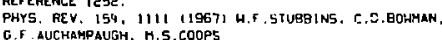

1084 PHY, REV, 137, 326 (1965, C.D.BOWHAH, H.S.COOPS.

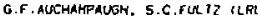

TIME OF FLJGHT TECHNIOUE. CROSS SECIION NORHAL, 12 LD IO 3.13 PLUSIMINUS 0.15 BAFNS AT O.OZS EV. CROSS SECTION OATA IBTAINEO FROH C.O.BOHAN. ARER ANO SHAPE ANALYSIS. UCPL -7971 119541

1085 PHYS. ANO CHEM. OF PIS\$10N. IAEA. SALZQURG, 2,25 11965) D. W. COLVIN. H.G.SOMEABY

PARTILL DATA PRESENTEO IN

AEAE-PR/HP-B PACE 911965 H

GORON PILE MEASURETENT. HE HAVE TAKEN MU PROMPT AS 2.414

(THERHAL) ANO 3.763 FOR U235 AND CFESE, FL SPE VELY

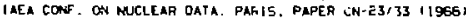
EANOCILR!-525 II965!
TARGET EN, RWHE IMEVI PIS OESCRIPIION

92-U - 339 2.30+00 3.75*00 $2 \mathrm{WJ}-\mathrm{PRMt}$

94-PU-239 1.00-04 2.99-02 5293 N,FISS 94-PU-239 1.00-04 2.99-02 S209: kTA

94-P1-239 $1.50-04$ 2.50-02 29 N,5ISS 5RECT.AV

94-PU-239 $1.50-04$ 2.50-02 20 N.G SPECT.AY.

94-PU-239 1.50-04 2.50-02 20 ALPHA SPECT.AV.

94-PU-E38 $\quad 1.40-01 \quad 1.74+00 \quad 75$ N.F15S

34-PU-245 2.50-DB 3.88-04 189 TOTAL

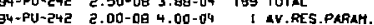
94-PU-242 $2.64-06$ 3.86-04 IS PES.PARAH.

gu-PU-238 $2.09-06 \quad 2.09-04 \quad 217$ N.F155

94-PIJ-238 2.90-06 2.80-04 I AV.PES.PARAH.

94-PU-230 1.51-04 2.80-04 G FES.PARAH.
95-AM-241 3.21-08 9.00-04 470 N.FISS

95-AM-241 3.10-07 1.50-05 Z6 RES.PARAM.

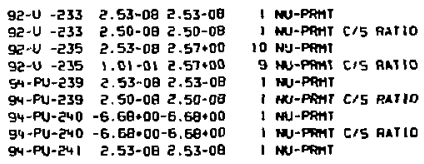

Fig. A-9b. Bibliographic information for Ref, 1079, as it appears in UCRL-50400, Vol. 2, Sec. 3. 